UNIVERSIDADE DE SÃO PAULO

FACULDADE DE CIÊNCIAS FARMACÊUTICAS

Programa de Pós-Graduação em Farmácia

Área: Fisiopatologia e Toxicologia

Pablo Rhasan dos Santos Scharf

EFEITO DA EXPOSIÇÃO A PRODUTOS FUMÍGENOS SOBRE A EXPRESSÃO DE METALOTIONEÍNAS NA ARTRITE EXPERIMENTAL E SOBRE FUNÇÕES DE LINFÓCITOS T

São Paulo

2021 
Pablo Rhasan dos Santos Scharf

\section{EFEITO DA EXPOSIÇÃO A PRODUTOS FUMIGENOS SOBRE A EXPRESSÃO DE METALOTIONEÍNAS NA ARTRITE EXPERIMENTAL E SOBRE FUNÇÕES DE LINFÓCITOS T}

Dissertação apresentada a Faculdade de Ciências Farmacêuticas da Universidade de São Paulo como requisito para obtenção do título de Mestre em Ciências: Área: Toxicologia.

Orientação: Prof. Dra. Sandra Helena Poliselli Farsky

São Paulo 
Ficha Catalográfica elaborada eletronicamente pelo autor, utilizando o programa desenvolvido pela Seção Técnica de Informática do ICMC/USP e adaptado para a Divisāo de Biblioteca e Documentação do Conjunto das Químicas da USP

Bibliotecária responsável pela orientação de catalogação da publicação: Marlene Aparecida Vieira - CRB - 8/5562 expressão de metalotioneinas na artrite experimental e sobre funçōes de linfócitos T / Pablo Rhasan dos Santos Scharf. - São Paulo, 2021.

$$
91 \mathrm{p} \text {. }
$$

Dissertação (mestrado) - Faculdade de Ciências

Farmacêuticas da Universidade de São Paulo.

Departamento de Análises Clínicas e Toxicológicas -

Programa de Pós-Graduação em Farmácia (Fisiopatologia

e Toxicologia).

Orientador: Farsky, Sandra Helena Poliselli

1. artrite reumatoide. 2. Iinfócitos T. 3. metalotioneinas. 4. nicotina. 5. AhR. I. T. II. Farsky, Sandra Helena Poliselli, orientador. 


\section{AGRADECIMENTOS}

Ter decidido ingressar no mestrado foi, sem sombra de dúvidas, um divisor de águas na minha vida, sendo um período que me fez ter a certeza de que fiz a escolha certa ao ingressar no mundo da pesquisa científica. Nesse período, diversas pessoas foram cruciais para que eu pudesse chegar neste atual momento, pessoas estas que eu sou muito grato.

Primeiramente, gostaria de agradecer à professora Sandra Farsky por, basicamente, tudo durante o mestrado. Foi um período de muito aprendizado, onde sob a sua orientação, diversos desafios foram superados. Muito obrigado pela oportunidade e pela confiança em mim depositada para desenvolver o presente projeto, além de todos os ensinamentos, conselhos e incentivos durante essa trajetória. Você é uma pessoa inspiradora e sou muito grato por ter sido seu orientando.

Gostaria de agradecer aos meus colegas de laboratório: Cris, Sil, Marina, Gustavo, Milena, Luana, Cintia e Anna pelo companheirismo, os ensinamentos e pelas conversas científicas e filosóficas que sempre foram muito enriquecedoras. Fico feliz em saber que dentro do laboratório pude encontrar, não somente cientistas brilhantes, mas também bons amigos.

Ao serviço de pós-graduação da FCF-USP pelos auxílios e também aos funcionários e pesquisadores do bloco 13B pelos auxílios, troca de experiências e cafés matinais na copa. Em especial, as técnicas Stephanie, Bia e Dani.

Aos colaboradores do presente trabalho, que sempre foram muito solícitos e prestativos. À Ayda Schneider, Paula Barbim e ao professor Fernando Cunha da Faculdade de Medicina da USP de Ribeirão Preto pelo auxílio nos experimentos in vivo. Ao Walter Pedreira Filho da FUNDACENTRO por abrir o seu laboratório para realizarmos as análises de metais. Ao prof. Tiago de Oliveira da Universidade Federal de Ciências da Saúde de Porto Alegre por me receber em seu laboratório e por auxiliar nas análises de nicotina e cotinina.

Agradeço aos meus pais, que sempre estiveram me auxiliando e me dando suporte para que eu conseguisse alcançar meus objetivos, e que tanto batalharam para que eu e meus irmãos pudéssemos estar cada vez mais próximos de nossos objetivos. Um agradecimento especial à minha mãe, dona Maria da Conceição, pela eterna 
companhia, pelas longas noites de conversa e por sempre estar incentivando e apoiando minha vida acadêmica, e também por compreender os meus momentos de ausência.

Aos meus irmãos Ruan, Emmanoel e Gabriel por sempre estarem dispostos e interessados em ouvir sobre a minha vida acadêmica e em acompanhar e vibrar as minhas vitórias. Ao meu tio Jorge por sempre estar presente e incentivar a minha jornada.

Aos meus eternos amigos e ouvintes pessoais Miguel, Taya, Mari, Daisy e Ana Alice. Sei que nesse período, nossas vidas tomaram rumos muito diferentes, mas sou muito feliz em perceber que apenas a distância física mudou e que sempre poderei contar com vocês. Seria um erro meu não reservar um parágrafo para destacar todo companheirismo, conselhos e a amizade de vocês. Mesmo que distante, sempre estaremos próximos.

Por fim, agradeço a Deus por ter me proporcionado todos esses momentos e a todos os seres iluminados que me acompanham, e que, de um modo único, me guiam em momentos de dificuldade e sempre me auxiliam a seguir em constante evolução como ser humano. 
“Aqueles que se sentem satisfeitos sentam-se e nada fazem. Os insatisfeitos são os únicos benfeitores do mundo." Walter S. Landor 


\section{LISTA DE ABREVIATURAS}

3-MC - 3-metilcolantireno

8-OHdG - 8-oxo-hidroxi-deoxiguanosina

ACPAs - Autoanticorpos anti-proteínas citrilinadas

AhR - Receptor de Hidrocarbonetos Arila

AIA - Artrite Induzida por Antígeno

AIC - Artrite Induzida por Colágeno

AnxV - Anexina V

APC - Aloficocianina

AR - Artrite Reumatoide

ARNT - Translocador Nuclear de AhR

BaP - Benzo[a]pireno

CC - Cigarro Convencional

CCL20 - Ligante de Quimiocina 20

CCL7 - Ligante de Quimiocina 7

CD - Cluster of differentiation

CFA - Adjuvante Completo de Freund

CTLA-4 - Cytotoxic T-Lymphocyte Associated Protein 4

DAB - Diaminobenzidina

DAMPs - damage-associated molecular patterns

DCFH-DA - Diclorofluoresceína Diacetato

DPI - Doença Pulmonar Intersticial

EROs - Espécies Reativas de Oxigênio

FDA - Food and Drug Administration

FICT - Isotiocianato de Fluoresceína

FICZ - Formylindolo[3,2-b] Carbazole

FoxP3 - Forkhead box P3

FR - Fator Reumatoide

GM-CSF - Fator Estimulador de Colônias de Granulócitos e Macrófagos

HCI - Health Canada Intense Regime

HE - Hematoxilina \& Eosina 
HNBT - Heat-not-burn tobacco

HPAs - Hidrocarbonetos Aromáticos Policíclicos

HQ - Hidroquinona

i.a. - Intra-articular

i.p. - Intraperitoneal

ICP-MS - Espectrometria de Massas com Plasma Indutivamente Acoplado

IFA - Adjuvante Incompleto de Freund

IFN-y - Interferon Gama

IgG - Imunoglobulina G

IKK - Inibidor IאB Quinase

IL - Interleucina

IQOS - I quite ordinary smoke

LDH - Lactato Desidrogenase

Linfócitos Th - Linfócitos T helper

Linfócitos Treg - Lifócitos T regulatórios

MAPK - Proteínas Quinases Ativadas por Mitógenos

mBSA - Albumina Sérica Bovina Metilada

MCP-1 - Proteína Quimioatraente de Macrófagos 1

MFI - Intensidade Mediana de Fluorescência

MHC - Complexo Principal de Histocompatibilidade

MRTPs - Produtos de Tabaco com Risco Modificado

MTs - Metalotioneínas

MTT - \{brometo de [3-(4,5-dimetiltiazol-2yl)-2,5-difenil tetrazolium]

MTX - Metotrexato

nAChR - Receptor Nicotínico de Acetilcolina

NETs - Neutrophil Extracellular Traps

NFkB - Fator de transcrição nuclear kappa B

NO - Óxido Nítrico

NOX - p47phox NADPH oxidase

NRU - Neutral Red Uptake

OMS - Organização Mundial da Saúde

PAD - Peptidilarginina Deiminase

PBS - Tampão Fosfato Salino

PCB - Bifenilos Policlorados 
PD-L1 - Programmed Death Ligand 1

PI - Iodeto de Propídio

PKC - Proteína Intracelular Quinase C

PM - Material Particulado

PMA - Phorbol 12-myristate 13-acetate

PMI - Philip Morris International

ROR $\boldsymbol{\alpha}$ - Retinoic Acid Receptor Related Orphan Receptor alpha

ROR $\gamma$ - Retinoic Acid Receptor Related Orphan Receptor gamma

RPM - Rotação por Minuto

SFB - Soro Fetal Bovino

STAT - Transdutor de Sinal e Ativador da Transcrição

TBS-T - Tampão salino Tris com Tween 20

TCDD - 2,3,7,8-tetraclorodibenzo-p-dioxina

TGF- $\boldsymbol{\beta}$ - Fator transformante de crescimento beta

THC - Tetra-Hidrocanabinol

TNF- $\boldsymbol{\alpha}$ - Fator de Necrose Tumoral Alfa

UHPLC-ESI-MS - Cromatografia Líquida de Ultra-Eficiência Acoplada a

Espectrometria de Massas

XRE - Elementos de Resposta a Xenobióticos 


\section{LISTA DE FIGURAS}

Figura 1. Visualização esquemática de uma articulação saudável e uma articulação afetada pela AR

Figura 2. Sistema do dispositivo de tabaco aquecido IQOS

Figura 3. Delineamento Experimental de AIA

Figura 4. Sistema de Exposição in vivo

Figura 5. Sistema de Exposição in vitro

Figura 6. Níveis séricos de nicotina e cotinina em animais expostos por 1 hora

Figura 7. Efeito das exposições ao CC, HNBT e ao ar sobre parâmetros clínicos na fase tardia da AIA

Figura 8. Efeito das exposições sobre a inflamação pulmonar

Figura 9. Níveis de metais liberados nas câmaras de exposição in vivo

Figura 10. Expressão de MTs no pulmão e fígado de animais expostos

Figura 11. Exposições ao HNBT e ao CC reduzem a celularidade de órgãos linfoides.

Figura 12. Efeito das exposições in vitro ao HNBT e ao CC na frequência de células Th17 e ativação de AhR.

Figura 13. Exposições ao CC e HNBT alteram a viabilidade celular e aumentam a necrose em células T Jurkat

Figura 14. Exposições ao CC, mas não ao HNBT, aumentam espécies reativas de oxigênio e nitrogênio e 8-OHdG.

Figura 15. Quantificação dos metais liberados nas câmaras de exposição in vitro e expressão de MTs

Figura 16. Efeito das exposições in vitro sobre a secreção de citocinas e ativação de $\mathrm{NF} \kappa \mathrm{B}$

Figura 17. Impacto das exposições in vitro e da nicotina sobre a proliferação de células Jurkat

Figura 18. IL-2 exógena recupera a atividade proliferativa de células T Jurkat expostas ou tratadas com diferentes doses de nicotina.

Figura 19, Esquema representativo dos dados obtidos in vivo

Figura 20. Esquema representativo dos dados obtidos in vitro 


\section{RESUMO}

SCHARF, P. R. S. Efeito da exposição a produtos fumígenos sobre a expressão de metalotioneínas na artrite experimental e sobre linfócitos T. 2021. 86f. Dissertação (Mestrado) - Faculdade de Ciências Farmacêuticas, Universidade de São Paulo, São Paulo, 2021.

Produtos liberados pela queima do cigarro convencional (CC) estão relacionados com a progressão clínica da artrite reumatoide (AR). Produtos fumígenos não combustíveis surgiram com a premissa de apresentarem menor toxicidade que o CC, dentre os quais está o tabaco aquecido (heat-not-burn tobacco; HNBT). Neste projeto investigamos os efeitos do HNBT sobre eventos envolvidos na AR, focando na sintomatologia, expressão de metalotioneínas (MTs), e na biologia de linfócitos $\mathrm{T} \mathrm{CD}^{+}$primários e da linhagem Jurkat. Exposições in vivo ao ar, CC ou HNBT foram realizadas 2 vezes ao dia, 1 hora cada (12 CC ou 24 HNBT/hora), nos dias 14-21 da indução da artrite induzida por antígeno (AIA) em camundongos C57B1/6. Foram realizadas análises dos parâmetros clínico da doenças, histopatologia e imunohistoquímica; quantificação de nicotina e cotinina séricas por cromatografia líquida acoplada a espectrometria de massas (MS). Os efeitos das exposições in vitro sobre linfócitos $\mathrm{T}$ foram mensurados por citometria de fluxo e ELISA. A concentração de metais emitidas pelo CC ou HNBT durante as exposições foram mensurados por MS com plasma acoplado. Camundongos expostos ao CC apresentaram intensa inflamação pulmonar, expressões acentuadas de MTs hepáticas e pulmonares e exacerbação dos parâmetros de AIA quando comparados ao grupo expostos ao HNBT. Animais expostos ao CC ou ao HNBT apresentaram redução na celularidade de órgãos linfoides. Somente a exposição in vitro ao CC causou estresse oxidativo e secreção de citocinas inflamatórias, ativação do receptor de hidrocarbonetos arila (AhR) e polarização de células Th17. Diferentemente, exposição ao CC ou ao HNBT provocaram redução da secreção de IL-2 e proliferação de células Jurkat. A exposição de células Jurkat à nicotina mimetizou os efeitos inibitórios da exposição ao HNBT sobre a secreção de IL-2 e proliferação de linfócitos T. O CC liberou maiores concentrações de metais nas câmaras de exposição. Associados, nossos resultados mostram que embora exposições ao HNBT não exacerbem parâmetros inflamatórios de AIA e nem em funções linfócitos $\mathrm{T}$, ambos produtos prejudicam a celularidade de órgãos linfoides e a proliferação e secreção de IL-2 por linfócitos T.

Palavras-chave: artrite reumatoide; linfócitos T; metalotioneínas; nicotina; AhR 


\begin{abstract}
SCHARF, P. R. S. Effect of exposure to tobacco-related products on metallothionein expression in the experimental arthritis and on T lymphocytes functions. 2021. 86f. Dissertação (Mestrado) - - Faculdade de Ciências Farmacêuticas, Universidade de São Paulo, São Paulo, 2021.
\end{abstract}

Products released by burning conventional cigarettes (CC) are related to the worsening of rheumatoid arthritis (RA). Non-combustible smoking products appeared with the premise of presenting less toxicity than the $\mathrm{CC}$, among which is the heated tobacco (heat-not-burn tobacco; HNBT). Here, we investigate the effects of HNBT on events involved in RA, focusing on symptoms, expression of metallothioneins (MTs), and on the biology of primary CD4+ $\mathrm{T}$ lymphocytes and the Jurkat $\mathrm{T}$ cell lineage. In vivo exposures to air, CC or HNBT were performed twice a day, 1 hour each (12 CC or 24 HNBT / hour), on days 14-21 of the induction of antigen-induced arthritis (AIA) in C57B1 / 6 mice. Analyzes of the clinical parameters of the AIA, histopathology, and immunohistochemistry were performed; quantification of nicotine and cotinine by liquid chromatography coupled to mass spectrometry (MS). The in vitro effects of exposures on $\mathrm{T}$ lymphocytes were measured by flow cytometry and ELISA. The concentration of metals released by the $\mathrm{CC}$ or HNBT during the exposures was measured by MS with coupled plasma. Mice exposed to $\mathrm{CC}$ showed intense pulmonary inflammation, marked expressions of hepatic and pulmonary MTs, and exacerbation of AIA parameters when compared to the group exposed to HNBT. Animals exposed to $\mathrm{CC}$ or HNBT showed a reduction in the cellularity of lymphoid organs. Only in vitro exposure to $\mathrm{CC}$ caused oxidative stress and secretion of inflammatory cytokines, activation of the aryl hydrocarbon receptor (AhR), and polarization of Th17 cells. However, exposure to CC or HNBT led to reduced secretion of IL-2 and proliferation of Jurkat cells. The exposure of Jurkat $\mathrm{T}$ cells to nicotine mimicked the inhibitory effects of exposure to HNBT on IL-2 secretion and T lymphocyte proliferation. The CC released higher concentrations of metals in the exposure chambers. In association, our results show that although exposures to HNBT do not exacerbate inflammatory parameters of AIA or T lymphocyte functions, both products impair lymphoid organ cell function and the proliferation and secretion of IL-2 by T lymphocytes.

Keywords: rheumatoid arthritis; T lymphocytes; metallothioneins; nicotine; AhR 


\section{SUMÁRIO}

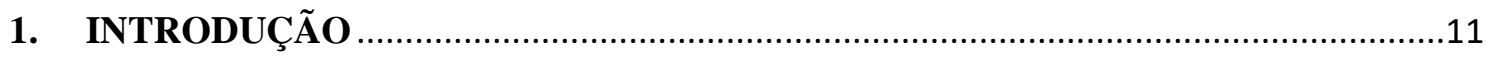

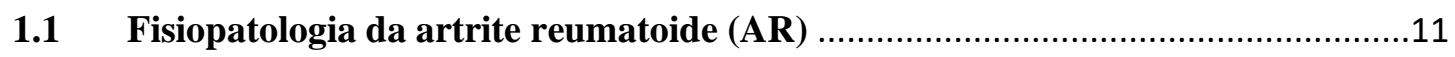

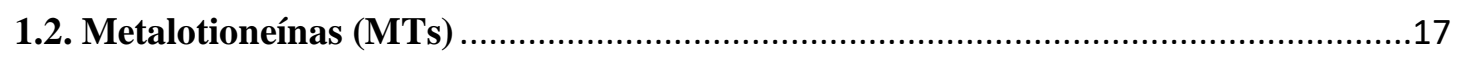

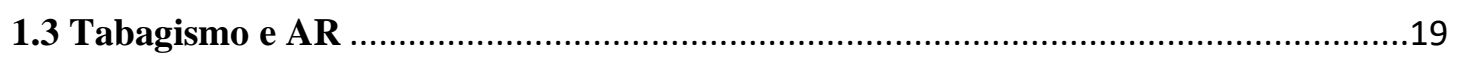

1.4 Novos produtos de tabaco: tabaco aquecido e sua toxicidade ..................................23

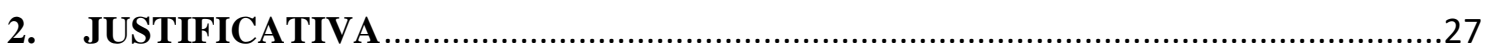

3. OBJETIVO

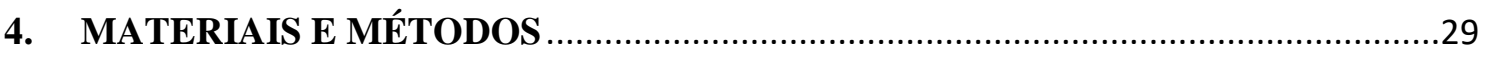

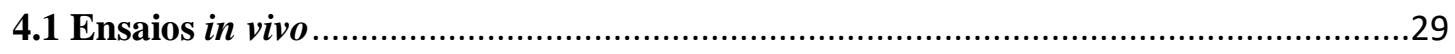

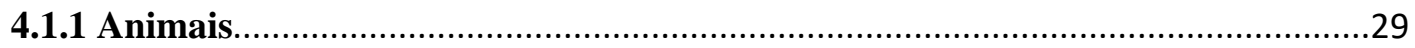

4.1.2 Indução da artrite induzida por antígeno (AIA) ...............................................29

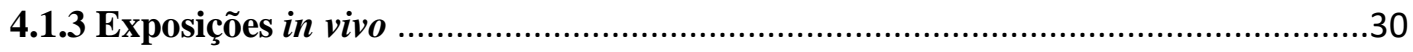

4.1.4 Determinação de nicotina e cotinina sérica..................................................................31

4.1.5 Quantificação de metais liberados na câmara de exposição ................................32

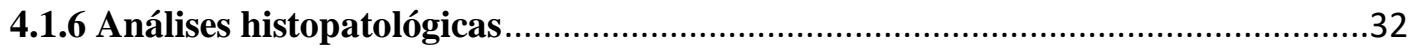

4.1.8 Imunohistoquímica para deteç̧ão de MTs .......................................................33

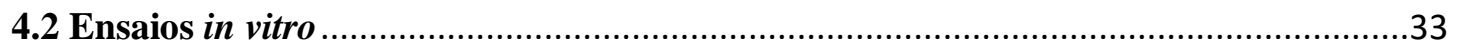

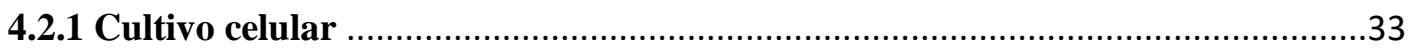

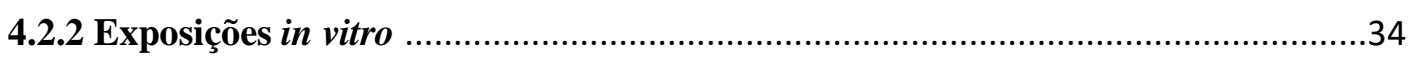

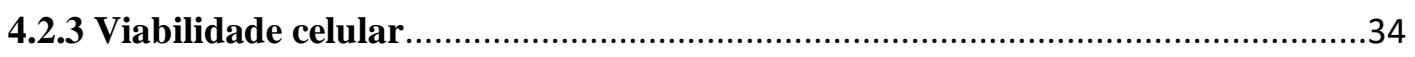

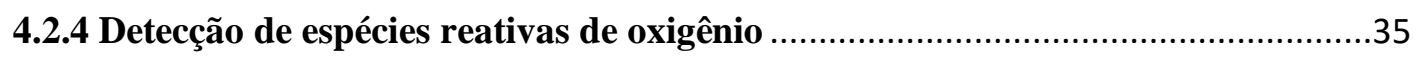

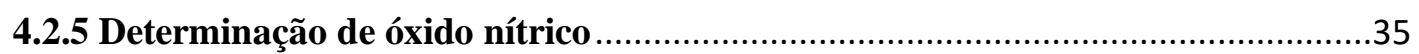

4.2.6 Expressão de MTs, 8-OHdG e NFkB por citometria de fluxo.............................35

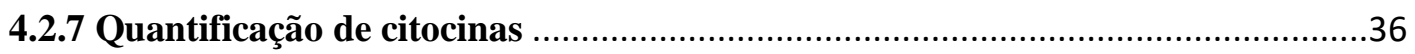

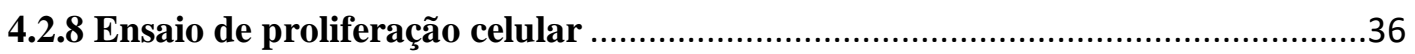

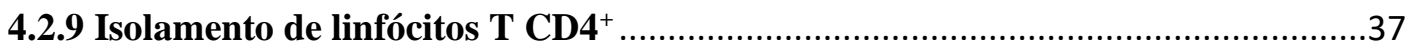

4.2.10 Ensaio de polarização de linfócitos Th17 ..........................................................38

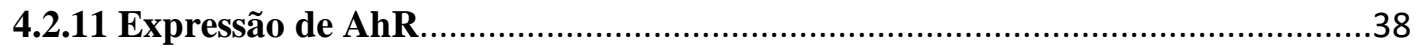

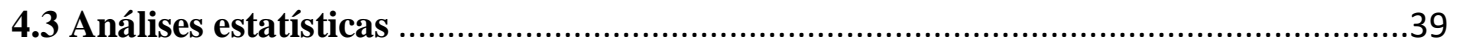

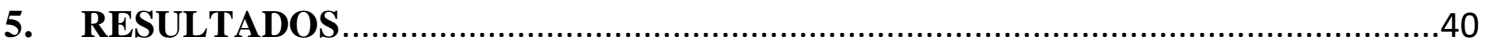

5.1 Dosagem dos níveis séricos de nicotina e cotinina em animais expostos 1 hora .........40

5.2 Exposições ao CC, mas não ao HNBT, exacerbam os sinais clínicos da AIA ..............40

5.3 Efeito das exposições ao CC e HNBT sobre a inflamação pulmonar..........................41 
5.4 Quantificação de metais liberados nas câmaras de exposição in vivo e expressão de MTs pulmonares e hepáticas

5.5 Impactos das exposições ao HNBT e ao CC na celularidade de órgãos linfoides .......45

5.6 Impacto das exposições in vitro sobre a viabilidade de células T Jurkat....................46

5.7 Efeito das exposições sobre a produção de espécies reativas de oxigênio e nitrogênio e dano de DNA.

5.8 Quantificação dos metais liberados nas câmaras de exposição in vitro e expressão de MTs

5.9 Efeito das exposições in vitro sobre a secreção de citocinas e ativação de NFKB .49

5.9 Impacto das exposições in vitro e da nicotina sobre a proliferação de células Jurkat

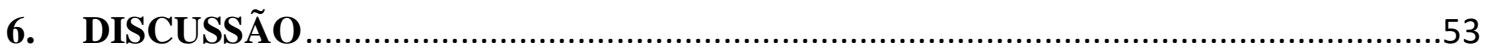

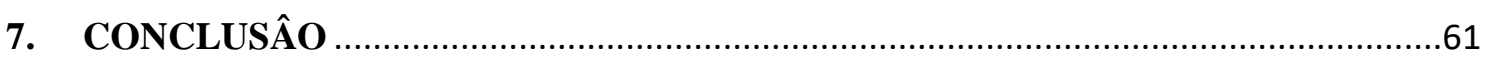

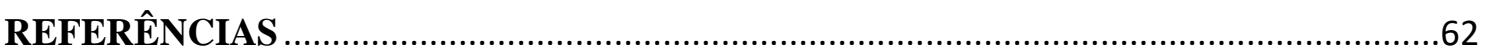

ANEXOS 


\section{INTRODUÇÃO}

\subsection{Fisiopatologia da artrite reumatoide (AR)}

A AR é uma doença autoimune sistêmica, caracterizada por um processo inflamatório crônico que afeta principalmente pequenas e grandes articulações sinoviais, levando ao surgimento da sinovite. Em decorrência de alterações na tolerância imunológica e instalação da autoimunidade, as articulações são alvos de componentes do sistema imune inato e adaptativo que desempenham um papel agravante na fisiopatologia da doença, favorecendo a perpetuação do processo inflamatório local (Moradi et al., 2014; Catrina et al., 2014).

A epidemiologia da AR possui prevalência mundial de 0,5 a $1 \%$, sendo uma das doenças autoimunes mais prevalentes no mundo, onde mulheres são cerca de 3 vezes mais susceptíveis a desenvolverem a doença (Scott et al 2010; Smolen et al., 2018). A AR é uma doença que gera preocupações de saúde pública, visto que causa incapacidades motoras crônicas e progressivas, além de gerar custos elevados aos sistemas de saúde, pois seu tratamento é complexo e nem sempre efetivo. A progressão e a fisiopatologia da AR envolvem diversos mecanismos celulares, humorais e moleculares que ocasionam danos estruturais irreversíveis, como a destruição cartilaginosa e óssea (Scott et al. 2010; Sun et al., 2018).

Morfologicamente, as articulações sinoviais são estruturas compostas por duas superfícies articulares ósseas, cartilagem articular, a sinóvia, cápsula articular, tendões e ligamentos, além de ser banhada pelo líquido sinovial, que, é responsável pela lubrificação e nutrição das articulações (Flandry \& Hommel 2011). A cartilagem articular é constituída por uma matriz extracelular composta por colágeno, proteoglicanos, ácido hialurônico e condrócitos. Por sua vez, a sinóvia é um tecido conjuntivo conectivo formado principalmente pela camada sinovial íntima e sub-íntima (Iwanaga et al. 2000; Flandry \& Hommel 2011). Enquanto a camada sinovial subíntima contém vasos sanguíneos e linfáticos, terminações nervosas e um perfil hipocelular, principalmente composto por macrófagos, fibroblastos e adipócitos, a camada íntima é populada por sinoviócitos semelhantes a macrófagos e por sinoviócitos semelhantes a fibroblastos, os quais são também conhecidos como sinoviócitos do tipo A e B, respectivamente (Iwanaga et al. 2000; Asif, Fox \& Ruth 2017). 
Durante a inflamação sinovial observada em portadores de AR ocorre uma hiperplasia de células sinoviais, seguida de processos de angiogênese e aumento da permeabilidade vascular que favorecem o intenso influxo de células inflamatórias para cavidade articular (Bartok \& Firestein 2010). De maneira sinérgica, a proliferação sinovial sustentada por novos vasos sanguíneos é seguida da intensa migração leucocitária que, associados, transformam a sinóvia de hipocelular no pannus tecidual, um tecido altamente inflamado e com potencial invasivo (Paleolog 2002). O pannus é um tecido hiperplásico rico em sinoviócitos semelhantes a fibroblastos ativados e macrófagos, que se estende para dentro do espaço articular e se fixa na superfície da cartilagem (interação pannus-cartilagem), invadindo e promovendo a degradação da matriz extracelular e, consequentemente, a destruição articular (Figura 1) (Bartok \& Firestein 2010).

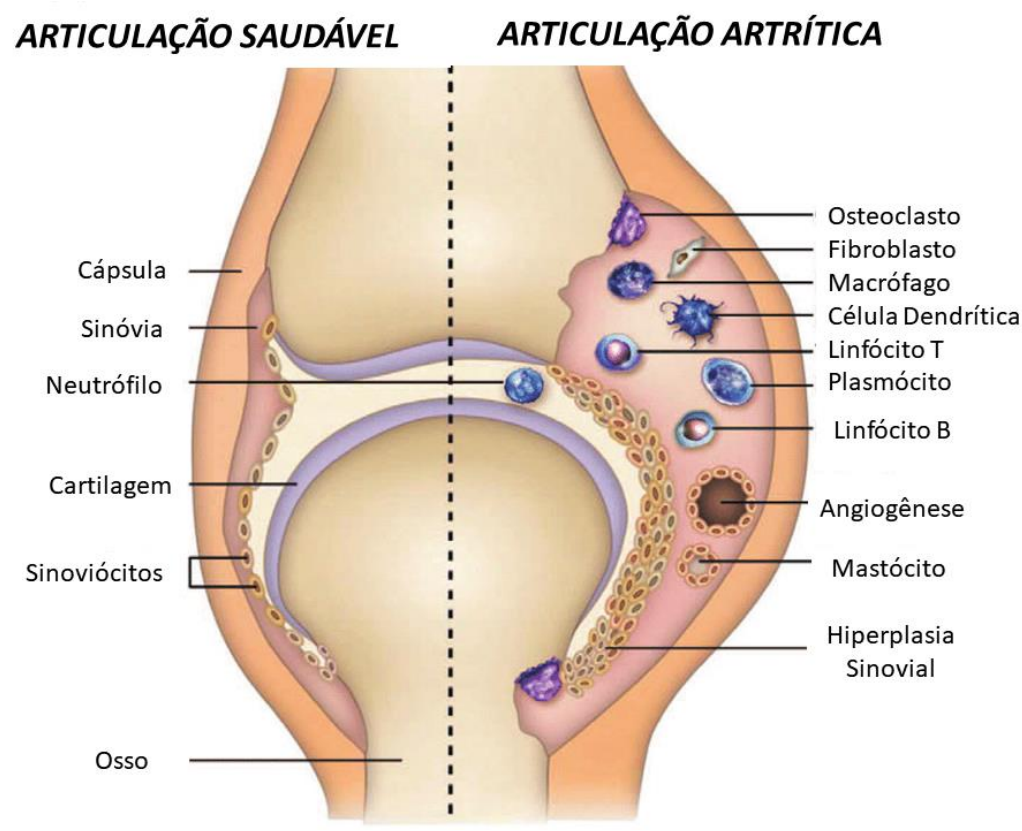

Figura 1. Visualização esquemática de uma articulação saudável e uma articulação afetada pela AR (Fonte: Adaptado de Das Phukan e Baruah 2018).

Embora a principal manifestação clínica da AR seja a inflamação sinovial, os sinais clínicos não se limitam apenas as articulações. Por se tratar de uma doença sistêmica, a AR pode apresentar manifestações extra articulares, levando a formação de nódulos reumatoides, danos oculares, pulmonares, e ainda afeta o sistema nervoso central e cardiovascular (Young \& Koduri, 2007; Roodenrijs et al. 2018). Além disso, se tratando de uma doença multifatorial, diversos fatores de riscos estão associados ao 
seu desenvolvimento e progressão, tais como desbalanços na microbiota intestinal, polimorfismos em genes que exacerbam a resposta imune, exposição a fatores ambientais e diferenças ligadas ao sexo (Smolen et al., 2018). A inalação de sílica, exposição a metais e a agentes infecciosos, obesidade e o hábito fumar estão entre os principais fatores de riscos associados a AR, sendo o tabagismo o principal fator ambiental relacionado ao desenvolvimento, exacerbação clínica e, em alguns casos, está ligado à baixa efetividade dos tratamentos eletivos para a doença (Koduri et al., 2010; Chang et al. 2014; Smolen et al., 2018).

A instalação da autoimunidade é marcada por uma capacidade imunorregulatória deficiente, permitindo a circulação de células auto-reativas, que por sua vez, não conseguem diferir o próprio do não-próprio e atacam estruturas do hospedeiro (Rosenblum et al. 2015). Este desbalanço em mecanismos centrais e periféricos de tolerância imunológica permite que o sistema imune reaja de maneira agressiva frente aos autoantígenos (Doyle and Mamula 2012). A formação de autoantígenos pode ocorrer por diversos mecanismos, como a geração de novos epítopos através de infecções virais, metabólitos advindos da microbiota intestinal e modificações póstraducionais, como a citrulinação, acetilação ou carbamilação, onde os peptídeos alterados se ligam a heterodímeros de proteína do complexo principal de histocompatibilidade (MHC), especialmente aqueles contendo epítopos compartilhados. Estes levam à apresentação antigênica a linfócitos $\mathrm{T}$, que por sua vez estimulam linfócitos B a produzirem uma variedade de anticorpos capazes de reconhecer proteínas próprias, os chamados autoanticorpos (Doyle and Mamula 2012; Holers 2013; Nguyen \& James 2016).

A citrulinação proteica é o principal processo pós-traducional envolvido na fisiopatologia da AR. Durante a citrulinação, ocorre a conversão do aminoácido arginina em citrulina através de ações enzimáticas das peptidil arginina deiaminases (PADs) (Darrha et al 2012; Darrah \& Andrade 2019). Em conjunto, a formação de proteínas citrulinadas e desbalanços na tolerância imunológica, que identificam tais proteínas como corpos estranhos, ocorre a geração de autoanticorpos anti-proteínas citrulinadas (ACPAs) (Blachère et al. 2017). Cerca de 80\% dos portadores de AR possuem níveis séricos detectáveis de ACPAs, sendo este um marcador importante para o diagnóstico da AR. Vale ressaltar que apenas a presença de marcadores séricos, como os ACPAs e o fator reumatoide (FR; ou anti-imunoglobulina G; anti-IgG), não são 
suficientes para diagnosticar a AR, uma vez que indivíduos podem apresentar sorologia positiva para autoanticorpos antes de desenvolverem qualquer sinal clínico, ou ainda, pacientes positivos para os marcadores séricos podem não desenvolver a doença (Nielen et al. 2004; Aletaha et al. 2015).

Linfócitos $\mathrm{T} \mathrm{CD}^{+}$são um subgrupo celular da imunidade adaptativa que desempenham um papel crucial na patogênese e desenvolvimento da $A R$, onde os principais subgrupos efetores e ativos nessa doença são os linfócitos T helper (Th) 1 e Th17 (Cope et al. 2007; Annunziato et al., 2009). A função reduzida de células T reguladoras (Treg) contribui para o aumento da proliferação de linfócitos T CD4 ${ }^{+}$auto reativos, assim como para aumento da produção do fator de necrose tumoral alfa (TNF$\alpha$ ), de interleucina (IL) 17 , interferon gama (IFN- $\gamma$ ), IL-1 $\beta$ e IL-6 na membrana sinovial (McGovern et al. 2012; Nie et al., 2013). Linfócitos T CD4 ${ }^{+}$recrutados para o interior da membrana sinovial, juntamente com monócitos e neutrófilos, medeiam a síntese e secreção de citocinas pró-inflamatórias importantes na patogênese e evolução da doença (Cope et al. 2007; Moradi et al., 2014).

A ação de linfócitos T efetores é importante não só para o estabelecimento da $\mathrm{AR}$, mas também para sua evolução clínica. Linfócitos $\mathrm{T} \mathrm{CD}^{+}$são dotados de uma grande plasticidade fenotípica, que pode ser modulada pelo microambiente inflamatório somado à ativação de fatores de transcrição (Zhou et al. 2009; Van Panhuys et al. 2014). Linfócitos Treg são caracterizados pela ativação do fator de transcrição forkhead box P3 (FoxP3) e pela secreção das proteínas anti-inflamatórias IL-10 e fator de crescimento transformante beta (TGF- $\beta$ ), além de expressarem marcadores de membrana relacionados com o seu potencial supressor, como cytotoxic T-lymphocyte associated protein 4 (CTLA-4) e programmed death ligand 1 (PD-L1) (Wing et al. 2008; Schmidt et al. 2012). Por sua vez, linfócitos Th17 são caracterizados pela secreção de IL-17, IL21 e IL-22, onde os principais fatores de transcrição de linfócitos Th17 são o retinoic acid receptor related orphan receptor (ROR $\gamma \mathrm{t}$ ) e $\mathrm{ROR} \alpha$ (Roeleveld et al. 2015; Castro et al. 2017). A polarização de linfócitos Th17 depende de fatores solúveis, sendo a combinação de TGF- $\beta$ e IL-6 os principais indutores dessa população. Embora a secreção de IL-17 per se seja responsável por desencadear diversos fenômenos inflamatórios na articulação de portadores de AR, esse dano tecidual pode ser sinérgico à presença de TNF- $\alpha$, IFN- $\gamma$ e pelo fator estimulador de colônias de granulócitos e macrófagos (GM-CSF) promovendo, dessa forma, a perpetuação da inflamação sinovial 
e gradativo dano articular e ósseo (Sonderegger et al. 2008; van Hamburg et al. 2011; Nanke et al. 2017).

A sinóvia de portadores de doenças articulares, como a AR e a osteoartrite, é caracterizada pela frequência elevada de células Th17 infiltradas, bem como grandes concentrações de IL-17 no lavado sinovial (Sarkar et al. 2010; Grose et al. 2012). Diversas células residentes na sinóvia expressam receptores para IL-17 (IL-17R), onde de forma inicial, a secreção de IL-17 inicia o processo inflamatório na sinóvia através da indução de quimiocinas, como a IL-8, proteína quimioatraente de macrófagos 1 (MCP-1), e dos ligantes de quimiocina 20 (CCL20) e 7 (CCL7) (Honorati et al. 2002; Raychaudhuri et al. 2012; Hattori et al. 2015). O recrutamento de células inflamatórias para a articulação desencadeia interações entre células residentes que exacerbam a resposta inflamatória, gerando um microambiente pró-inflamatório favorável para perpetuação da sinovite e, posteriormente, danos estruturais que irão refletir nos sinais clínicos observados nos portadores de AR (Bartok \& Firestein 2010).

Uma vez que sinoviócitos e condrócitos expressam o receptor de IL-17 (IL17R), a secreção de IL-17 induz a produção de metaloproteínases (MMPs) por estas células, levando a danos articulares e comprometendo o reparo tecidual (Agarwal et al. 2008; Beringer \& Miossec 2019). Além dos danos estruturais desencadeados pela IL17, esta citocina está relacionada também com o aumento da dor articular, sendo um mediador nociceptivo importante em modelos experimentais de artrite (Pinto et al. 2010; Ebbinghaus et al. 2017).

Embora populações de linfócitos $\mathrm{T}_{\mathrm{CD}} 4^{+}$sejam as principais envolvidas em doenças de caráter autoimune, componentes do sistema imune inato são de grande relevância na progressão clínica (Kaplan 2013). Neutrófilos são as células inflamatórias mais abundantes na sinóvia de portadores de AR, onde estudos tem sugerido que estas células estão intimamente relacionadas às fases iniciais da inflamação sinovial (Kaplan 2013; O’Neil et al. 2020). A secreção de quimiocinas, citocinas inflamatórias e o acúmulo de imunocomplexos na cavidade articular são responsáveis pelo recrutamento e a ativação de neutrófilos na sinóvia (Fossati et al. 2002; den Broeder et al. 2003; Verri et al. 2010; Cecchi et al. 2018).

Em resposta aos mediadores inflamatórios liberados na cavidade sinovial, neutrófilos migram até a sinóvia inflamada e geram altas concentrações de espécies reativas de oxigênio (EROs), além de secretarem quimiocinas e enzimas, como a 
mieloperoxidase e elastase (Cecchi et al. 2018; Gorlino et al. 2018). Neutrófilos migrados para cavidade sinovial apresentam retardo na apoptose, ou seja, apresentam maior tempo de meia vida, podendo chegar a até 5 dias viáveis no líquido sinovial de portadores de AR (Ottonello et al. 2002). Em decorrência ao acúmulo de imunocomplexos nas articulações, neutrófilos são ativados e liberarem armadilhas extracelulares (neutrophil extracellular traps; NETs), que lançam grânulos intracelulares e material genético ao microambiente (Kenny et al. 2017; Granger et al. 2019). Embora as NETs tenham o papel de eliminar possíveis ameaças ao organismo frente a infecções, em condições de inflamação estéril, como a observada na AR, as NETs desencadeiam a exacerbação dos sinais clínicos da AR, levando ao aumento no dano e dor articular (Brinkmann et al. 2004; Carmona-Rivera et al. 2020) e favorecendo o aumento na produção de ACPAs (Corsiero et al. 2016).

A inicialização e a progressão da AR resultam de diversas interações complexas, onde predisposições genéticas e exposições ambientais assumem uma combinação decisiva para o desenvolvimento da doença. Exposições a xenobióticos emergem como um gatilho ao desenvolvimento de certas condições de autoimunidade (Pollard et al. 2017). De fato, diversos estudos correlacionam a poluição ambiental com uma elevada prevalência de AR; além disso, o tabagismo surge como uma crescente ameaça a evolução clínica da AR (Essouma et al. 2015; Chang et al. 2016).

Embora a imunopatogênese da AR dependa de mecanismos celulares, moleculares e humorais que ocorrem de maneira dinâmica e crônica em seres humanos, modelos experimentais emergem como alternativas que compartilham eventos fisiopatológicos com a AR em humanos, permitindo estudar mecanismos e fatores envolvidos tanto no tratamento, quanto na exacerbação da AR. O modelo de artrite induzida por antígeno (AIA) é um modelo mediado por linfócitos T, que se baseia na sensibilização imunológica com um antígeno conhecido (albumina sérica bovina metilada, mBSA), seguido de um desafio antigênico local na cavidade articular, assim, após o desafio intra-articular, o camundongo apresenta uma inflamação sinovial limitada à cavidade desafiada (van den Berg et al. 2007). No modelo de AIA é possível obter diversos parâmetros comuns aos encontrados em humanos, como a cinética de linfócitos T. migração leucocitária, formação de edema e dor articular, além de alterações histopatológicas, como degeneração óssea e a formação do pannus tecidual (Pinto et al. 2010). 


\subsection{Metalotioneínas (MTs)}

Em resposta a diversos estresses, como concentrações elevadas de radicais livres, intoxicação por metais e processos inflamatórios agudos, ocorre a perpetuação do processo inflamatório que favorece o surgimento de danos celulares e estruturais. No sentido de proteger os tecidos das ações oxidativas, o organismo possui maquinarias antioxidantes para neutralizar e diminuir os níveis de EROs, onde os principais agentes antioxidantes não-enzimáticos expressos frente ao estresse oxidativo são as MTs (Chiaverini et al., 2010; Ruttkay-Nedecky, 2013).

MTs são proteínas de baixo peso molecular (aproximadamente $7 \mathrm{kDA}$ ), ricas em resíduos de cisteína, altamente conservadas durante o processo evolutivo e responsáveis pela homeostase e proteção frente a intoxicação por metais pesados, danos oxidativos e citocinas pró-inflamatórias, como TNF- $\alpha$ e IL-1 $\beta$. Estruturalmente, as MTs expressam 4 isoformas, onde as principais são as isoformas 1 e 2 que são distribuídas em todas as células e possuem ações pleiotrópricas sobre sistema imune, além de serem rapidamente expressas após estimulação (Kizek et al., 2013; Lynes et al. 2014).

As expressões de MTs 1 e 2 são reguladas pela elevação de íons de zinco e cobre, exposição a metais pesados, como o cádmio e mercúrio, na presença de EROs e no processo de proliferação e diferenciação celular, indicando que as MTs desempenham papel importante durante o desenvolvimento da resposta imunológicas (Lynes et al. 2014). A relação entre a expressão de MTs e o sistema imune é complexa, uma vez que as concentrações intra e extracelulares destas proteínas atuam em processos imunomodulatórios e influenciam diversos comportamentos celulares, como quimiotaxia, apoptose e proteção celular contra agentes estressores (Wei et al., 2008; Ruttkay-Nedecky et al., 2013). Além disso, a expressão de MTs está relacionada com a progressão de processos tumorais, e por esta razão são marcadores de mal prognósticos, já que em determinados tumores, altos níveis de MTs impactam negativamente a vida do paciente, pois estão ligados com a resistência à quimioterapia e radioterapia (Lee et al. 2015; Si \& Lang, 2018).

A distribuição e expressão de MTs não ocorre de modo universal, podendo estar suprimida ou elevada dependendo do sítio anatômico. Em injúrias hepáticas, por exemplo, as expressões de MTs estão diminuídas, sendo este efeito um fator importante para o desenvolvimento de processos carcinogênicos (Lee et al. 2015; Si \& Lang, 2018). Dentre as atividades imunorregulatórias das MTs, foi observado que a indução 
de MTs in vitro modula a diferenciação de linfócitos Th17 e influencia o balanço entre populações Th17/Treg, resultando em maior polarização para Treg e supressão de eventos celulares importantes na evolução das doenças autoimunes (Sun et al. 2018). Ainda, MTs liberadas no meio extracelular são capazes de atuar como damageassociated molecular patterns (DAMPs) e aumentar o influxo de células inflamatórias ao sítio lesado, sendo esse um fator agravante na exacerbação de doenças inflamatórias, como doença de Crohn e colite ulcerativa (Devisscher et al. 2014).

Devido a sua rápida expressão em resposta a estresses, as MTs são utilizadas como biomarcadores frente ao dano celular e de doenças, como por exemplo em tumores (Lee et al., 2015). Pouco tem sido descrito sobre a exposição à fumaça do cigarro e expressão de MTs, a despeito do grande dano celular que esta exposição acarreta. Análises de expressão gênica demonstraram que exposições agudas e crônicas à fumaça de cigarro foram capazes de alterar a expressão de MTs nas vias aéreas, ressaltando que o consumo e à exposição a fumaça do $\mathrm{CC}$ são fatores relacionados ao aumento na expressão de MTs (Billatos et al., 2018). Ainda, mulheres fumantes diagnosticadas com câncer de mama apresentam maior expressão de MTs no tumor, sendo este, um prognóstico negativo por estar associada a resistência ao tratamento (Gallicchio et al. 2004).

Durante a AR, portadores da doença apresentam aumento na expressão de MT-1 em células mononucleares do sangue periférico (PBMCs) em comparação a indivíduos saudáveis. O mesmo foi observado em esplenócitos, células dos linfonodos drenantes e da sinóvia de camundongos na vigência de AIC, onde a indução local de MT-1 foi capaz de reduzir o score clínico e a secreção de citocinas pró-inflamatórias (Sun et al. 2018).

O potencial imunorregulatório das MTs está relacionada a sua capacidade de modular o fenótipo de linfócitos T (Youn et al. 2002; Sun et al. 2018). Células dendríticas com potencial tolerogênico apresentam uma alta expressão de MT-1 na membrana celular, sendo essa população responsável por induzir linfócitos T CD4 ${ }^{+}$ naive a adquirirem um fenótipo $\mathrm{FoxP}^{+}$e expandirem populações de linfócitos Treg in vitro (Spiering et al. 2014). Além disso, o tratamento com MT-1 foi capaz de modular o balanço Th17/Treg no modelo de AIC, além de inibir a fosforilação de STAT3, um fator de transcrição importante por mediar a polarização de linfócitos Th17 na presença de IL-6 e TGF- $\beta$ (Ju et al. 2012; Sun et al. 2018). Vale ressaltar que, em camundongos, 
as isoformas MT-1 e MT-2 apresentam atividades biológicas muito similares, onde administrações repetidas de MT-1 e MT-2 em camundongos na vigência de AIC suprimiram a evolução clínica da doença, marcada por acentuada redução nos níveis de TNF- $\alpha$ e ciclooxigenase 2 e na expansão clonal de linfócitos $\mathrm{T}$ específicos para colágenos do tipo II (Youn et al. 2002).

\subsection{Tabagismo e AR}

O tabagismo é a principal causa de morte evitável no mundo, sendo uma das maiores ameaças aos sistemas de saúde pública. Segundo a Organização Mundial da Saúde (OMS), aproximadamente 8 milhões de óbitos por ano estão relacionados ao tabagismo, sendo que 7 milhões destas mortes são resultado do uso direto de produtos de tabaco; porém cerca de 1,2 milhões são não-fumantes que foram expostos passivamente aos componentes da combustão do tabaco. A exposição à fumaça de cigarro e a produtos de tabaco está relacionada a diversas complicações, como doenças cardiovasculares, autoimunes, infecciosas, problemas respiratórios e o desenvolvimento de cânceres (WHO, 2019).

Grande parte da toxicidade do CC está atribuída aos produtos liberados pela combustão incompleta do tabaco. Cerca de 8.700 substâncias químicas são geradas após a queima do tabaco, onde cerca de 70 destes componentes são conhecidamente carcinogênicos. Produtos como cádmio, nicotina, alcatrão, cianeto, monóxido de carbono, nicotina e hidrocarbonetos aromáticos policíclicos fazem parte dos compostos tóxicos liberados pela combustão do CC (Rodgman \& Perfetti, 2013; Stabbert et al. 2017).

Diversos componentes isolados do $\mathrm{CC}$, bem como a sua fase gasosa por completo, exercem potenciais efeitos imunotóxicos capazes de modular o funcionamento do sistema imune inato e adaptativo. Estes compostos podem agir de maneiras antagônicas no sistema imune, podendo gerar processos de estimulantes, como a iniciação e perpetuação de processos inflamatórios, ou suprimir a resposta imunológica, levando a quadros de imunossupressão (Sopori 2002; Qiu et al. 2017).

Quando inalada, a fumaça de CC é responsável por liberar níveis elevados de radicais livres e desencadear danos oxidativos a diversas macromoléculas, inclusive ao DNA (Yamaguchi 2019). O estresse oxidativo desencadeado pela fumaça do CC é responsável pela ativação de vias inflamatórias importantes na inicialização e 
cronificação da resposta inflamatória, como a ativação do fator nuclear kappa $\mathrm{B}$ (NFkB), proteínas quinases ativadas por mitógenos (MAPKs), e do transdutor de sinal e ativador da transcrição (STAT). Além da inicialização de processo inflamatório, a fumaça do CC modula o comportamento de diversos componentes da resposta imune, causando a sua modulação fenotípica, ativação e/ou supressão (Qiu et al. 2017; Strzelak et al. 2018)

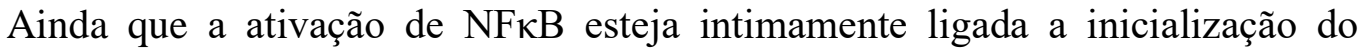
processo inflamatório, exposições ao $\mathrm{CC}$ apresentam efeitos divergentes na resposta imune, podendo ativar ou inativar a via de NFkB (Ahn et al. 2005; Yang et al. 2006; Zhong et al. 2008; Manzel et al. 2011). Embora a via canônica de ativação de NFkB seja iniciada através da degradação proteossomal do inibidor de NFKB (IKB) após a ativação do inibidor IאB quinase (IKK), que permite a sua translocação ao núcleo e a inicialização da transcrição gênica (Hasnis et al. 2007), o NFkB pode ser ativado em decorrência do estresse oxidativo (Ahn et al. 2005). Exposições agudas ao CC geram altas concentrações de radicais livres e são capazes de gerar a degradação de IKB e ativar NFאB em linfócitos e monócitos, resultando na expressão dos mediadores inflamatórios ciclooxigenase 2 e IL-8, respectivamente (Hasnis et al. 2007; Lerner et al., 2009). Entretanto, exposições crônicas ao CC podem comprometer a imunidade pulmonar inibindo a ativação de NFאB, e consequentemente, favorecendo a infecção por bactérias, como Haemophilus influenzae (Lori et al. 2011).

O hábito de fumar é um potente gatilho para o desenvolvimento da AR. De fato, homens fumantes são cerca de duas vezes mais susceptíveis a desenvolverem AR, enquanto mulheres podem ser cerca de três vezes mais susceptíveis ao surgimento da doença (Sugiyama et al. 2010). Em portadores de AR, o tabagismo está intimamente relacionado à aceleração das manifestações clínicas, aumento da concentração sérica de mediadores inflamatórios e, ainda, este grupo apresenta maior prevalência das manifestações extra-articulares da AR, em especial, o comprometimento pulmonar e cardiovascular (Turesson et al. 2003; De Rooy et al 2014).

Sendo o pulmão o primeiro órgão exposto ao cigarro, diversos estudos sugerem que a inalação da fumaça do cigarro contribui para o processo de citrulinação, onde a produção de ACPAs no pulmão pode favorecer o estabelecimento da autoimunidade e levar ao estabelecimento da AR (Makrygiannakis et al. 2008; Lugli et al. 2015). Além disso, os componentes do CC são capazes de aumentar a atividade das enzimas 
peptidilarginina deiminase (PAD2 e PAD4), as principais PADs envolvidas no processo de citrulinação e na patogênese da $\mathrm{AR}$, onde polimorfismos no gene PADI4 aumentam a predisposição de fumantes a desenvolverem a AR (Kochi et al. 2010; Damgaard et al. 2015).

A respeito do tratamento, o tabagismo implica em menor efetividade aos fármacos antirreumáticos em fumantes (Saevarsdottir et al. 2011). A administração de metotrexato (MTX) é uma escolha "ouro" para o tratamento da AR, onde o hábito de fumar está dentre os principais motivos para a não-responsividade ao MTX (Romao et al. 2013; Verstappen 2012). Ainda, fumantes portadores de AR tem maior chance a não responder aos tratamentos com medicamentos biológicos, como por exemplo infliximabe, um anticorpo anti-TNF- $\alpha$ (Saevarsdottir et al. 2011).

Compostos do CC são capazes ativar o receptor de hidrocarbonetos arila (AhR), um clássico sensor ambiental de exposições a xenobióticos (Kasai et al. 2006). A ativação de AhR desencadeia uma complexa modulação imunológica relacionada à evolução clínica de doenças imuno-mediadas, em especial, as de caráter autoimune (Zhu et al. 2014; O'Driscoll et al. 2018). A fumaça de CC libera diversos ligantes de AhR, como por exemplo, hidrocarbonetos aromáticos policíclicos (HPAs); 2,3,7,8tetraclorodibenzo-p-dioxina (TCDD), metilcolantireno (3-MC), benzo[a]pireno (BaP) e hidroquinona (HQ) (Kitamura et al. 2007; Choi et al. 2008; Vu et al. 2015). Em modelos experimentais de artrite, animais expostos a ligantes de AhR, como TCDD, formylindolo[3,2-b] carbazole (FICZ) ou HQ apresentaram exacerbação dos parâmetros clínicos, além de destruição óssea, desarranjo no depósito de colágeno e aumento no infiltrado de células secretoras de IL-17 nas articulações sinoviais inflamadas (Heluany et al 2018a; Heluany et al. 2018b; Fu et al. 2018). De fato, a expressão de AhR é importante para progressão da inflamação sinovial, uma vez que a expressão de AhR é cerca de duas vezes maior na sinóvia de portadores de AR do que de pacientes saudáveis ou com outras doenças articulares (Kobayashi et al. 2009; Kazantseva et al. 2012; Fu et al. 2018).

A ativação de $\mathrm{AhR}$ em linfócitos $\mathrm{T} \mathrm{CD}^{+}$naive pode induzir o perfil Th17 patogênico (Kimura et al. 2008). Camundongos submetidos à artrite experimental e expostos à fumaça do CC apresentaram piora no quadro clínico, bem como aumento na frequência de linfócitos Th17; fato não observado em animais deficientes para AhR ou tratados com antagonistas de AhR (Nakahama et al., 2011; Nguyen et al., 2015; Cheng 
et al., 2017; Talbolt et al. 2018). Ainda, a ativação de AhR em células Th17 expostas à fumaça do CC é capaz de elevar a produção do microRNA-137, o qual é empacotado e liberado em vesículas extracelulares capazes de induzir a osteoclastogênese durante a artrite (Donate et al. 2021).

A nicotina é o principal composto liberado por produtos de tabaco, sendo responsável pelos quadros de dependência à exposição ao CC (Hatsukami et al. 2008). A nicotina é um alcaloide encontrado nas folhas do tabaco (Nicotiana tabacum) e age como um potente agente ansiolítico, trazendo bem-estar logo após ser absorvida (Hatsukami et al. 2008). Além dos seus efeitos psicoativos, a nicotina age diretamente sobre o sistema imune, uma vez que diversos componentes imunitários expressam receptores nicotínicos, sendo a isoforma do receptor nicotínico de acetilcolina alfa 7 (nAChR- $\alpha 7)$ a mais estudada; entretanto vale ressaltar que outras isoformas também estão envolvidas na modulação do sistema imune, como as nAChR- $\alpha 2$, nAChR- $\alpha 5$ e nAChR- $\alpha 9$ (Qian et al. 2011; Fujii et al. 2017; Gomes et al. 2018). Estudos in vitro mostram que a nicotina age de maneira anti-inflamatória e imunossupressiva (NouriShirazi \& Guinet 2003; Kalra et al. 2004; Hoover et al. 2017). No entanto, os efeitos da nicotina in vivo sobre o sistema imune são controversos, em especial na vigência de doenças como a AR.

A administração de nicotina em camundongos com artrite induzida por colágeno (AIC) foi capaz de retardar o desenvolvimento da doença, levando à diminuição do score clínico e os títulos séricos de anti-CCPs (Lindbland et al. 2009). Linfócitos T isolados de portadores de $\mathrm{AR}$ e tratados in vitro com nicotina apresentaram diminuição da frequência de células Th1 e Th17, e aumento de populações Treg (Wu et al. 2018). Entretanto, no modelo de AIC, camundongos tratados com altas doses de nicotina apresentaram exacerbação da doença através de intensa formação de NETs, e animais tratados com antagonista do receptor nAChR- $\alpha 7$ e tratados com nicotina não apresentaram piora da doença. Assim a nicotina foi considerada um potente indutor de NETs via a ativação de nAChR- $\alpha 7$ (Lee et al. 2017). É possível que as diferenças observadas nos estudos da literatura sejam decorrentes de protocolos de experimentação distintos, em especial quanto a via e dose de administração de nicotina, além destes serem administrados em diferentes fases da AR ou de ativação celular.

Com base nos inúmeros efeitos danosos da exposição ao $\mathrm{CC}$ e da sua toxicidade estar relacionada com a queima do tabaco, diversos produtos de tabaco que não sofram 
combustão começaram a surgir no mercado como alternativas ao CC. Dentre os principais produtos de tabaco não combustíveis estão os cigarros eletrônicos e os tabacos aquecidos (WHO, 2020). Embora o surgimento de produtos de tabaco não combustíveis tenham sido propostos como ferramentas para redução de danos através de uma menor emissão de compostos tóxicos, a toxicidade de novos produtos de tabaco e o impacto destas exposições em portadores de diversas doenças crônicas, como a AR, ainda são pouco conhecidos.

\subsection{Novos produtos de tabaco: tabaco aquecido e sua toxicidade}

A toxicidade exercida pelos produtos da queima do tabaco é inquestionável. $\mathrm{O}$ processo de pirólise incompleta do CC é responsável pela liberação de uma miríade de compostos tóxicos responsáveis pelo comprometimento da homeostasia do indivíduo, tanto aos expostos de maneira ativa ou passiva (Benowitz et al. 1999; Stämpfli et al. 2009; Jha et al. 2013). Novos produtos de tabaco começaram a surgir mundialmente como alternativas para o consumo de nicotina (WHO 2020). Embora as tecnologias envolvidas nos produtos sejam diferentes, ambos se objetivam na liberação da nicotina através da ausência da queima do tabaco. Alguns destes dispositivos são caracterizados, segundo o Food and Drug Administration (FDA), como produtos de tabaco com risco modificado (MRTPs). Um produto tido como MRTPs precisa provar ser menos tóxico que o CC, mas ainda gerar a mesma sensação de "prazer" ao ser consumido (Dittrich et al. 2011). Além disso, possíveis candidatos a MRTPs precisam prover estudos in vivo, in vitro e ensaios clínicos comparativos ao $\mathrm{CC}$, apresentando potenciais reduções de toxicidade (Murphy et al. 2017).

Cigarros eletrônicos (e-cigars e vapers) e o tabaco aquecido são produtos fumígenos que liberam nicotina e outros produtos através de um vapor ou aerossol (FDA, 2019; CDC, 2020). Cigarros eletrônicos são soluções líquidas contendo nicotina e/ou aromatizantes, enquanto o tabaco aquecido são produtos que contém tabaco e são baseados na tecnologia heat-not-burn tobacco (HNBT), ou seja, permite o aquecimento do tabaco, mas não a sua combustão (Murphy et al. 2017; FDA, 2019; CDC, 2020). Tanto os cigarros eletrônicos como os HNBT liberam principalmente nicotina, propileno glicol e glicerina, além de emitir cerca de 90-95\% menos produtos tóxicos que um CC (Simonavicius et al. 2019). 
Novos produtos de tabaco podem ser classificados de acordo com o seu sistema de liberação, podendo ser um produto de tabaco com sistema aberto ou fechado. $\mathrm{O}$ sistema aberto permite que o usuário manipule o produto a ser consumido, podendo alterar as concentrações de nicotina, o aromatizante ou até adicionar outras substâncias químicas, como por exemplo, a substância psicoativa da Cannabis sativa, o tetrahidrocanabinol (THC) (Qarajeh \& Kitchen 2020). O sistema fechado não permite tal alteração, onde o produto é adquirido e consumido conforme fabricado (Breland et al. 2018).

O HNBT é baseado no princípio fechado, em que a queima do tabaco é desnecessária para liberação da nicotina. No CC, a nicotina é obtida pela combustão do tabaco, a temperaturas superiores a $600^{\circ} \mathrm{C}$ durante a queima, mas uma liberação semelhante de nicotina é alcançada pelo HNBT através da volatilização do tabaco em temperaturas de cerca de $350^{\circ} \mathrm{C}$. A diminuição da temperatura pela qual o tabaco é aquecido está relacionada à diminuição da emissão de produtos tóxicos oriundos da sua combustão incompleta (Glantiz et al. 2018a). Atualmente, um dos principais dispositivos de HNBT comercializados mundialmente é o IQOS (I quite ordinary smoking) desenvolvido pela Philip Morris International (PMI) (Figura 2).

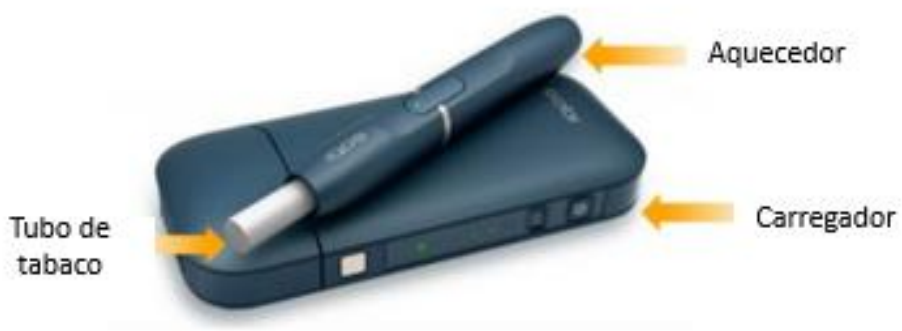

Figura 2. Sistema do dispositivo de tabaco aquecido IQOS. No IQOS, o tabaco é aquecido por uma lâmina no dispositivo de aquecimento inserido na extremidade do tubo de tabaco (heatstick) de modo que o calor se dissipe através do tabaco e libere em forma de aerossol as substâncias presentes nas folha do tabaco e para performance do aerossol. O dispositivo não permite o uso direto de vários heatsticks, sendo que ao final do consumo do heatsick (cerca de 5/6 minutos), o aparelho precisa ser recarregado para ser utilizado novamente (Fonte: PMI).

Acerca da toxicidade do HNBT, em especial o IQOS, poucos estudos independentes sobre os seus efeitos tóxicos em culturas celulares, modelos experimentais e estudos clínicos estão apresentados na literatura (Glantz et al. 2018a; Glantz et al. 2018b; Simonavicius et al. 2019). Os produtos emitidos pelo vapor do 
HNBT, mesmo que em menores concentrações, contêm números similares de substâncias nocivas e potencialmente prejudiciais que a fumaça do CC (Auer et al. 2017; Farsalinos et al. 2018; St Helen et al. 2018). Estudos independentes analisando os componentes tóxicos liberados pelo HNBT apresentaram níveis em cerca de $62 \%$ mais baixos do que os encontrados na fumaça do $\mathrm{CC}$, e uma concentração de aproximadamente 75\% menor de material particulado (PM) (Jaccard et al. 2017; Auer et al. 2017; Bekki et al. 2017; Ruprecht et al. 2017). As concentrações de nicotina encontradas no vapor do HNBT variam de acordo com os métodos analisados e o regime de exposição empregado, onde alguns estudos mostram que o HNBT apresenta concentrações similares ao CC, enquanto outras pesquisas apontam que o HNBT libera cerca de 57 a 83\% de nicotina em relação a cigarros de referência (Jaccard et al. 2017; Auer et al. 2017; Bekki et al. 2017; Farsalinos et al. 2018; Simonavicius et al. 2019).

Estudos independentes avaliando a toxicidade do HNBT ainda são escassos. De maneira geral, modelos in vitro empregando ensaios de citotoxicidade como o ensaio de captação de vermelho neutro (Neutral Red Uptake; NRU), dosagem de lactato desidrogenase (LDH) e \{brometo de [3-(4,5-dimetiltiazol-2yl)-2,5-difenil tetrazolium]\} (MTT) mostraram que células pulmonares (BEAS-2B, A547, NHBE e/ou H292) tratadas com o extrato condensado do $\mathrm{CC}$ apresentaram menor viabilidade quando comparado com o grupo tratado com o extrato condensado do HNBT; porém o HNBT apresentou maior citotoxicidade quando comparado ao grupo exposto a cigarros eletrônicos (Leight et al. 2018a; Davis et al. 2019; Sohal et al. 2019). Além disso, o HNBT libera maiores concentrações de compostos altamente carcinógenos como as nitrosaminas tabaco-específicas ( $N^{\prime}$-nitrosoanabasina, $N^{\prime}$-nitrosoanatabina, 4(metilnitrosamino)-1-(3-piridil)-1-butanona (NNK) e $N^{\prime}$-nitrosonornicotina) do que cigarros eletrônicos, porém menores níveis quando comparado aos emitidos pelo CC (Leight et al. 2018b).

A respeito dos ensaios clínicos, poucos estudos estão publicados na literatura. Os dados disponíveis mostram que a mudança do consumo do CC para o HNBT foi associada à diminuição de biomarcadores relacionados ao estresse oxidativo (8-epiprostaglandina F2 $\alpha$ ), ativação plaquetária (11-desidro-tromboxano B2), função endotelial (molécula de adesão intracelular solúvel-1) e de metabolismo lipídico (HDL) em humanos (Lüdicke et al. 2016). Ainda, outro estudo clínico mostrou que usuários de 
HNBT também apresentaram redução de marcadores de estresse oxidativo e inflamação vascular quando comparado a fumantes de CC (Biondi-Zoccai et al. 2018).

Os sistemas cardiovascular e respiratório são os principais sítios anatômicos investigados nos estudos sobre os efeitos do HNBT (Lüdicke et al. 2016; Biondi-Zoccai et al. 2018). Pouco se sabe sobre os impactos do seu consumo no sistema imune e em portadores de doenças inflamatórias. Em 2016, a PMI solicitou ao FDA a comercialização do dispositivo IQOS na categoria MRTP, onde os dados pré-clínicos apresentadas mostraram que ratos expostos durante 90 dias ao HNBT apresentaram níveis maiores de citocinas inflamatórias no lavado broncoalveolar do que o grupo controle (expostos ao ar). Além disso, os dados apresentados mostraram potencial efeito imunomodulatório das exposições ao HNBT, uma vez que a análise histopatológica do timo de ratos expostos ao HNBT apresentou uma atrofia acentuada, bem como a diminuição do peso do órgão, sugerindo, então, que as exposições ao HNBT desencadearam efeitos imunossupressores nos animais (Wong et al. 2016; Moazed et al. 2018; St. Helen et al. 2018).

O consumo de produtos fumígenos alternativos tem crescido de forma significativa ao redor do mundo, tanto em países onde são aprovados como naqueles que os usuários os utilizam de forma irregular (Palazzolo et al., 2013; Schneider et al., 2016). A literatura, bem como a mídia, tem mostrado que o emprego destes produtos tem facilitado a iniciação ao hábito de fumar em jovens, fato que é muito preocupante, e que fumantes trocam o $\mathrm{CC}$ por estes e os usam indiscriminadamente por acreditarem que não causam toxicidade (Camenga et al. 2014; Staudt et al., 2018).

Desta forma, é primordial que estudos científicos independentes mostrem o real efeito destes produtos alternativos ao $\mathrm{CC}$ e que possam esclarecer a população sobre potenciais efeitos tóxicos. 


\section{JUSTIFICATIVA}

Atualmente, diversas formas para o consumo inalatório da nicotina têm surgido. Entretanto, a toxicidade destes produtos ainda precisa ser investigada. Produtos liberados pela combustão do tabaco são conhecidos por modular mecanismos fisiopatológicos relacionados com a exacerbação da AR, entretanto o efeito de produtos fumígenos não combustíveis, como o HNBT, sobre a AR ainda são desconhecidos, bem como possíveis biomarcadores associados a exposição a estes produtos. Elucidar os potenciais efeitos imunotóxicos de novos produtos de tabaco, além de compreender os mecanismos envolvidos durante a $\mathrm{AR}$ e marcadores expressos frente às exposições, permitirá a implementação de novas políticas regulatórias para produtos de tabaco, além de compreender a imunotoxicidade destes produtos. 


\section{OBJETIVO}

Investigar os efeitos das exposições ao $\mathrm{CC}$ ou ao HNBT sobre os parâmetros clínicos da AIA, além de analisar a expressão de MTs e como exposições a produtos fumígenos afetam funções de linfócitos T, células efetoras na AR. 


\section{MATERIAIS E MÉTODOS}

\subsection{Ensaios in vivo}

\subsubsection{Animais}

Foram utilizados 18 camundongos machos das linhagens C57B1/6 selvagem de 8 a 12 semanas de idade. Os animais foram fornecidos pelo Biotério da Faculdade de Medicina de Ribeirão Preto - USP e pela Rede USP de Biotérios e foram mantidos em caixas de polipropileno, em salas com temperatura controlada $\left(22-25^{\circ} \mathrm{C}\right)$, umidade constante $(60 \%)$ e ciclos controlados (claro/escuro 12 horas cada), tendo ração e água ad libitum. Para os procedimentos experimentais, os animais foram anestesiados com isofluorano. Todos os experimentos foram realizados conforme as normas editadas pelo Conselho Nacional de Controle de Experimentação Animal (CONCEA). Este projeto foi aprovado pela Comissão de Ética no Uso de Animais da Faculdade de Ciências Farmacêuticas de Ribeirão Preto da Universidade de São Paulo (ANEXO 1 e 2).

\subsubsection{Indução da artrite induzida por antígeno (AIA)}

Para a indução da AIA, camundongos machos da linhagem C57B1/6 receberam no dia 0 uma injeção subcutânea de $500 \mu$ g de albumina sérica bovina metilada (mBSA) em uma emulsão de salina e adjuvante completo de Freund (CFA; Sigma Aldrich, St. Louis, MO, EUA), e posteriormente, receberam um reforço nos dias 7 e 14 com a mesma preparação, porém contendo adjuvante incompleto (IFA). No dia 21, os animais foram desafiados na articulação sinovial da pata posterior direita com uma injeção intra-

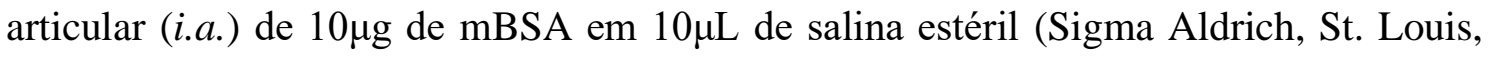
MO, EUA) (Figura 3). Todos os procedimentos foram realizados com os animais anestesiados com isofluorano $2 \%$.

Os parâmetros clínicos avaliados foram: formação de edema, avaliação da hipernocicepção articular pela técnica de von Frey e contagem de células presentes no lavado sinovial 24 horas após o desafio. O edema articular foi medido com o auxílio de um paquímetro eletrônico antes (basal) e 24 horas após o desafio com mBSA. No dia seguinte ao desafio, a cavidade sinovial da articulação desafiada foi lavada com $10 \mu \mathrm{L}$ de PBS com o auxílio de uma micropipeta. Para mensuração da hipernocicepção articular pela técnica de von Frey, os animais foram dispostos em caixas forradas por 
uma malha de arame não maleável, onde antes da avaliação da hipernocicepção, os animais ficaram cerca de 30 a 45 minutos nas caixas para a ambientação. A hipernocicepção foi avaliada utilizando o von Frey eletrônico na região medial da pata posterior direita (região desafiada). A resposta nociceptiva é caracterizada pela flexão seguida de súbita retirada da pata, onde os resultados foram apresentados como limiar mecânico (g).

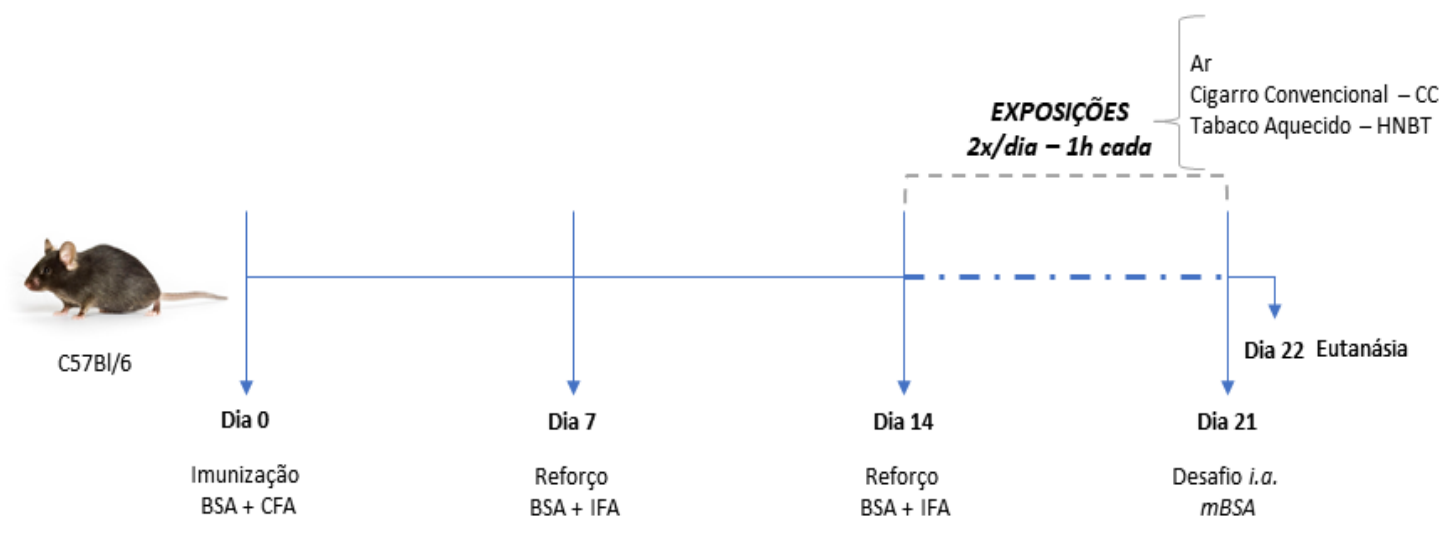

Figura 3. Delineamento Experimental do modelo de AIA.

\subsubsection{Exposições in vivo}

Camundongos foram expostos ao ar, fumaça de CC (Marlboro Red, Phillip Morris) ou vapor de tabaco aquecido (HNBT; IQOS, Phillip Morris International) sob o regime de exposição do Canadá (Health Canada Intensive; HCI) $(55 \mathrm{~mL}$ de fumaça durante um puff de 2 segundos, a cada 30 segundos; Health Canada, 1999). Para tanto, foi projetada uma máquina de exposição (Bonther, Ribeirão Preto, SP, Brasil) permitindo a exposição simultânea de todos os grupos experimentais sob controle da umidade relativa, temperatura e com a exaustão constante do ar para evitar a intoxicação dos camundongos. A fumaça do CC e o vapor do HNBT gerado pelos heatsticks foram aspirados por uma bomba de pistão a vácuo e enviados para as respectivas câmaras de exposição contendo os animais. Os camundongos foram expostos durante 1 hora, duas vezes ao dia (uma exposição no período matutino e outra no período vespertino) para mimetizar o consumo de cigarros por fumantes pesados (Wilson et al., 1992). O número de cigarros e heatsticks usados foi igualado pela quantidade de nicotina para cada hora de exposição. Um total de 12 cigarros convencionais e 24 heatsticks foram usados por 
hora de exposição (Figura 4). Salientamos que, uma vez que a comercialização do dispositivo IQOS não é permitida no Brasil, a importação dos insumos e dos aparelhos foi autorizada pela ANVISA para o desenvolvimento do presente projeto.

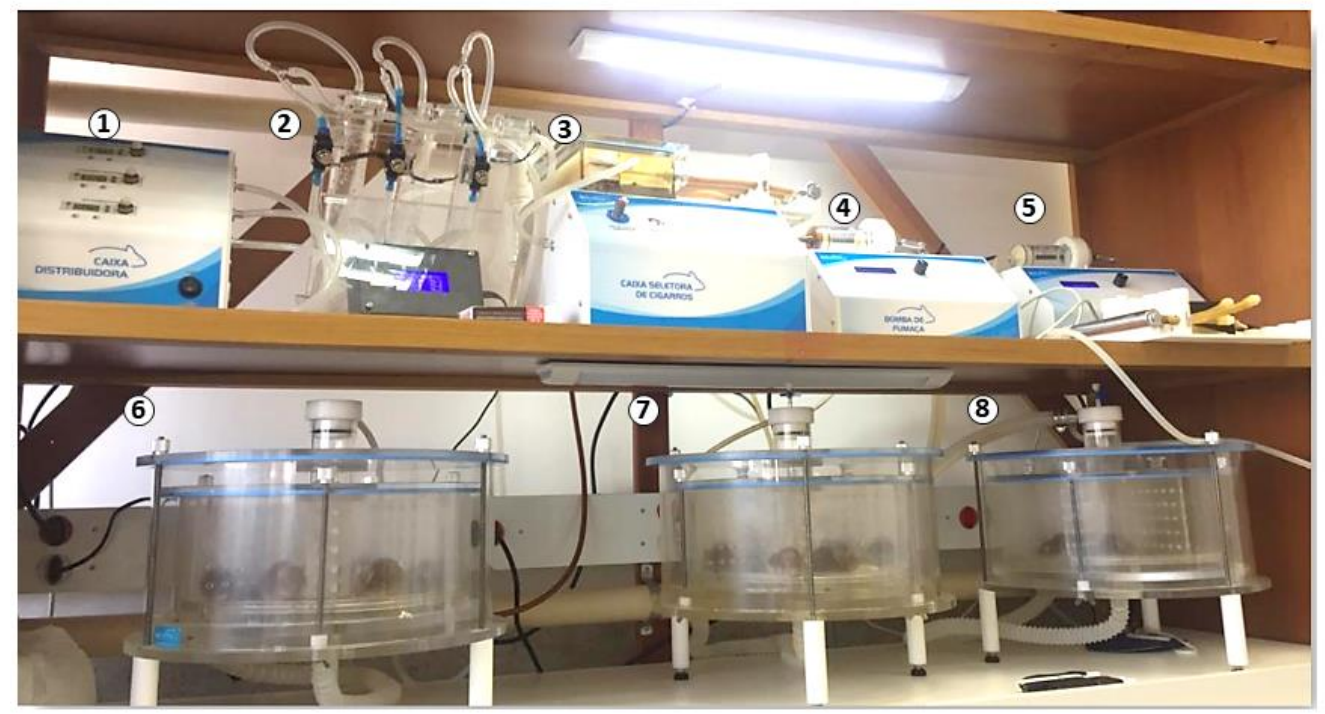

Figura 4. Sistema de exposição in vivo. A máquina de exposição consiste em uma caixa distribuidora de fumaça, que regula a pressão e o fluxo da fumaça para as câmaras (1) e a umidade relativa do ar (2). A fumaça de cigarro é gerada pela combustão do cigarro (3) e entregue aos animais através da sucção por uma bomba de pistão (4), enquanto o vapor do HNBT é liberado por uma bomba de pistão acoplada a um banho-maria que mantém as características físicas do vapor, evitando a sua condensação (5). No final, cada câmara recebe simultaneamente um fluxo de ar (6), fumaça de cigarro diluída com ar ambiente (7) ou vapor do HNBT diluído com ar ambiente (8).

\subsubsection{Determinação de nicotina e cotinina sérica}

Para determinação dos níveis séricos de nicotina e cotinina, uma alíquota de $15 \mu \mathrm{L}$ de uma solução de acetonitrila/metanol (80:20, v/v) foi adicionada às amostras de

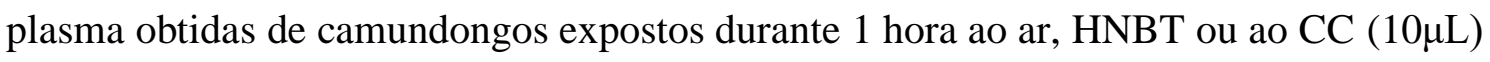
com adição de $5 \mu \mathrm{L}$ do padrão interno (testosterora-d3; $1 \mu \mathrm{g} / \mathrm{mL}^{-1}$ ). Após centrifugação por 10 minutos a $9000 \mathrm{~g}$, uma alíquota de $10 \mu \mathrm{L}$ foi injetada no sistema UHPLC-ESI-MS / MS para quantificação de nicotina e cotinina. O sistema analítico consistiu em um sistema Nexera UFLC acoplado a um espectrômetro de massa quadrupolo triplo (LCMS-8040; Shimadzu, Kyoto, Japão). Os parâmetros de electrospray foram definidos no modo de íon positivo da seguinte forma: tensão capilar, $4500 \mathrm{~V}$; temperatura da linha de dessolvatação, $250^{\circ} \mathrm{C}$; temperatura do bloco de aquecimento, $400^{\circ} \mathrm{C}$; gás de secagem, 181/min; e nebulização de gás, 21/min. A dissociação induzida por colisão foi 
obtida com pressão de gás argônio de $230 \mathrm{kPa}$. As análises foram realizadas com monitoramento de reação múltipla $(\mathrm{MRM})$ usando as seguintes fragmentações $[\mathrm{M}+\mathrm{H}]$ +: $\mathrm{m} / \mathrm{z} 163,3 \rightarrow 130,1$ para detecção de nicotina; $\mathrm{m} / \mathrm{z} 176,9 \rightarrow 80,0$ para detecção de cotinina; e m/z 292,0 $\rightarrow 97,0$ para detecção de testosterora-d3. As curvas de calibração foram construídas nos intervalos de 5 a $250 \mathrm{ng} / \mathrm{mL}^{-1}$ para cada composto. A separação cromatográfica foi alcançada em $75 \times 2,0 \mathrm{~mm}$ id, 2,2 $\mu \mathrm{m}$, coluna Shim-pack XR-ODS II (Shimadzu, Kyoto, Japão) eluida com taxa de fluxo de $300 \mu \mathrm{L} \mathrm{min}{ }^{-1}$ e $50^{\circ} \mathrm{C}$ com um gradiente de 0,1\% de ácido fórmico em água (A) e metanol (B) como segue: 0 - 1,5 min, 10 - 100\% de B; 1,5 - 2,0 min, 100 de B; 2,0 - 2,1 min, 100 - 10\% de B; 2,1 - 5,0 min, 10\% de B. Para avaliação de dados, o software LabSolutions (Shimadzu, Kyoto, Japão) foi usado para obter áreas de pico. Os dados foram apresentados em $\mathrm{ng} / \mathrm{mL}$ de analito.

\subsubsection{Quantificação de metais liberados na câmara de exposição}

Filtros de membrana de éster-celulose (porosidade de $0,8 \mu \mathrm{m}$, diâmetro de 37 mm; Millipore, Burlington, MA, EUA) foram colocados na câmara de exposição e expostos ao ar, CC e vapor de HNBT durante 1 hora para os ensaios in vivo ou 30 minutos para os ensaios in vitro (4.2.2). Os filtros foram cuidadosamente removidos e digeridos usando um forno de micro-ondas (MARS 6) seguindo um método de digestão ácida. O método se baseia na adição de $5 \mathrm{~mL}$ de água ultrapura (MiliQ) e $5 \mathrm{~mL}$ de HNO3 (Sigma Aldrich, St Louis, MO, EUA) em recipientes contendo os filtros expostos durante 25 minutos ( 15 minutos no estágio de rampa e 10 minutos em espera a $180^{\circ} \mathrm{C}$ ). Em seguida, foram adicionados $5 \mathrm{~mL}$ de água ultrapura e a concentração dos metais ( $\mathrm{Mn}, \mathrm{Al}, \mathrm{Cr}, \mathrm{Fe}, \mathrm{Ni}, \mathrm{Cu}, \mathrm{Zn}, \mathrm{As}, \mathrm{Cd}$ ) foi quantificado por um Espectrômetro de massa com plasma indutivamente acoplado (ICP-MS; Agilent Technologies, Santa Clara, CA, EUA).

\subsubsection{Análises histopatológicas}

Após os períodos de exposições e a eutanásia, o pulmão foi coletado para processamento histológico e para posteriores análises histopatológicas. As amostras obtidas foram embebidas em paraformaldeído $4 \%$ (para fixação), seguida da inclusão das amostras em parafina para o processo de microtomia. Após a montagem das lâminas, estas foram coradas com solução de hematoxilina e eosina (HE) para análise histopatológica. Para quantificar as alterações histopatológicas observadas nas secções, 
foi realizada uma quantificação da inflamação tecidual. Para avaliar a inflamação pulmonar, os seguintes critérios foram aplicados: infiltrado de células inflamatórias, diminuição dos espaços interalveolares e presença de focos hemorrágicos. Para tal análise, 7 campos de cada lâmina foram analisados no aumento de 10x, onde foram aplicadas pontuações arbitrárias de 0 a 4 de acordo com a intensidade do parâmetro avaliado, onde no final, sendo 0 a ausência dos parâmetros analisados e $4100 \%$ do comprometimento pulmonar (Matute-Bello et al., 2011). Os parâmetro foram somados e uma média foi obtida referente ao score de inflamação pulmonar.

\subsubsection{Imunohistoquímica para detecção de MTs}

Para avaliar a expressão de MTs nos tecidos, foi empregado a técnica de imunohistoquímica, onde as lâminas passaram por processo de desparafinização em banhos de xilol, hidratação em banhos gradativos de etanol, e seguido pela revelação antigênica através da incubação com citrato de sódio $(0,1 \mathrm{M})$ por 30 minutos em banhomaria a $96^{\circ} \mathrm{C}$. Em seguida, as lâminas foram lavadas com tampão Tris com 0,25\% de polissorbato 20 (TBS-T), permeabilizadas com solução de TBS e Triton-100X 0,01\% (Sigma Aldrich, St. Louis, MO, EUA), seguido do bloqueio de peroxidase endógena com 3 incubações de 10 minutos com solução de peróxido de hidrogênio $3 \%$ e bloqueio de sítios inespecíficos com solução de TBS e BSA 5\%. Em seguida, as lâminas foram incubadas com o anticorpo purificado anti-MTs 1 e 2 (Diluição 1:250; ABCAM, London, UK) overnight. Por fim, as lâminas foram lavadas com tampão TBS-T e incubadas com anticorpo secundário conjugado com HRP (1:250; ABCAM, London, UK), seguindo para revelação com substrato de diaminobenzidina (DAB), (Invitrogen, Carlsbad, CA, USA). A quantificação da intensidade relativa das áreas imunorreativas foi realizada utilizando o software ImageJ.

\subsection{Ensaios in vitro}

\subsubsection{Cultivo celular}

Para avaliar os efeitos das exposições in vitro sobre a biologia de linfócitos $\mathrm{T}$, utilizamos células T Jurkat, uma linhagem de linfócitos $\mathrm{T}$ de origem humana adquiridas do Banco de Células do Rio de Janeiro (BCRJ; Rio de Janeiro, RJ, Brasil). Para simular os efeitos das exposições em um ambiente inflamatório, células Jurkat foram tratadas com 5nM de phorbol 12-myristate 13-acetate (PMA). Para os ensaios de polarização, foram utilizados linfócitos $\mathrm{T} \mathrm{CD}^{+}$isolados do baço e dos linfonodos drenantes de 
camundongos macho C57B1/6 naive. As células foram mantidas em cultura em meio RPMI 1640 contendo $10 \%$ de soro fetal bovino e $1 \%$ de penicilina e estreptomicina (InvitroCell, Campinas, SP, Brasil), sob atmosfera de $5 \%$ de $\mathrm{CO}^{2}$ a $37^{\circ} \mathrm{C}$.

\subsubsection{Exposições in vitro}

Células T Jurkat foram cultivadas sobre inserts transwell de $12 \mathrm{~mm}$ de diâmetro e $0,4 \mu \mathrm{m}$ de porosidade (Corning, New York, NY, EUA) em uma densidade celular de $1 \times 10^{6}$ por poço, e expostas ao ar, HNBT ou CC utilizando uma câmara de acrílico desenvolvida pela British American Tobacco - BAT (Londres, UK). O sistema de exposição in vitro empregado (Bonther, Ribeirão Preto, SP, Brasil) é composto por dois bombas peristálticas, uma responsável por bombear o fluxo de ar, fumaça ou vapor para a câmara de exposição, e outro para manter o fluxo contínuo do meio de cultura. $\mathrm{O}$ regime de exposição consistiu em um ciclo de 2 segundos de exposição a fumaça ou ao vapor do tabaco aquecido (à 45 RPM) seguido de 58 segundos de fluxo de ar (à 25 RPM) durante 30 minutos, juntamente ao fluxo contínuo de meio RPMI 1640 não suplementado (à 20 RPM) (Figura 4).

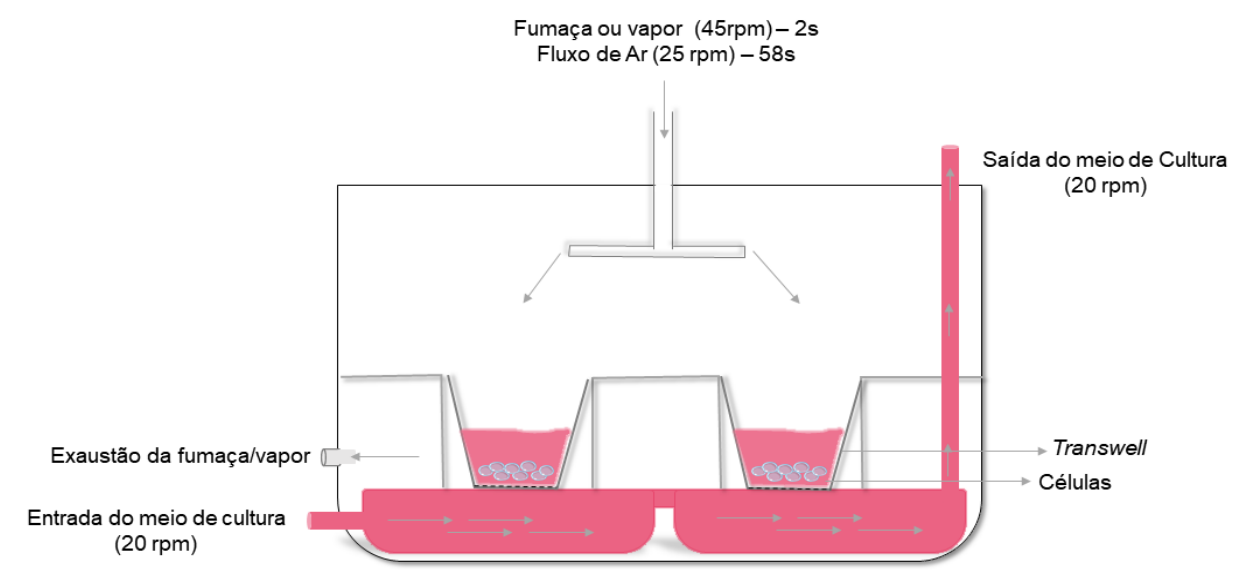

Figura 5. Sistema de exposição in vitro

\subsubsection{Viabilidade celular}

Para analisar o impacto das exposições na viabilidade celular e o tipo de morte gerada pelas exposições, células T Jurkat foram coletadas 24 horas após as exposições. Em seguida, foram centrifugadas a $200 g$ por 10 minutos, e ressuspendidas em $200 \mu \mathrm{L}$ de tampão de ligação para a marcação com Anexina V conjugada com isotiocianato de fluoresceína (AnxV-FICT) (diluição 1:100) e com Iodeto de Propídio (PI) (diluição 1:400) (BD Biosciences, Franklin Lakes, NJ, USA). As células foram incubadas por 30 
minutos ao abrigo da luz e em temperatura ambiente, onde em seguida, foi realizada a leitura por citometria de fluxo utilizando o equipamento Accuri C6 (BD Biosciences, Franklin Lakes, NJ, USA). Foram recordados 10 mil eventos, onde os resultados foram expressos em porcentagem (\%). O grupo duplo negativo para marcação AnxV-PI se refere as células viáveis, marcação única com $\mathrm{AnxV}$ se refere as células em apoptose, marcação única com PI se refere as células em necrose e o grupo duplo positivo para AnxV-PI se refere ao grupo de células em apoptose tardia ou necroapoptose.

\subsubsection{Detecção de espécies reativas de oxigênio}

A produção de espécies reativas de oxigênio (EROs) foi avaliada 45 minutos após as células serem expostas. Para tanto, após as exposições células T Jurkat foram incubadas por 45 minutos a $37^{\circ} \mathrm{C}$, em seguida, foram coletadas e centrifugadas a $200 \mathrm{~g}$ por 10 minutos para remoção do meio de cultivo. Posteriormente, foram lavadas com $200 \mu \mathrm{L}$ de PBS gelado, centrifugadas novamente e incubadas com $200 \mu \mathrm{L}$ de uma solução a 1mM de diclorofluoresceína diacetato (DCFH-DA; Invitrogen, Carlsbad, CA, USA) diluída em metanol por 30 minutos a $37^{\circ} \mathrm{C}$ e em seguida, $200 \mu \mathrm{L}$ de PBS gelado foram adicionados e a leitura por citometria de fluxo foi realizada em seguida. Dez mil eventos foram recordados e os resultados foram expressos como intensidade mediana de fluorescência (MFI).

\subsubsection{Determinação de óxido nítrico}

A concentração de óxido nítrico (NO) foi realizada no sobrenadante celular 24 horas após as exposições e tratamentos com PMA (5 nM). Para tanto, 100 $\mu \mathrm{L}$ de sobrenadante foram adicionados a $100 \mu \mathrm{L}$ de reagente de Griess $(1 \%$ de sulfanilamida com 0,1\% de alfa-naftil etilenodiamina; Sigma Aldrich, St Louis, MO, EUA). Após 10 minutos de incubação em temperatura ambiente, a absorbância foi determinada por espectrofotometria (Spectra Max 190, Molecular Devices, Sunnyvale, CA, EUA) com comprimentos de onda de 550nm. Uma curva padrão de nitrito de sódio $(0,2-200 \mu \mathrm{M})$ para determinação da concentração de NO das amostras foi utilizada.

\subsubsection{Expressão de MTs, 8-OHdG e NFkB por citometria de fluxo}

A ativação de NFkB, expressão de MTs e formação de 8-oxo-hidroxideoxiguanosina (8-OHdG) em células $\mathrm{T}$ Jurkat expostas foi avaliada por citometria de fluxo. Ao final das exposições, células foram tratadas ou não com PMA (5 nM) por 30 
minutos para avaliar a ativação de NFאB (p65) e 24 horas para determinar as expressões de MTs e 8-OHdG. Para análise, as células expostas foram submetidas aos mesmos processamentos. As células foram fixadas com $100 \mu \mathrm{L}$ de FACS Lysing (BD Biosciences, San Jose, CA, EUA) por 20 minutos em temperatura ambiente, depois lavadas com 0,1M de glicina e com PBS contendo $1 \%$ de BSA. As células foram permeabilizadas com solução de PBS e Triton-100X a 0,1\% (Sigma-Aldrich) por 30 minutos em temperatura ambiente. Depois de permeabilizadas, as células foram incubadas com anti-NFkB-p65 conjugado com aloficocianina (APC; 1:150; BioLegend, CA, EUA), ou com os anticorpos primários purificados anti-MTs 1 e 2 ou anti-8-OHdG (1:200; Abcam, Cambridge, Reino Unido) overnight a $4^{\circ} \mathrm{C}$. Após as incubações, as células foram lavadas com PBS contendo 0,1\% BSA e incubado com anticorpos secundários conjugados com ficoeritrina (PE), FITC ou AlexaFluor 647 (todos diluídos a 1:200; Abcam, Cambridge, UK) por 1 hora em temperatura ambiente e ao abrigo da luz. Por fim, 10.000 eventos foram recordados no citômetro de fluxo (Accuri C6; Becton Dickinson, EUA). Os dados foram apresentados como intensidade mediana de fluorescência (MFI).

\subsubsection{Quantificação de citocinas}

Níveis de fator de necrose tumoral alfa (TNF- $\alpha$ ), interferon gama (IFN- $\gamma$ ) e interleucina-8 (IL-8) e 2 (IL-2) foram quantificados 24 horas após o término das exposições no sobrenadante das células Jurkat tratadas ou não com PMA (5 nM; 24 horas). TNF- $\alpha$, IFN- $\gamma$ e IL- 8 foram quantificados usando ELISA Ready-SET- GO-2 ${ }^{\text {a }}$ geração (sensibilidade analítica: $4 \mathrm{pg} / \mathrm{mL}, 4 \mathrm{pg} / \mathrm{mL}$ e $2 \mathrm{pg} / \mathrm{mL}$, respectivamente; Invitrogen, Carlsbad, CA, EUA). A secreção de IL-2 foi quantificada usando o kit BD OptEIA (sensibilidade analítica: 7,8 pg/mL BD Biosciences, San Jose, CA, EUA). Os procedimentos foram realizados de acordo com as instruções do fabricante.

\subsubsection{Ensaio de proliferação celular}

Para monitorar o impacto das exposições na proliferação celular, células $T$ Jurkat foram incubadas com uma solução de éster succinimidil carboxifluoresceína $\left(5 \mu \mathrm{M}, \mathrm{CFSE}\right.$; Thermo Fischer, Carlsbad, CA, EUA) por 20 minutos a $37^{\circ} \mathrm{C}$, lavadas uma vez com PBS e ressuspensas em meio RPMI 1640 contendo 10\% FBS. Em seguida, as células foram expostas de acordo com o item 4.2.2, plaqueadas em uma 
densidade celular de $5 \times 10^{5}$ células/poço em uma placa de 96 poços de fundo U (Corning, NY, EUA) estimuladas com PMA (5nM) e cultivado por 72 horas. A fim de investigar os efeitos da fumaça de CC, vapor de HNBT e da nicotina na proliferação celular, as células T Jurkat foram expostas a vapor de CS ou HNBT ou tratadas com diferentes concentrações de nicotina $(1 \mu \mathrm{M}, 10 \mu \mathrm{M}$ ou $100 \mu \mathrm{M}$; Sigma Aldrich, St. Louis, MO, EUA) e estimuladas com 10UI/mL de interleucina-2 recombinante humana (rIL-2, BD Bioscience, Becton Dickinson, EUA). A intensidade de fluorescência das células marcadas com CFSE foi mensurada por citometria de fluxo (Accuri C6, Becton Dickinson, EUA) e 30.000 eventos foram recordados para as análises. Os dados foram analisados no software FlowJo e apresentados através da razão do MFI das células expostas em relação ao grupo basal/controle.

\subsubsection{Isolamento de linfócitos T CD4 ${ }^{+}$}

Após anestesiados e eutanasiados, o baço e os linfonodos drenantes inguinais de camundongos macho C56B1/6 naive foram coletados com auxílio de pinças e tesouras cirúrgicas. Após a coleta, os órgãos foram macerados gentilmente em meio RPMI 1640 com $10 \%$ de SFB com o auxílio de um êmbolo de seringa. O homogenato foi submetido a extração celular com o auxílio de um Cell Strainer de $40 \mu \mathrm{m}$, sendo completado para $10 \mathrm{~mL}$ de meio de cultivo celular após a extração. A suspenção celular foi centrifugada a $200 \mathrm{~g}$ durante 10 minutos, onde após isso, o sobrenadante foi cuidadosamente desprezado e 5mL de tampão de lise (tampão de cloreto de amônia a 0,1M gelado) foi adicionado, homogeneizando cuidadosamente o pellet celular, e após isso, a suspenção celular permaneceu 3 minutos em gelo, sendo centrifugada a $200 \mathrm{~g}$ durante 10 minutos novamente. Após a lise completa das hemácias, o sobrenadante foi desprezado e o pellet foi homogeneizado em tampão MACS (solução de PBS, 5\% de SFB e 0,2 $\mu \mathrm{M}$ de EDTA) para contagem celular e incubação com o coquetel de microesferas magnéticas para posterior passagem pelo separador magnético. Para a separação de linfócitos T CD4 ${ }^{+}$ naive foi utilizado o método de seleção negativa, ou seja, as células marcadas ficam retidas na coluna, permitindo a passagem apenas da população de interesse. Ao final do isolamento, a pureza da população de interesse foi averiguada por citometria de fluxo,

onde $1 \times 10^{5}$ células foram incubadas com anti-CD4 conjugado com FICT. Apenas amostras com pureza acima de $90 \%$ foram utilizadas nos ensaios. 


\subsubsection{Ensaio de polarização de linfócitos Th17}

Linfócitos T CD4+ naive isolados do baço e dos linfonodos drenantes de camundongos C56B1/6 foram expostos ao CC, HNBT e ou ar de acordo com o item 4.2.2. Após as exposições as células foram cultivadas em condições de polarização para Th17. Para tanto, placas de 96 poços em fundo em $U$ foram sensibilizadas 2 horas antes dos ensaios com anti-CD3 $(2 \mathrm{ng} / \mathrm{mL})$. Em seguida, $5 \times 10^{5}$ de linfócitos T CD4 ${ }^{+}$foram adicionados a cada poço em condições de polarização para Th17 $(25 \mathrm{ng} / \mathrm{mL}$ de mIL-6 e $5 \mathrm{ng} / \mathrm{mL}$ de mTGF- $\beta$ ) e estimuladas com anti-CD28 solúvel $(2 \mathrm{ng} / \mathrm{mL})$. As células permaneceram em cultura durante 72 horas, onde ao final, foram estimuladas com ionomicina $(500 \mathrm{ng} / \mathrm{mL})$ e PMA $(50 \mathrm{ng} / \mathrm{mL})$ durante 4 horas. As células foram coletadas, lavadas com PBS, fixadas e permeabilizadas por 20 minutos em temperatura ambiente com $100 \mu \mathrm{L}$ do kit CytoPerm/CytoFix (BD Bioscience), e em seguida, foram lavadas com $100 \mu \mathrm{L}$ do tampão de lavagem específico do kit. Após isso, as células foram centrifugadas 10 minutos a $200 \mathrm{~g}$ e o pellet foi incubado com os anticorpos anti-CD4FICT e anti-IL17-PE (diluição 1:50 e 1:100, respectivamente; BD Bioscience). Os dados obtidos foram expressos em porcentagem, onde 10 mil eventos foram obtidos por citometria de fluxo.

\subsubsection{Expressão de AhR}

Para analisar os efeitos das exposições sobre a expressão de AhR, esplenócitos foram expostos conforme o item 4.2.2, onde os níveis de AhR foram analisados 2 horas após as exposições através de citometria de fluxo. Para tanto, após as exposições, as células foram coletadas, fixadas e permeabilizadas por 20 minutos a temperatura ambiente com $100 \mu \mathrm{L}$ do kit CytoPerm/CytoFix (BD Bioscience), e em seguida, foram lavadas com $100 \mu \mathrm{L}$ do tampão de lavagem específico do kit. Após isso, as células foram centrifugadas 10 minutos a $200 \mathrm{~g}$ e o pellet foi incubado overnight com anticorpo purificado anti-AhR (1:200; Abcam, UK). No dia seguinte, as células foram lavadas 2 vezes com PBS e incubadas 1 hora em temperatura ambiente e ao abrigo da luz com anticorpo secundário conjugado com FICT (1:200). Finalmente, as células foram novamente lavadas e ressuspendidas em $200 \mu \mathrm{L}$ de PBS para leitura no citômetro de fluxo. Para as análises, 10 mil eventos foram recordados e os resultados foram apresentados com base na intensidade mediana de fluorescência (MFI). 


\subsection{Análises estatísticas}

Os resultados obtidos foram apresentados como média \pm erro padrão da média (E.P.M.) e foram analisados estatisticamente pelo Teste " $t$ " de Student ou pela Análise de Variância com comparações múltiplas (ANOVA), seguido do teste de TukeyKramer, quando necessário. Para tanto, foi utilizado o programa estatístico Graphpad Prism 7.0. Os valores obtidos serão considerados significativos quando $p<0,05$. 


\section{RESULTADOS}

\subsection{Dosagem da concentração sérica de nicotina e cotinina em animais expostos 1 hora}

Produtos de tabaco aquecido são categorizados por libarem concentrações de nicotina similares ao CC e por emitirem níveis menores de produtos de combustão. Os animais foram expostos ao $\mathrm{CC}$ ou ao HNBT com base nos níveis de nicotina liberada e absorvida pelos camundongos. Visando validar nossa abordagem experimental, empregamos um grupo de animais expostos apenas 1 hora ao CC, HNBT ou ao ar, onde após este período, o sangue total foi coletado e foram quantificados os níveis séricos de nicotina e cotinina e. Animais expostos ao vapor do HNBT ou a fumaça do CC apresentaram concetrações equivalentes de nicotina e cotinina sérica 1 hora após as exposições (Figura 6A e B). Em conjunto, os dados obtidos certificam que os animais dos grupos CC e HNBT estavam expostos às mesmas concentrações de nicotina.

A)

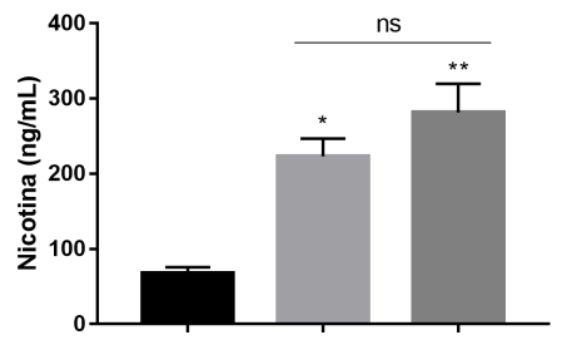

B)

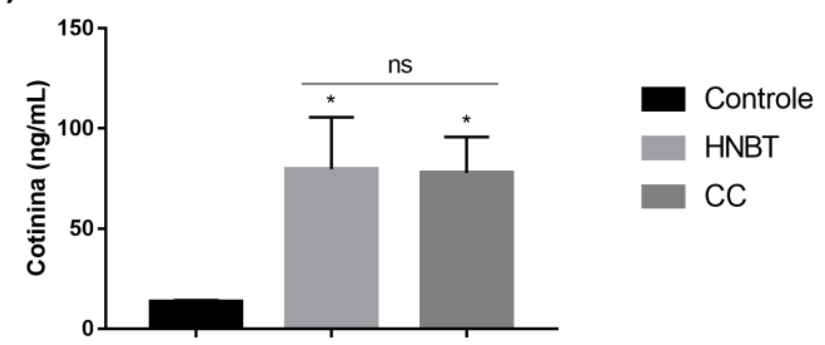

Figura 6. Concentração sérica de nicotina e cotinina em animais expostos. Camundongos C57B1/6 foram expostos durante 1 hora ao ar, CC (12 cigarros) ou HNBT (24 heatsticks). Ao término das exposições, o sangue total e plasma foram coletados para determinação dos níveis séricos de nicotina (A) e cotinina (B). Resultados exibidos como média \pm erro padrão da média (n=5). ns: não significativo; ${ }^{*} \mathrm{p}<0,05 \mathrm{e} * * \mathrm{p}<0,01$ vs grupo ar.

\subsection{Exposições ao CC, mas não ao HNBT, exacerbam os sinais clínicos da AIA}

O presente projeto de mestrado foi desenvolvido concomitantemente ao projeto de pós-doutoramento da Dr. Cintia Heluany e em colaboração com o professor Dr. Fernando Cunha, do laboratório de Inflamação e Dor da Faculdade de Medicina da USP-RP. Sendo assim, os resultados dos parâmetros clínicos são compartilhados com a Dra. Heluany, uma vez que coletamos amostras dos mesmos animais no sentido de otimizar o número de animais e insumos de exposição empregados. A apresentação 
destes dados neste trabalho é importante para correlacionar a intensidade da artrite experimental com os demais resultados aqui obtidos.

Durante o protocolo de AIA, optamos por expor os animais na fase tardia do modelo experimental, visando observar se as nossas condições experimentais modulavam a fase mais crítica da doença. Animais expostos ao CC apresentaram aumento na hipernocicepção e na formação de edema quando comparados ao grupo expostos ao ar ou ao HNBT (Figura 7). Ainda, o grupo exposto ao CC apresentou maior infiltrado celular na cavidade articular 24 horas após o desafio, em relação ao grupo exposto ao HNBT ou ao ar (Figura 7).
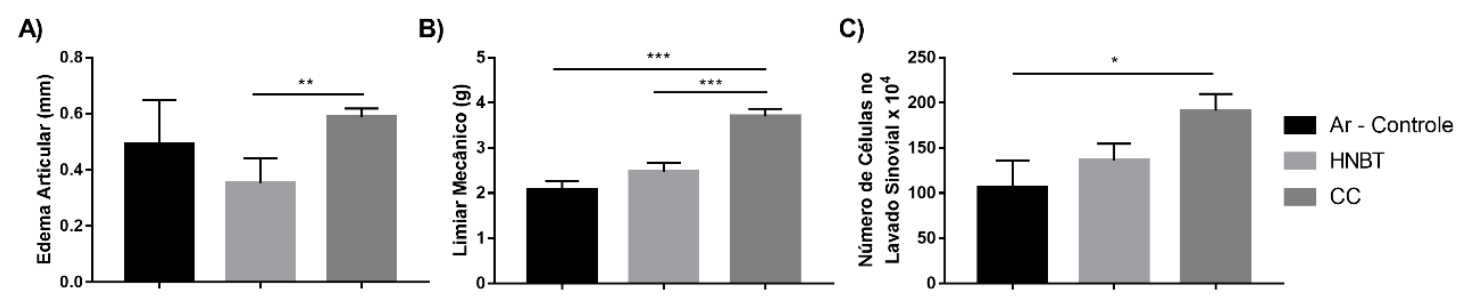

Figura 7. Efeito das exposições ao CC, HNBT ou ao ar sobre parâmetros clínicos na fase tardia da AIA. Camundongos na vigência de AIA foram expostos entre os dias 14 e 21 após a primeira imunização. As exposição ocorreram duas vezes ao dia, por 1 hora cada. As exposições compreenderam 12 cigarros ou 24 heatsticks de HNBT por hora. No dia 21, os animais receberam desafio intra-articular de mBSA ou salina, onde o edema (A) e hipernocicepção (B) foram quantificados com base no valor basal prévio ao desafio. As células do lavado sinovial (C) foram quantificadas 24 horas após o desafio. Resultados expressos em média \pm erro padrão da média $(\mathrm{n}=5)$. ${ }^{*} \mathrm{p}<0,05$ vs grupo ar, **p<0,01 vs grupo HNBT, *** p $<0,001$ vs grupo ar e HNBT.

\subsection{Efeito das exposições ao CC e HNBT sobre a inflamação pulmonar}

A AR é uma doença inflamatória sistêmica que apresenta manifestações extra articulares, dentre elas, se destaca a doença intersticial pulmonar que está relacionada com a mortalidade de 10 a $20 \%$ dos pacientes com AR (Yount \& Solomon, 2015). A pleura, as vias aéreas, bem como os espaços intersticiais do pulmão, podem ser afetadas em decorrência de uma intensa infiltração leucocitária no pulmão, ocorrendo comprometido da funcionalidade do órgão (Schurgers et al., 2012). Animais expostos ao CC apresentaram aumento na inflamação pulmonar em comparação ao demais grupos (Figura 8A-F). As alterações histopatológicas observadas e pontuadas na figura mostram o aumento de infiltrado inflamatório e diminuição dos espaços intra-alveolares associados com uma inflamação pulmonar intersticial e aumento da espessura da parede alveolar (Figura 8G). 


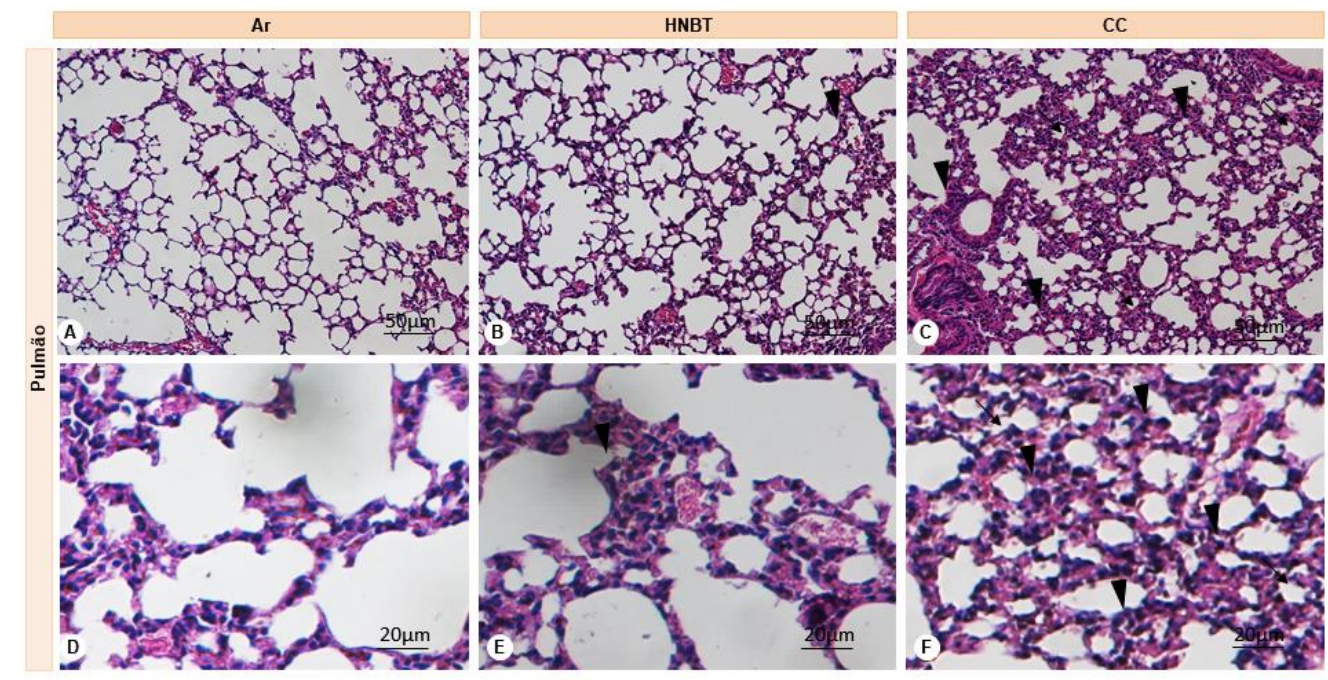

G)

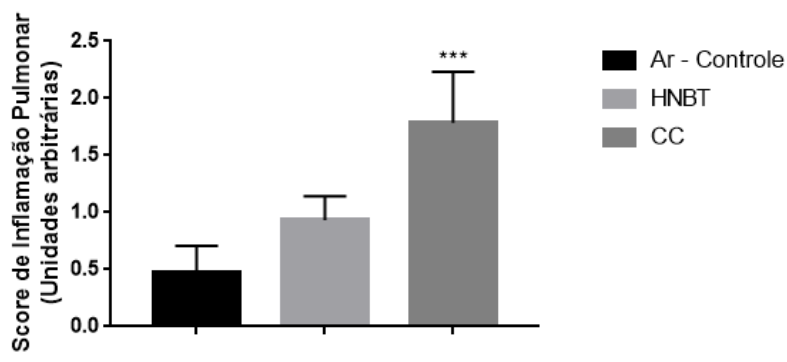

Figura 8. Efeitos das exposições ao ar, HNBT ou CC sobre a histopatologia e inflamação pulmonar.

As exposição ocorreram duas vezes ao dia, por 1 hora cada e as exposições compreenderam 12 cigarros ou 24 heatsticks de HNBT por hora. No dia 21, os animais receberam um desafio intra-articular de mBSA ou salina e foram sacrificados 24 horas após. Campos representativos de animais expostos ao ar (A-D), ao HNBT (B-E) ou ao CC (C-F) As flechas indicam o espessamento dos espaço alveolares, e cabeça de flexa indica infiltrado leucocitária. A avaliação do score inflamatório foi realizada com base na presença de infiltrados inflamatórios e diminuição dos espaços intra-alveolares, onde 7 campos por lâminas foram analisados e pontuados de 0 a 4 de acordo a intensidade do parâmetro analisado (G). Resultados expressos em média \pm erro padrão da média $(\mathrm{n}=5)$. Corte de $4 \mu \mathrm{M}$, aumento de 10x (A-C) e 40x (D-F), coloração de hematoxilina e eosina. *** $<<0,001$ vs ar e HNBT.

\subsection{Quantificação de metais liberados nas câmaras de exposição in vivo e expressão de MTs pulmonares e hepáticas}

A combustão do tabaco é responsável por liberar diversos componentes tóxicos ao ambiente e ao usuário, dentre eles, metais pesados (Kiezek et al., 2013). Para detectar a liberação de metais nas exposições preconizadas no estudo, filtros de éster celulose foram dispostos nas câmaras de exposições para quantificar os níveis de metais pesados aos quais os animais estavam expostos. Durante 1 hora de exposição, foi possível 
detectar apenas níveis de alumínio $(\mathrm{Al})$, crômio $(\mathrm{Cr})$, cobre $(\mathrm{Cu})$ e níquel (Ni) (Figura 9), onde a concentração dos demais metais analisados (cádmio, arsênio, ferro e manganês) ficou abaixo do limite de detecção do método empregado (dados não reportados).

A queima do $\mathrm{CC}$ liberou quantidades elevadas de $\mathrm{Al}, \mathrm{Cr}, \mathrm{Cu}$ e $\mathrm{Ni}$, sendo muito superiores às quantidades liberadas pelo HNBT. Os valores para exposição ao HNBT foram similares à exposição ao ar, sendo que os valores de al e $\mathrm{Cu}$ não foram detectados, indicando a liberação muito menor destes metais do que o CC (Figura 9 A e D).
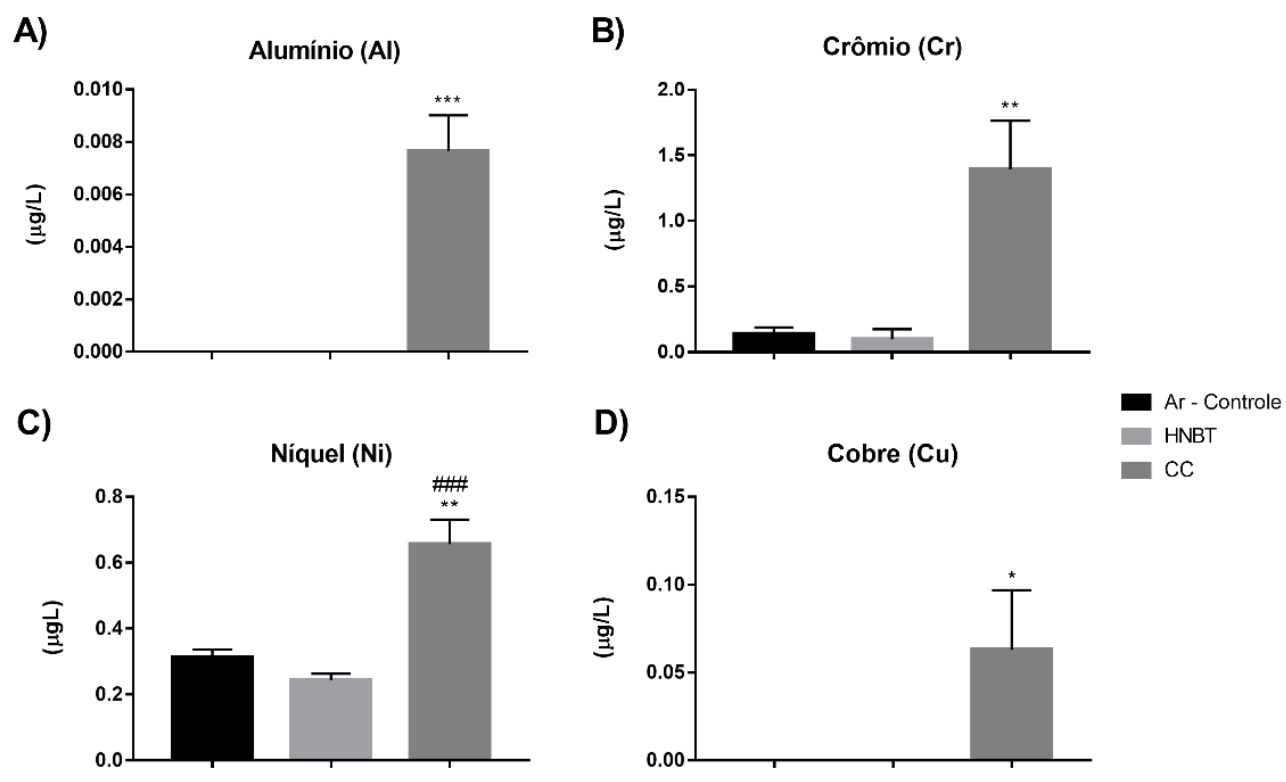

Figura 9. Níveis de metais liberados nas câmaras de exposição in vivo. Filtros de éster celulose foram dispostos nas câmaras dos camundongos e expostos durante 1 hora a 12 cigarros e 24 heatsticks de HNBT para avaliar as concentrações dos metais alumínio $(\mathbf{A})$; crômio $(\mathbf{B})$, níquel $(\mathbf{C})$ e cobre $(\mathbf{C u})(\mathbf{D})$. Resultados expressos em média \pm erro padrão da média $(\mathrm{n}=5)$. ${ }^{*} \mathrm{p}<0,05$ vs grupo ar e HNBT, $* * \mathrm{p}<0,01 v s$ grupo ar e HNBT, *** $\mathrm{p}<0,001$ vs grupo ar e HNBT. \#\#\# $\mathrm{p}<0,01$ vs grupo HNBT.

Metais pesados, assim como diversos componentes presentes na fumaça de cigarro, possuem potencial imunotóxico e geram efeitos danosos ao organismo, como inflamação e estresse oxidativo (Shen et al. 2001; Ohsawa, 2008). Em resposta, o organismo lança mão de mecanismos capazes de neutralizar o estresse sofrido, como por exemplo, expressando MTs (Lynes et al., 2014; Richter et al. 2017). De acordo com os dados obtidos, animais expostos ao CC expressaram maiores níveis de MTs 
pulmonares e hepáticas quando comparado aos demais grupos (Figura 10). Embora o pulmão seja o primeiro órgão-alvo das exposições, o fígado é o principal órgão que expressa MTs, além de ser responsável pela metabolização de xenobióticos (Lynes et al. 2014).

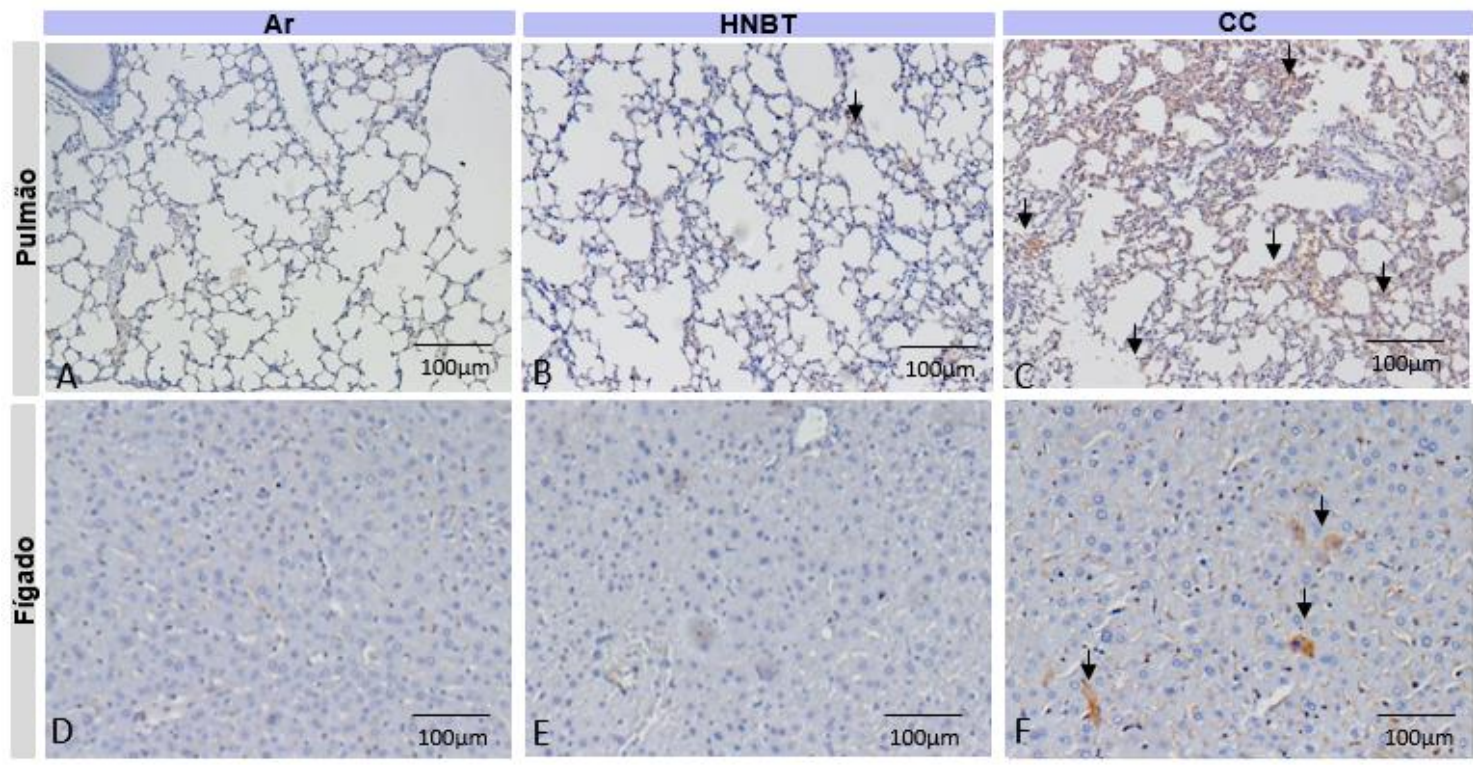

G)

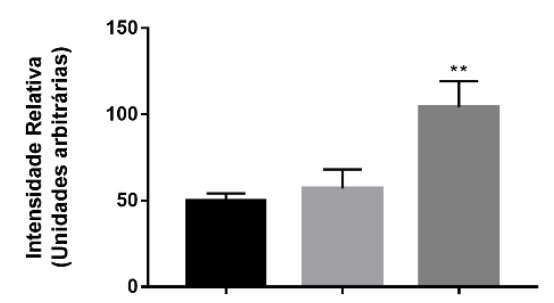

H)

Expressão de MTs - Figado

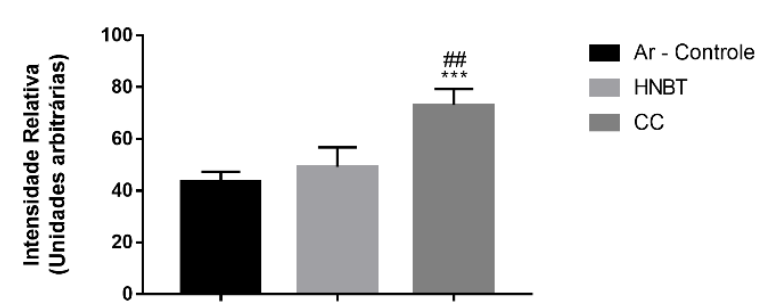

Figura 10. Expressão de MTs 1 e 2 no tecido pulmonar e hepático. Flechas apresentam locais de imunorreatividade para MTs 1 e 2 no fígado e pulmão de animais na vigência de AIA e expostos ao ar (A e B), ao HNBT ( $\mathbf{C}$ e $\mathbf{D})$ ou expostos ao CC ( $\mathbf{E}$ e $\mathbf{F})$. As exposição ocorreram duas vezes ao dia, por 1 hora cada e as exposições compreenderam 12 cigarros ou 24 heatsticks de HNBT por hora. No dia 21, os animais receberam desafio intra-articular de mBSA ou salina. Determinação da intensidade relativa da reatividade para MTs ( $\mathbf{G}$ e $\mathbf{H}$ ), onde 7 campos por lâmina foram analisados para determinar a intensidade da marcação. Resultados expressos em média \pm erro padrão da média $(\mathrm{n}=5)$. ** $<<0,01$ vs grupo ar e HNBT, *** $\mathrm{p}<0,001$ vs grupo ar. \#\# $\mathrm{p}<0,01$ vs HNBT. Corte de $4 \mu \mathrm{m}$, marcação com DAB e contra coloração com hematoxilina. Aumento de 20x para tecido pulmonar e hepático. 


\subsection{Impactos das exposições ao HNBT e ao CC na celularidade de órgãos linfoides}

$\mathrm{O}$ modelo de AIA é um modelo experimental mediado, principalmente, por linfócitos T. Tendo em vista que a nicotina é conhecida por agir na proliferação de células imunes, analisamos a celularidade de órgãos linfoides periféricos. Animais na vigência de AIA e expostos tanto ao HNBT ou quanto ao CC apresentaram acentuada redução no número total de células do baço e dos linfonodos drenantes inguinais e poplíteos em comparação aos animais com AIA expostos ao ar (Figura 11).
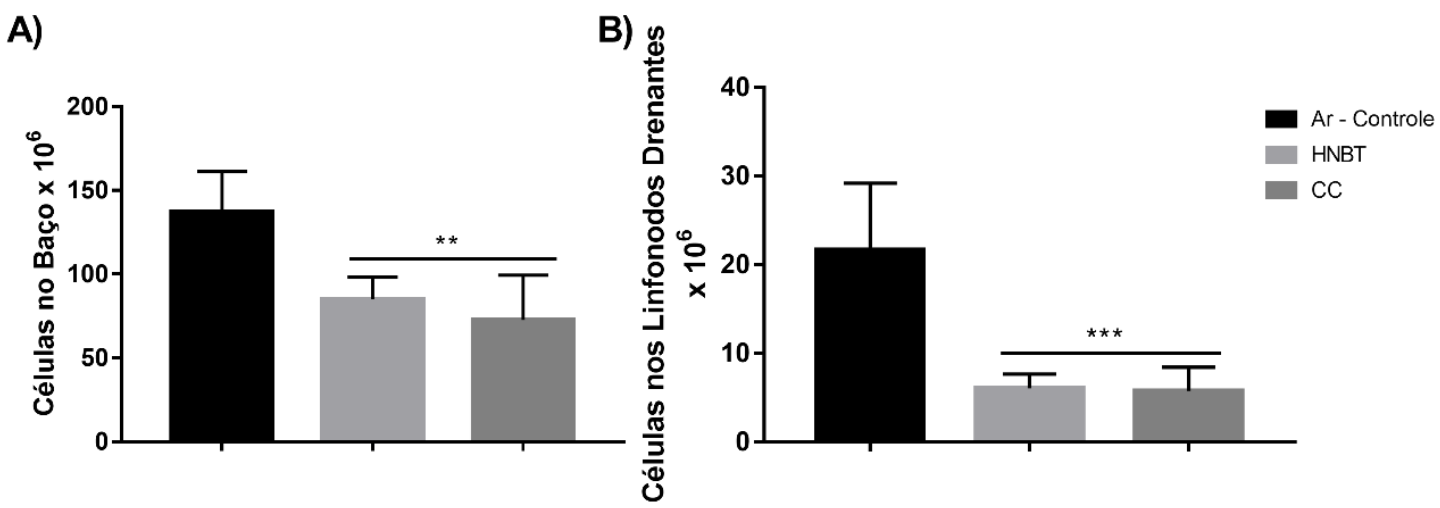

Figura 11. Exposições ao HNBT e ao CC reduzem a celularidade de órgãos linfoides. Animais expostos tanto ao HNBT quanto ao CC apresentaram redução no número de células totais do baço (A) e dos linfonodos drenantes poplíteos e inguinais (B). As exposição ocorreram duas vezes ao dia, por 1 hora cada e as exposições compreenderam 12 cigarros ou 24 heatsticks de HNBT por hora. No dia 21 , os animais receberam um desafio intra-articular de mBSA, Resultados expressos em média \pm erro padrão da média $(\mathrm{n}=5)$. ** $\mathrm{p}<0,05$ vs grupo ar, *** $\mathrm{p}<0,001$ vs grupo ar.

\subsection{Efeito das exposições in vitro ao HNBT e ao CC na frequência de células Th17 e} ativação de AhR

Linfócitos $\mathrm{T} \mathrm{CD}^{+}$expostos ao $\mathrm{CC}$ apresentaram aumento na frequência linfócitos Th17 (CD4 ${ }^{+} \mathrm{IL}_{-1} 7^{\mathrm{A}+}$ ) (Figura 13A). A expressão de AhR em linfócitos T naive está relacionada com a aquisição de um perfil Th17, sendo esta polarização dependente do microambiente inflamatório (Kimura et al. 2008). Esplenócitos expostos ao $\mathrm{CC}$ e ao HNBT apresentaram aumento na expressão de AhR duas horas após serem expostos (Figura 12B). 
A)

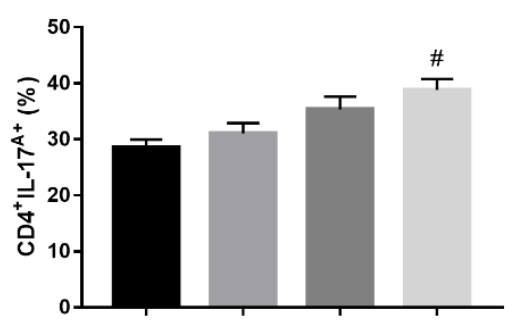

B)

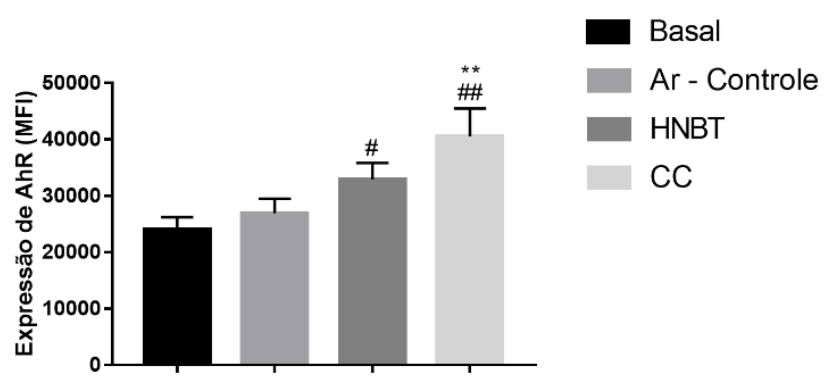

Figura 12. Efeito das exposições in vitro ao HNBT e ao CC na frequência de células Th17 e ativação de AhR. Linfócitos T CD4 ${ }^{+}$foram expostos ao ar, HNBT ou ao CC para avaliação do perfil Th17 em condições de polarização (A). Esplenócitos isolados foram expostos para analisar a expressão de AhR duas horas após as exposições $(\mathbf{B})$. As exposições ocorreram por 30 minutos, em um ciclo de 2 segundos de fumaça de CC ou vapor de HNBT a 45rpm seguido por 58 segundos de ar a 25rpm. Resultados expressos em média \pm erro padrão da média $(\mathrm{n}=5)$. **p<0,01 vs ar, \# $\mathrm{p}<0,05$ e \# \# $\mathrm{p}<0,01$ vs grupo basal (células não expostas).

\subsection{Impacto das exposições in vitro sobre a viabilidade de células T Jurkat}

Células T Jurkat são uma linhagem celular humana bem estabelecida para investigar a biologia de linfócitos T (Abraham \& Weiss 2004). Empregamos células Jurkat para investigar os impactos das exposições in vitro sobre diversos parâmetros celulares biológicos a fim de minimizar a utilização de ensaios com animais e diminuir a variabilidade experimental que observamos em ensaios in vivo. Além disso, utilizamos um estímulo com PMA para simular um ambiente em que as células estivem ativadas, a fim de analisar se as exposições causariam efeitos diferentes em uma célula ativada ou não. O PMA é um ativador lipossolúvel da proteína intracelular quinase $\mathrm{C}(\mathrm{PKC})$, desencadeando a translocação de NFkB para o núcleo e gerando a ativação de p47phox NADPH oxidase (NOX), causando um burst oxidativo e secreção de citocinas (Min et al. 2005).

O potencial citotóxico das exposições foi averiguado através da dupla marcação com AnxV e PI (Figura 13). Exposições ao CC apresentaram efeito citotóxico mais intenso em comparação as células expostas ao HNBT. O CC causou aumento na frequência de células necróticas e em apoptose tardia em comparação ao grupo exposto ao HNBT (Figura 13). A exposição ao HNBT levou ao maior índice de apoptose que necrose (Figura 13). 
A)

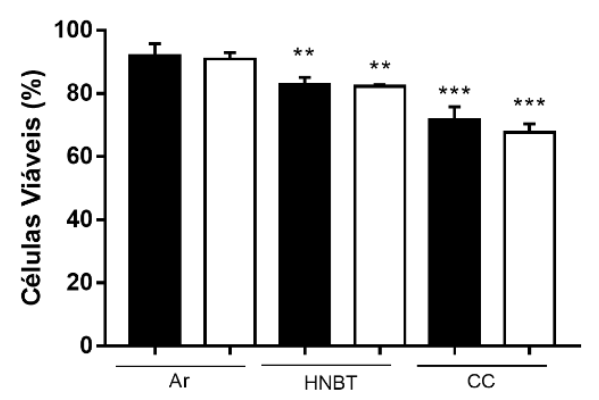

C)

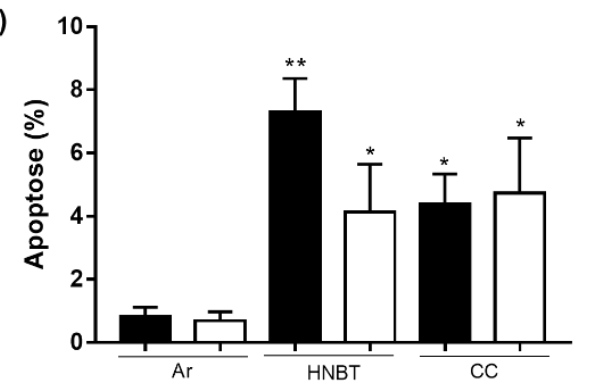

B)

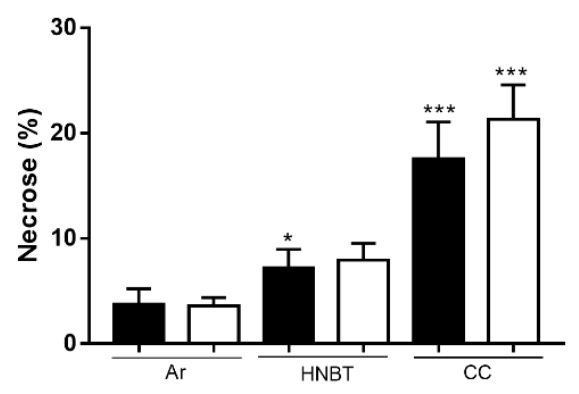

D)

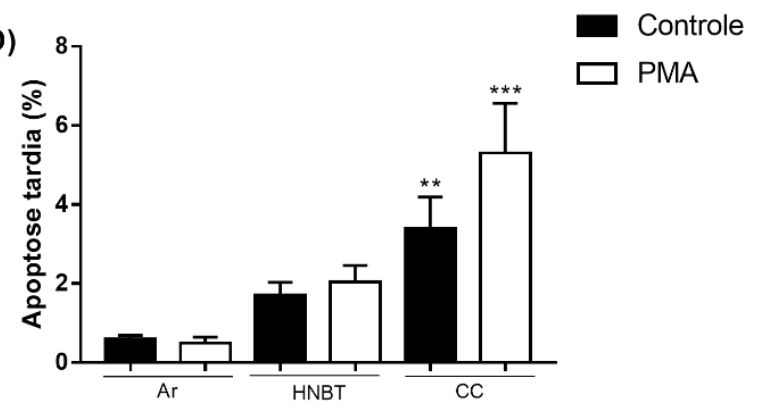

Figura 13. Exposições ao CC e HNBT alteram a viabilidade celular e aumentam a necrose em células T Jurkat. A viabilidade celular foi avaliada 24 horas após as exposições e tratamento com PMA (5nM). Células viáveis (A), células em necrose (B), apoptose (C) e apoptose tardia (D). As exposições ocorreram por 30 minutos, em um ciclo de 2 segundos de fumaça de CC ou vapor de HNBT a 45rpm seguido por 58 segundos de ar a $25 \mathrm{rpm}$. Os dados foram obtidos por citometria de fluxo e expressos em média \pm erro padrão da média $(\mathrm{n}=6)$. $* \mathrm{p}<0,05 ; * * \mathrm{p}<0,01$ vs. respectivos grupos (exposto e/ou tratado com PMA)

\subsection{Efeito das exposições sobre a produção de espécies reativas de oxigênio e nitrogênio e dano de DNA}

A citotoxicidade do CC está relacionada com o potencial dos produtos liberados causarem dano oxidativo (Isik et al. 2007) Células Jurkat expostas ao CC apresentaram aumento significativo na produção de EROS e NO quando comparadas com as células expostas ao HNBT ou ao ar (Figura 14). Concentrações elevadas de EROs e NO levam a formação de peroxinitrito, uma molécula altamente reativa que se liga rapidamente a macromoléculas e é responsável por induzir morte celular. A formação de peroxinitrito causa danos oxidativos a estruturas do DNA e leva a formação da molécula 8-hidroxioxo-2'-deoxiguanosina (8-OHdG), um aduto de DNA relacionado com dano oxidativo em fumantes (Chen et al. 2016). Nossos dados, mostraram que apenas exposições ao CC foram capazes de aumentar a formação de 8-OHdG em células Jurkat (Figura 14C). 
A)

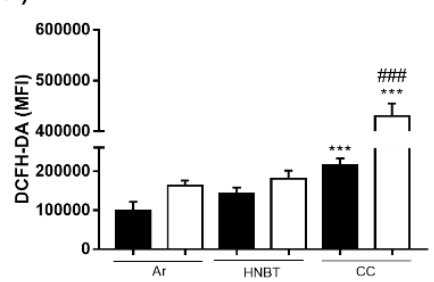

B)

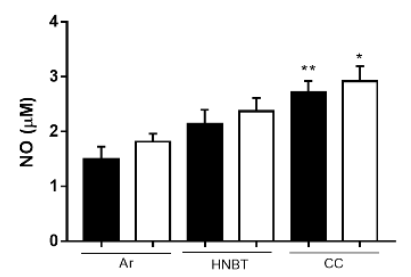

C)

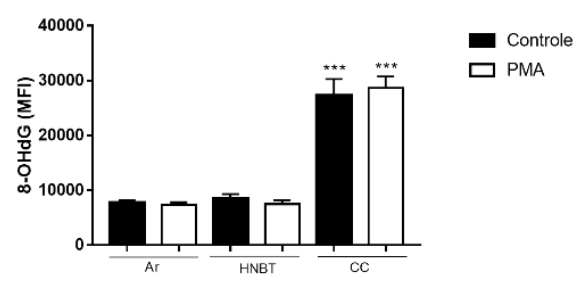

Figura 14. Exposições ao CC, mas não ao HNBT, aumentam espécies reativas de oxigênio e nitrogênio e 8-OHdG. Parâmetros oxidativos e os danos de DNA induzidos pelas exposições foram avaliados 45 minutos após o fim das exposições ou tratamento com PMA (5nM) para produção de EROs (A), e 24 horas após para liberação de $\mathrm{NO}(\mathbf{B})$ e formação de 8-OHdG $(\mathbf{C})$. As exposições ocorreram por 30 minutos, em um ciclo de 2 segundos de fumaça de CC ou vapor de HNBT a 45rpm seguido por 58 segundos de ar a 25rpm. Os dados expressam a média \pm erro padrão da $(\mathrm{n}=5)$. * $\mathrm{p}<0,05 ; * * \mathrm{p}<0,01$,

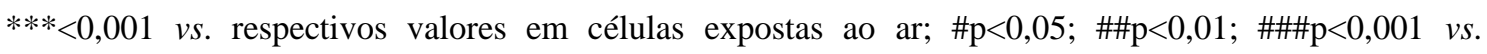
respectivas células não tratadas (controle) $(n=5)$.

\subsection{Quantificação dos metais liberados nas câmaras de exposição in vitro e expressão de MTs}

De mesma forma que o observado nas exposições in vivo, a combustão do tabaco observada no CC foi responsável pelo aumento da liberação de metais pesados na câmara de exposição quando comparado com o ar e o HNBT (Figura 15). Além disso, 24 horas após as células serem expostas ao CC ocorreu um aumento na expressão de MTs em comparação aos demais grupos (Figura 15I).
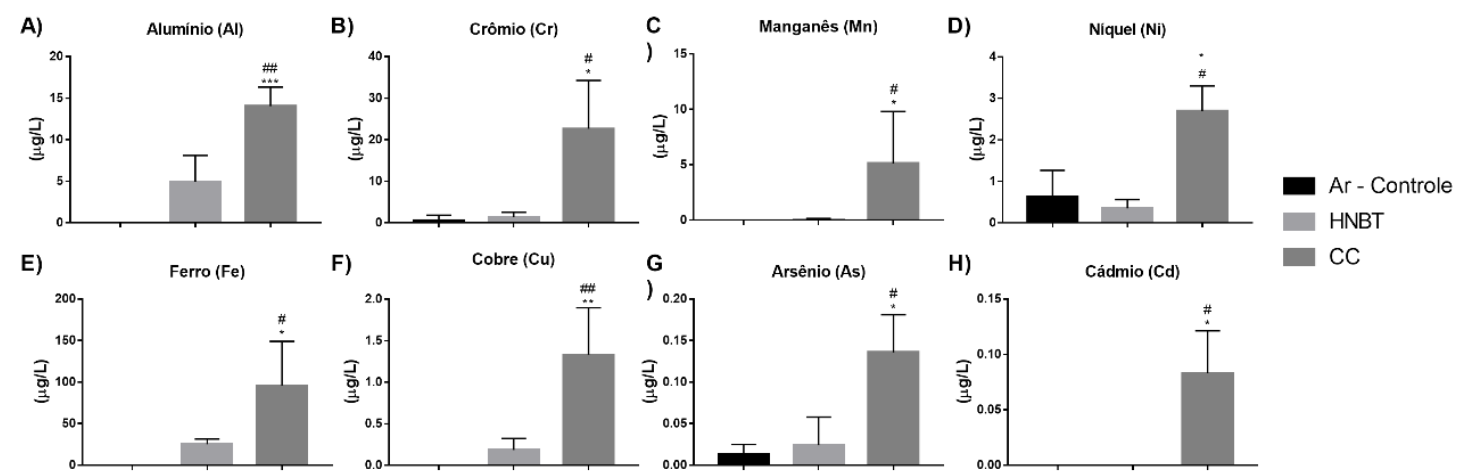

H) 0.155

I)

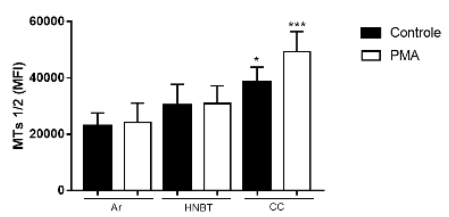

Figura 15. Figura 8. Níveis de metais liberados nas câmaras de exposição in vitro e expressão de MTs em células Jurkat. Filtros de éster celulose foram dispostos na câmara de exposição in vitro e 
expostos durante 30 minutos ao regimentos de exposição para avaliar as concentrações dos metais alumínio (A); crômio $(\mathbf{B})$, manganês $(\mathbf{C})$, níquel $(\mathbf{D})$, ferro $(\mathbf{E})$, cobre $(\mathbf{F})$, arsênio $(\mathbf{G})$ e cádmio $(\mathbf{H})$. As exposições ocorreram por 30 minutos, em um ciclo de 2 segundos de fumaça de CC ou vapor de HNBT a 45rpm seguido por 58 segundos de ar a $25 \mathrm{rpm}$. Resultados exibidos como média \pm erro padrão da média. ${ }^{*} \mathrm{p}<0,05, * * \mathrm{p}<0,01 \mathrm{e} * * * \mathrm{p}<0,001$ vs ar e \# $\mathrm{p}<0,05, \# \# \mathrm{p}<0,01 \mathrm{e} \# \# \# \mathrm{p}<0,001$ vs HNBT (n=3). A expressão de MTs 1 e 2 foi avaliada 24 horas após células Jurkat serem expostas e/ou estimuladas com PMA (5nM) (I). Resultados exibidos como média \pm erro padrão da média. ${ }^{*} \mathrm{p}<0.05 ; * * * \mathrm{p}<0.001$ vs. respectivos controles (ar controle ou PMA). ( $\mathrm{n}=5$ )

\subsection{Efeito das exposições in vitro sobre a secreção de citocinas e ativação de NFкB}

Visando compreender o efeito das exposições frente a um estímulo inflamatório, células $\mathrm{T}$ Jurkat foram tratadas ou não com PMA após serem expostas. Apenas exposições ao $\mathrm{CC}$ foram capazes de aumentar de desencadear a ativação de NFkB (p65), além de levar a secreção de IL-8, IFN-y e de TNF- $\alpha$ em células Jurkat tratadas ou não com PMA (Figura 16). Embora exposições ao HNBT não levou a modulação de NFאB ou impactou a secreção das demais citocinas, células expostos ao HNBT ou ao CC apresentaram secreção reduzida de IL-2 mesmo após serem estimuladas com PMA (Figura 16D). Tendo em vista que a nicotina presente em ambos os produtos apresenta um papel imunossupressor, células Jurkat foram tratadas com a mesma concentração de nicotina encontrada nos cigarro e heatsticks empregados nas exposições $(4,25 \mathrm{ng} / \mathrm{mL}$; Auer et al. 2017) durante 30 minutos para avaliarmos a secreção de IL-2. Assim como o observado nas células expostas ao $\mathrm{CC}$ ou ao HNBT o grupo de células tratadas com nicotina também apresentaram redução na secreção de IL-2 na presença ou ausência de PMA (Figura 16D). 
A)

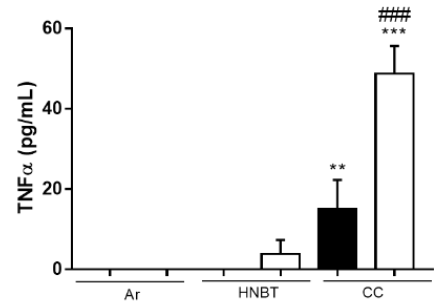

C)

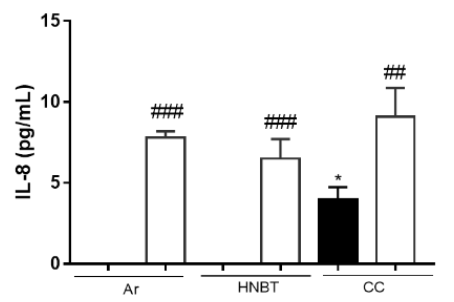

B)

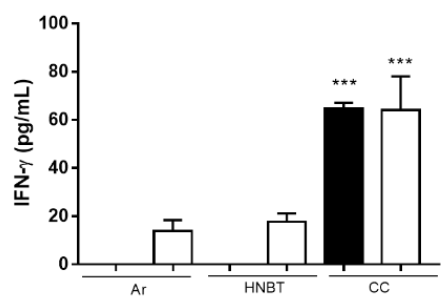

D)

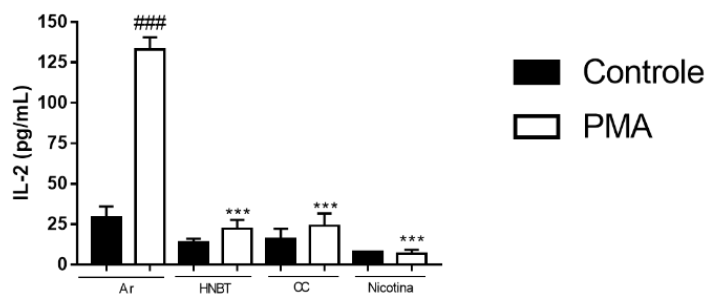

E)

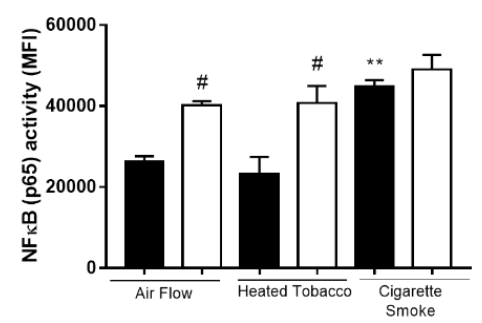

Figura 16. Efeito das exposições ao ar, HNBT ou CC na secreção de citocinas e ativação de NFkB. A secreção de TNF- $\alpha$ (A), IFN- $\gamma$ (B), IL-8 (C) e IL-2 (D) foi dosada no sobrenadante 24 horas após as exposições. A atividade de NFkB p65 (E) foi avaliada 30 minutos após as exposições. As exposições ocorreram por 30 minutos, em um ciclo de 2 segundos de fumaça de CC ou vapor de HNBT a 45rpm seguido por 58 segundos de ar a $25 \mathrm{rpm}$. Resultados exibidos como média \pm erro padrão da média. ${ }^{*} \mathrm{p}<0.05 ; * * \mathrm{p}<0.01 \mathrm{e} * * * \mathrm{p}<0.001$ vs. respectivos controles (ar controle ou PMA); \#p<0.05; \#\#p<0.01 e \#\#\# $<0.001$ vs. respectivo grupo não tratado (controle). $(\mathrm{n}=5)$

\subsection{Impacto das exposições in vitro e da nicotina sobre a proliferação de células Jurkat}

Como mencionado anteriormente, a IL-2 é importante para a atividade e proliferação de linfócitos T (Ouyang et al. 2000). A proliferação de células Jurkat foi monitorada por 72 horas após serem expostas e/ou estimuladas com PMA (Figura 17). De acordo com o padrão observado nos níveis de IL-2 (Figura 16D), a secreção reduzida de IL-2 foi acompanhada de uma atividade proliferativa prejudicada nas células expostas aos produtos fumígenos. Além disso, células tratadas com nicotina nas 
mesmas concentrações presentes no CC e HNBT tiveram proliferação celular reduzida (Figura 17).

A)

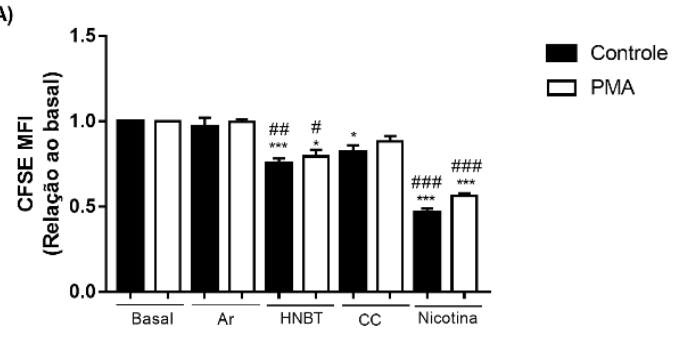

B)

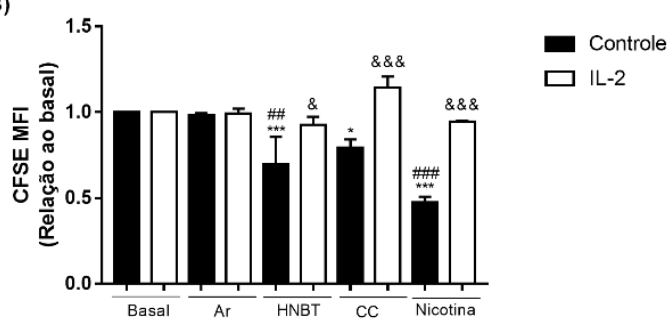

C)

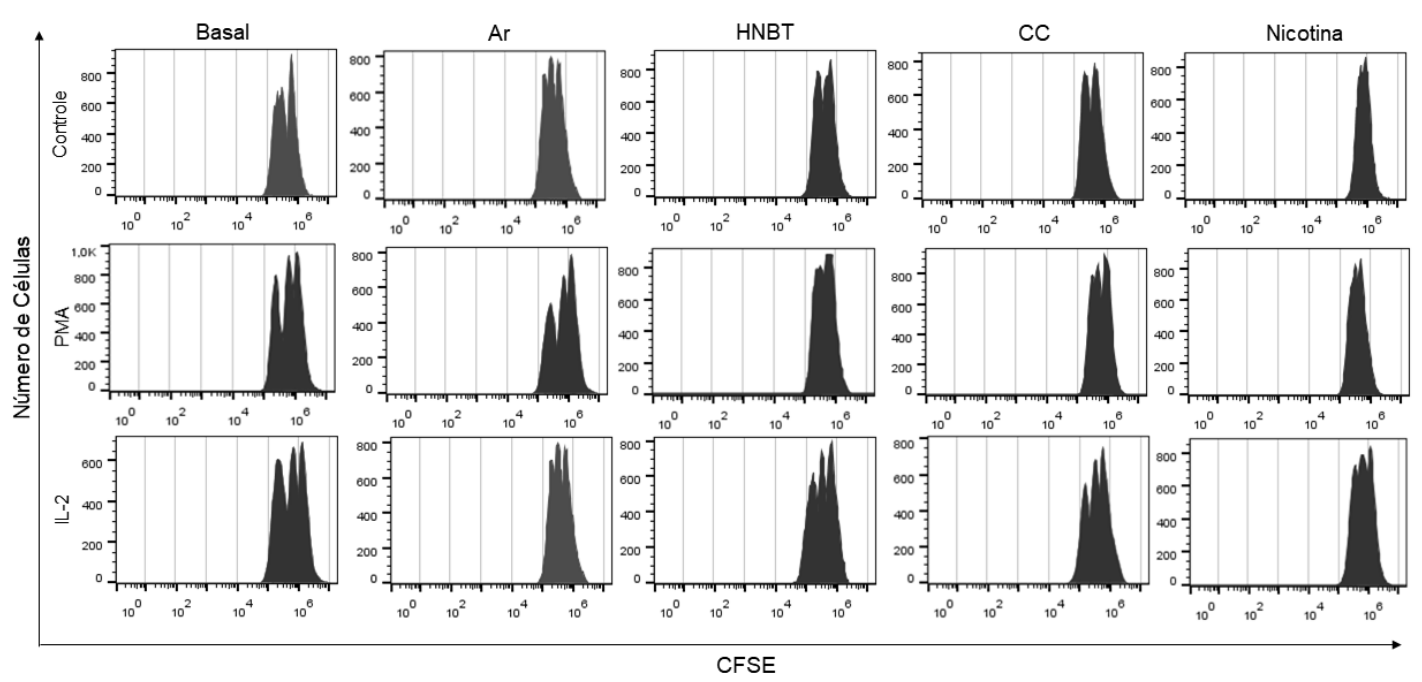

Figura 17. Exposições ao HNBT, CC e à nicotina prejudica a proliferação de células $\mathrm{T}$ Jurkat e a adição de rIL-2 exógena recupera a capacidade proliferativa. A proliferação de células Jurkat foi monitorada por 72 horas após as exposições e tratamento com PMA (5nM) ou rIL-2 (10UI/mL). Relação do MFI da marcação de CFSE em relação ao basal (A) de células tratadas com ou sem PMA ou com rIL2 (B). Histogramas representativos da marcação de CFSE (C). Os dados expressam a média \pm erro padrão da média $(\mathrm{n}=5)$. ** $\mathrm{p}<0,01 ; * * * \mathrm{p}<0,001$ vs. respectivo grupo basal (células estimuladas ou não com

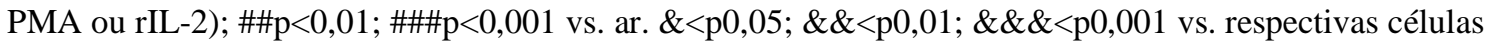
não tratadas (controle).

Buscando estabelecer uma relação dos níveis de IL-2 com a atividade proliferativa reduzida, células Jurkat expostas ao ar, HNBT, CC ou a diferentes concentrações de nicotina $(1 \mu \mathrm{M}, 10 \mu \mathrm{M}$ ou $100 \mu \mathrm{M})$, foram estimuladas com $10 \mathrm{UI} / \mathrm{mL}$ de rIL-2 e a proliferação celular foi monitorada por 72 horas. A adição exógena de rIL-2 foi capaz de reverter a capacidade proliferativa das células tratadas com nicotina com diferentes concentrações de nicotina (Figura 18). 
A)
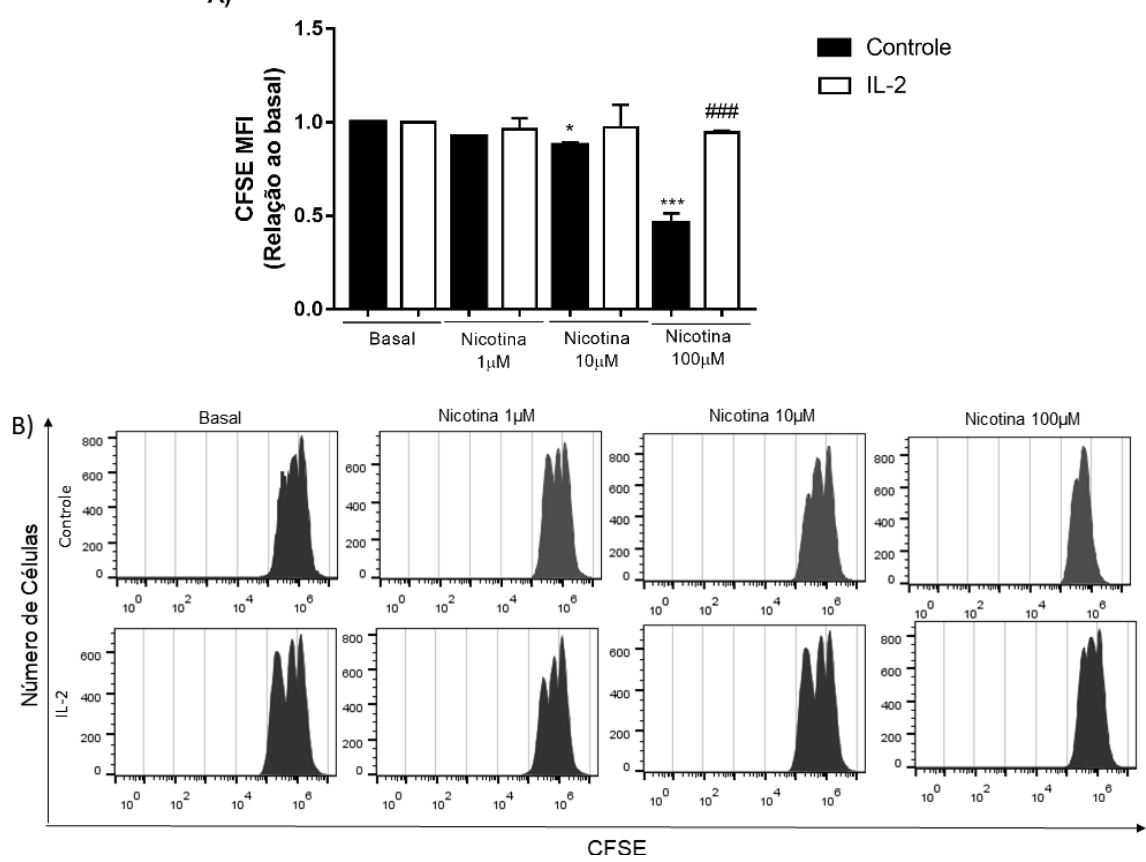

Figura 18. A adição exógena de IL-2 recuperou a proliferação de células Jurkat tratadas com diferentes concentrações de nicotina. A proliferação de células Jurkat foi monitorada por 72 horas após o tratamento com diferentes concentrações de nicotina por 30 minutos e com a adição de $10 \mathrm{IU} / \mathrm{mL}$ de rIL2 (A). Histogramas representativos da marcação de CFSE (B). Os dados expressam a média \pm erro padrão da média $(\mathrm{n}=3) . * \mathrm{p}<0,01 ; * * * \mathrm{p}<0,001$ vs. respectivo grupo basal (células estimuladas ou não com rIL-2); \#\#㓌 $<0,001$ vs. respectivas células não tratadas com rIL-2 (controle). 


\section{DISCUSSÃO}

Com base nos efeitos danosos relacionados à exposição ao $\mathrm{CC}$, novas formas para o consumo de nicotina inalatória foram desenvolvidas e comercializadas sobre a alegação de redução de efeitos tóxicos advindos da combustão do tabaco (Weitkunat et al. 2015). Assim, estes novos produtos de tabaco podem vir a representar ameaças aos sistemas públicos de saúde, tornando desafiador a conscientização e o entendimento da toxicidade destes produtos. Em virtude do fato destes novos produtos de tabaco serem recentes, pouco se sabe sobre a toxicidade causada pelo seu uso, em especial sobre o sistema imune. No presente projeto mostramos que a exposição a um produto alternativo a combustão do CC, o HNBT, mimetizando a exposição de fumantes, não exacerbou os sintomas da AIA, nem as atividades inflamatórias de linfócitos T CD4 ${ }^{+}$, como ocorreu durante à exposição ao CC. No entanto, a exposição ao CC ou ao HNBT causou prejuízos na proliferação e secreção de IL-2 em linfócitos e reduziu a celularidade nos linfonodos dos animais com AIA. É possível que os efeitos tóxicos da exposição ao CC ou ao HNBT sejam devidos à nicotina, uma vez que as exposições in vivo determinaram concentrações equivalentes de nicotina aos animais expostos ao CC ou ao HNBT, e que a exposição in vitro à nicotina causou efeitos similares à exposição ao produtos fumígenos em linfócitos.

Fatores ambientais estão intimamente ligados a efeitos tóxicos ao sistema imune, uma vez que exposições a xenobióticos presentes no meio ambiente estão relacionadas à maior incidência de doenças autoimunes (Farhat et al. 2011; Zhao et al. 2019). O surgimento da autoimunidade depende de diversos fatores, onde a causa exata é desconhecida; porém é sabido que o estilo de vida e o meio-ambiente desempenham um papel crucial no desbalanço da tolerância imune (Vojdani et al. 2014). A AR é uma das doenças autoimunes com maior incidência mundial, principalmente em países em desenvolvimento, onde a sua evolução clínica é diretamente afetada pelo tabagismo (Sugiyama et al. 2010; Smolen et al. 2018). De fato, fumantes estão susceptíveis a uma miríade de doenças, incluindo o surgimento de tumores, problemas respiratórios, cardiovasculares e doenças inflamatórias crônicas (Sundar et al. 2014).

A literatura sobre os efeitos da nicotina, principal componente do tabaco e responsável pela dependência ao tabagismo, na AR é complexa e conflitante. O período de exposições a nicotina, além das doses empregadas são os principais motivos 
relacionados a divergência de dados da literatura, onde as vias de administração (ingestão ou i.p) podem não refletir os efeitos inalatórios observados em fumantes. Administração de nicotina na água durante o início da artrite induzida por colágeno (AIC) em camundongos diminuiu o dano articular e os níveis de TNF- $\alpha$ no plasma e no lavado sinovial (Vaan Maanen et al., 2009), enquanto a administração via i.p. melhorou o score clínico da doença, levando à redução da destruição óssea, e suprimiu células Th17 via ativação do receptor nACh- $\alpha 7$, exercendo assim, efeitos anti-inflamatórios (Wu et al., 2014). No entanto, altas doses de nicotina têm se mostrado potentes indutoras de NETs, exacerbando a inflamação sinovial em camundongos com AIC, através da ativação do receptor nACh- $\alpha 7$, (Lee et al., 2017). Os efeitos da nicotina podem ser dependentes da fase da doença, uma vez que tratamentos com nicotina após a imunização de Mycobacterium tuberculosis em ratos Lewis para indução de artrite experimental aliviaram os sinais clínicos da doença, enquanto a administração de nicotina previamente a imunização levou a exacerbação do modelo experimental (Yu et al., 2011).

Estas informações se complicam ainda mais quando a nicotina é proveniente da fumaça do cigarro, uma vez que neste caso, a administração ocorre pela via respiratória, e a absorção, em picos por cada tragada, ocorre pelos pulmões. Como a nicotina é uma base fraca, sua absorção via oral ocorre no intestino e sofre a primeira passagem do metabolismo hepático. Por outro lado, a nicotina do tabaco em aerossol é ionizada e atravessa facilmente as membranas alveolares e das pequenas vias aéreas (Benowitz et al., 2009). Assim, a cinética da nicotina administrada por diferentes vias é distinta, o que pode ter impactos nos efeitos farmacológicos e toxicológicos.

No presente trabalho, além de comparar em modelos in vitro e in vivo que mimetizam a exposição inalatória, em pulsos, dos produtos fumígenos, foi também possível inferir que os efeitos observados tanto nas exposições ao CC quanto ao HNBT possam ser decorrentes da ação da nicotina, uma vez que a exposição inalatória ao HNBT leva à exposição à nicotina na vigência de baixa quantidade de produtos de combustão do CC. Esta conclusão foi baseada no fato dos animais expostos ao CC e ao HNBT terem apresentados a mesma concentração sérica de nicotina e cotinina. Ainda, o sistema de exposição por nós empregado, tanto in vivo quanto in vitro, mostrou que a exposição ao HNBT não acarreta exposição à metais, como ocorre de forma significativa na exposição ao CC. Sabe-se que metais pesados causam toxicidade ao 
sistema imune, em especial pela indução de estresse oxidativo (Shen et al. 2001; Ohsawa, 2008).

Embora a AR seja uma doença multifatorial e crônica, o modelo AIA é um modelo experimental bem caracterizado na literatura e mediado por linfócitos T, o tornando uma ferramenta versátil para estudar vários parâmetros e mecanismos relacionados ao tratamento e exacerbação dos sintomas da AR, como hipernocicepção, formação de edema, inflamação articular e migração celular (van den Berg et al. 2007). Os dados obtidos no presente projeto mostram claramente que a exacerbação dos sintomas locais e sistêmicos de AIA estão relacionados à exposição a produtos da combustão do tabaco, uma vez que o vapor de HBNT não agravou a inflamação articular ou pulmonar Esses dados corroboram dados anteriores, onde foi observado uma piora da artrite experimental em ratos expostos à hidroquinona, um metabólito do benzeno encontrado em grandes quantidades no CC (Heluany et al., 2018a, b) e a maior incidência de AR em indivíduos expostos a dioxinas (Nguyen et al., 2017; Lee et al., 2007) e metais (Cappelletti et al., 2016).

Em relação às principais manifestações extra-articulares da $\mathrm{AR}$, doenças pulmonares e cardiovasculares surgem como riscos de morbidade e mortalidade entre os pacientes com AR (Cojocaru et al. 2010; Roodenrijs et al. 2019). Frente a inflamação e ao influxo leucocitário intenso durante a AR, o tabagismo potencializa a inflamação sistêmica, onde o acúmulo de infiltrados celulares compromete o funcionamento pulmonar, uma das principais causas de morte em pacientes com AR (Bongartz et al., 2010). Frente a liberação de inúmeros compostos tóxicos liberados pela combustão do tabaco, o estresse oxidativo, aumento da apoptose de células epiteliais e a indução de processos inflamatórios emergem como mecanismos ligados ao dano pulmonar causado pelo CC (Van der Vaart et al. 2004; Antoniou et al. 2014).

A doença pulmonar intersticial (DPI) é uma das principais manifestações extraarticulares na AR, afetando até 50\% dos pacientes. A DPI é caracterizada por uma intensa inflamação pulmonar, onde infiltrados inflamatórios intersticiais favorecem a instalação da fibrose pulmonar, podendo levar a insuficiência respiratória (Biederer et al. 2004; Hamblin et al. 2011; Johnson et al. 2016). O dano causado pelo CC nas vias aéreas está ligado à instalação da DPI na AR, onde homens com AR e fumantes apresentaram maior incidência de DPI e complicações pulmonares (Hamblin et al. 2011; Sparks et al. 2016). Assim, o CC age com um gatilho na inflamação pulmonar, que pode 
ser exacerbada na vigência da AR. Com base nestes fatos, investigamos se nossas condições experimentais seriam capazes de comprometer o pulmão, o primeiro órgãoalvo do CC e comumente afetado durante a AR.

Observamos que a redução na emissão de produtos da combustão do tabaco não gerou inflamação pulmonar em animais expostos ao HNBT, e o aumento da liberação de metais pelo CC levou a expressão de MTs, uma proteína com importante ação antioxidante e neutralizante de metais pesados (Bilatos et al., 2018). Comprovando a ação do CC sobre a expressão de MTs in vivo, observamos que somente a exposição ao CC causou expressão de MTs por linfócitos $\mathrm{T}$, os quais também foram expostos a concentrações elevadas de metais pesados durante à exposição ao CC. É interessante salientar que a expressão de MTs após a exposição à fumaça do CC, mas não a cigarros eletrônicos, também foi observado em nematódeos, sendo essa expressão associada à inflamação e ao dano oxidativo gerado pela queima do CC (Cobb et al., 2018).

Associados, os estudos in vivo mostraram que a exposição ao HNBT não exacerba a sintomatologia local e pulmonar no modelo de AIA, o que ocorre com o CC, reforçando o papel dos produtos da combustão do tabaco na exacerbação da AR. A expressão de MTs foi bastante evidente in vivo e in vitro nos grupos expostos ao $\mathrm{CC}$, o que indica a atividade compensatória das células quanto a agressão causada pelos produtos da combustão, como os metais e os indutores de estresse oxidativos. Os estudos in vitro adicionais, realizados em células Jurkat, também mostraram que somente a exposição ao CC aumentou significantemente o burst oxidativo e a geração de NO em cultura linfócitos. Assim, aqui nós sugerimos, a partir dos dados obtidos, que as MTs podem ser indicadores biológicos importantes da exposição a produtos fumígenos (Figura 19).

O impacto deletério da fumaça de CC na exacerbação da AR está intimamente relacionado à ativação de AhR por produtos da combustão do tabaco (Nguyen et al; 2013). AhR é um fator de transcrição citoplasmático, que após ser ativado, se transloca para o núcleo, e se liga ao translocador nuclear de AhR (ARNT), onde o complexo AhR/ARNT evoca na transcrição de elementos de resposta a xenobióticos (XRE) e expressão de genes-alvo de AhR, como o citocromo P450s (Guyot et al. 2013). Embora AhR tenha uma natureza promíscua e possa ser ativado por vários ligantes, como compostos derivados da microbiota e metabólitos da cascata do triptofano, a ativação por xenobióticos, principalmente por HPAs e bifenilos policlorados (PCBs), é a via 
central descrita até o momento que relaciona exposições poluentes ambientais à exacerbação da AR (Nguyen et al 2013; Abella et al. 2016; Talbot et al.2018).

A ativação de AhR está estritamente ligada ao desenvolvimento de células Th17 (Veldhoen et al. 2007; Quintana et al. 2008). É bem conhecido que o tratamento com agonistas AhR, como FICZ, na presença de TGF- $\beta$ e IL-6, leva linfócitos T CD4 ${ }^{+}$a adquirirem um fenótipo Th17 (Quintana et al. 2008). Células Th17 são as principais secretoras de IL- 17, uma citocina crítica na fisiopatologia da AR (Niu et al. 2012). Nossos dados mostram que esplenócitos expostos ao HNBT e ao CC apresentaram aumento significativo na expressão de $\mathrm{AhR}$, sendo que o grupo $\mathrm{CC}$ apresentou aumento acentuado da expressão do receptor. Entretanto, somente linfócitos T CD4 ${ }^{+}$expostos ao CC apresentaram elevação na frequência de células Th17. O aumento da expressão de AhR no grupo exposto ao HNBT, mas a não modulação da frequência de células Th17, pode ser explicada pelos menores níveis de compostos da combustão do tabaco liberados pelo HNBT em comparação ao CC, onde os compostos emitidos não geraram estímulos para ativar AhR de maneira suficiente para aquisição do perfil Th17 in vitro.

Reforçando os efeitos tóxicos de componentes do CC sobre linfócitos (Anto et al. 2002; Wickenden et al. 2002; Feng et al. 2011; Hernandez et al., 2013), os dados obtidos mostraram que exposições ao CC foram mais citotóxicas, e com maior potencial inflamatório em comparação ao HNBT. A identificação da citotoxicidade é um indicador fundamental para a avaliação da toxicidade de xenobióticos. A necrose celular é uma forma de morte causada por danos físicos que leva ao comprometimento da integridade da membrana celular e resulta na liberação componentes intracelulares que induzem inflamação (Rock \& Kono 2008). Por outro lado, a indução da apoptose é caracterizada por um processo de morte celular programado que evita a inicialização de processos inflamatórios, sendo um evento multimediado e complexo, controlado por diversos mecanismos, como a ativação das caspases (Hotchkiss et al. 2009). Enquanto exposições ao CC apresentaram sua citotoxicidade mediada principalmente pela indução de necrose, células Jurkat expostas ao HNBT apresentaram aumento na frequência de células apoptóticas. Embora produtos da combustão do tabaco são caracterizados por exercerem danos estruturais e causarem necrose tecidual, a ativação de receptores colinérgicos através da nicotina pode aumentar a atividade das caspases e levar à apoptose em linfócitos T (Oloris et al. 2010). 
A toxicidade de xenobióticos está relacionado ao potencial oxidativo destes compostos, onde altos níveis de EROs causam danos a organelas e macromoléculas, resultando em danos de DNA e até morte celular. A inalação da fumaça de CC está relacionada à elevação de radicais livres e aumento na produção de EROs (Chen et al. 2015). Células Jurkat expostas ao CC, mas não ao HNBT, apresentaram acentuada diminuição da viabilidade celular, sendo a morte por necrose a mais prevalente. Exposições ao CC foram capazes de elevar a produção de EROs e NO por células Jurkat. Além disso, a conjunção de EROs e NO leva a formação de peroxinitrito, uma molécula altamente reativa e citotóxica que desencadeia a peroxidação do DNA (Hayashi et al. 2004). A formação de peroxinitrito resulta na geração de 8-OHdG, um aduto de DNA relacionado a danos oxidativos e comumente presente no pulmão de fumantes (Cao et al. 2016). Corroborando com a literatura, células expostas ao CC apresentaram maiores níveis de 8-OHdG. Embora as exposições ao HNBT não foram capazes de elevar os níveis de EROs ou NO por linfócitos, a literatura recente mostrou que produtos liberados pelo HNBT são potenciais indutores de EROs em células de epitélio bronquial (Malinska et al. 2018; Dusautoir et al. 2020).

Exposições ao CC são bem estabelecidas por gerar inflamação e ativar a via de NFkB (Anto et al. 2002; Zhong et al. 2016), mas a capacidade de exposições ao HNBT em ativar esta via é desconhecida. Em nossos estudos, apenas a exposição ao CC levou a ativação de NFkB por linfócitos, que pode ser responsável pela maior secreção de citocinas pró-inflamatórias por estas células. Diferentemente, células expostas ao HNBT e ao CC apresentaram secreção reduzida de IL-2, bem como uma atividade proliferativa comprometida, mesmo após estímulos com PMA. A IL-2 é produzida por células T $\mathrm{CD}^{+}$, se liga ao seu receptor (IL2R ou CD25) e exibe um papel fundamental na diferenciação de linfócitos $\mathrm{T}$, controlando fenótipos celulares que são cruciais em doenças infecciosas, autoimunes e tumorais (Spolski \& Leonard, 2018). A secreção de IL-2 induz polarização e proliferação de linfócitos Treg, protegendo a instalação de doenças autoimunes, além de favorecer a proliferação e geração de linfócitos $\mathrm{T}$ citotóxicos e de memória contra células tumorais (Orozco et al. 2020).

A secreção reduzida de IL-2 frente a exposição ao CC in vivo e in vitro foi descrita previamente, e embora alguns estudos apresentem dados controversos, a maioria deles sugere que a nicotina inibe a secreção de IL-2 e, consequentemente, prejudica a proliferação celular via a ativação do receptor nACh $\alpha 7$, (Madretsma et al. 
1996 ; Nizri et al. 2009; Ouyang et al. 2000). A redução da proliferação e secreção de IL-2 observada em células expostas ao CC ou ao HNBT também foi observada em células tratadas com diferentes concentrações de nicotina, sugerindo que a presença de nicotina no CC e no HNBT está relacionada com a imunotoxicidade sobre a secreção de IL-2 e proliferação celular. A exposição à nicotina exerce uma atividade imunossupressora em fumantes, suprimindo a proliferação de células $\mathrm{T}$ e induzindo anergia celular (Geng et al. 1996; Qiu et al. 2017). Camundongos expostos a fumaça do CC apresentaram redução da maturação de células dendríticas, além da redução na atividade proliferativa de células $\mathrm{T}$ de linfonodos drenantes torácicos (Nouri-Schirazi e Guinet, 2003; Robbins et al., 2008). Uma vez que o grupo exposto ao ar exibiu maior celularidade no baço e LDNs durante a AIA, e com base nos resultados obtidos em linhagem de linfócitos, formulamos a hipótese de que a supressão da celularidade dos órgãos linfoides em animais expostos ao CC ou ao HNBT foi devido a nicotina presente em ambos os produtos do tabaco, os quais foram expostos à fumaça do $\mathrm{CC}$ ou do vapor do HNBT por via inalatória aos animais e por diluição em culturas de linfócitos. Estudos adicionais com o antagonista de receptor nicotínico a ser realizado num futuro breve confirmará o efeito tóxico da nicotina em produtos fumígenos, prejudicando a proliferação de linfócitos (Figura 20).

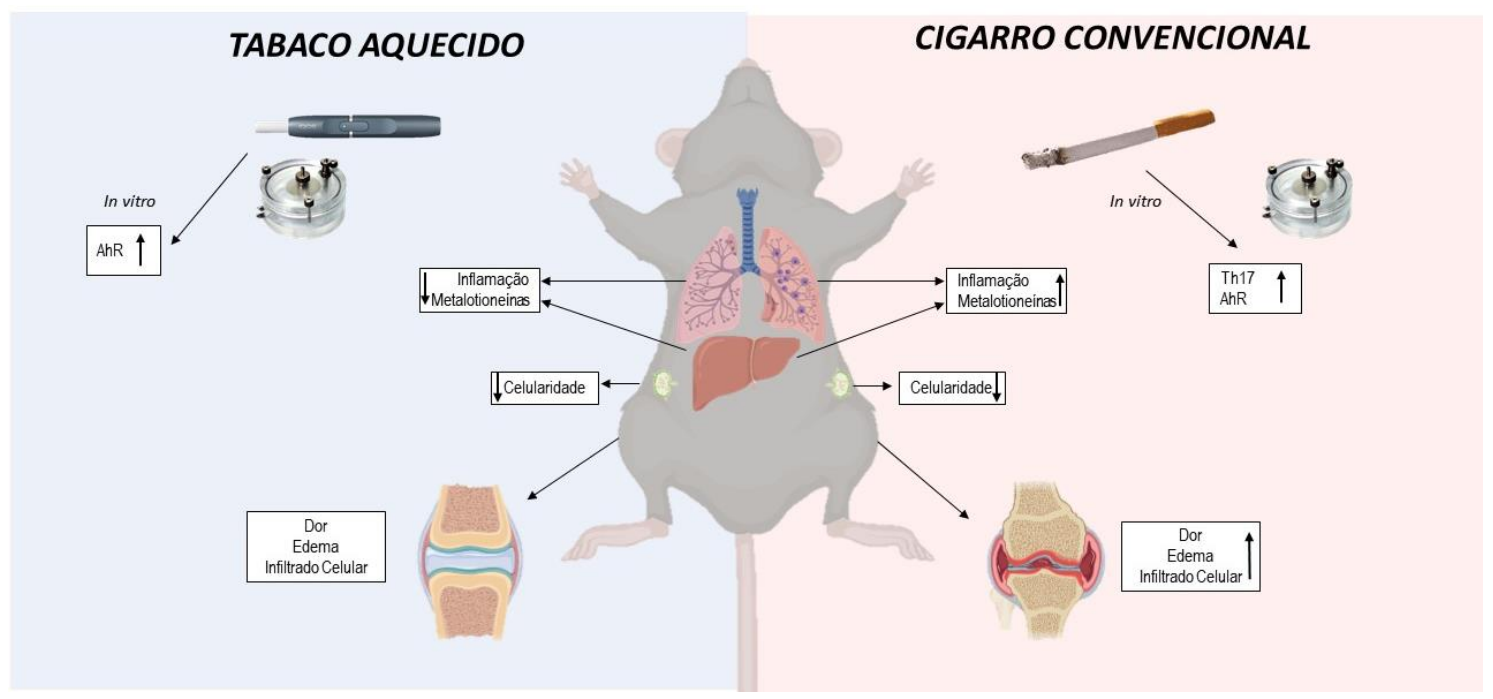

Figura 19. Desenho esquemático dos principais dados obtidos in vivo. 


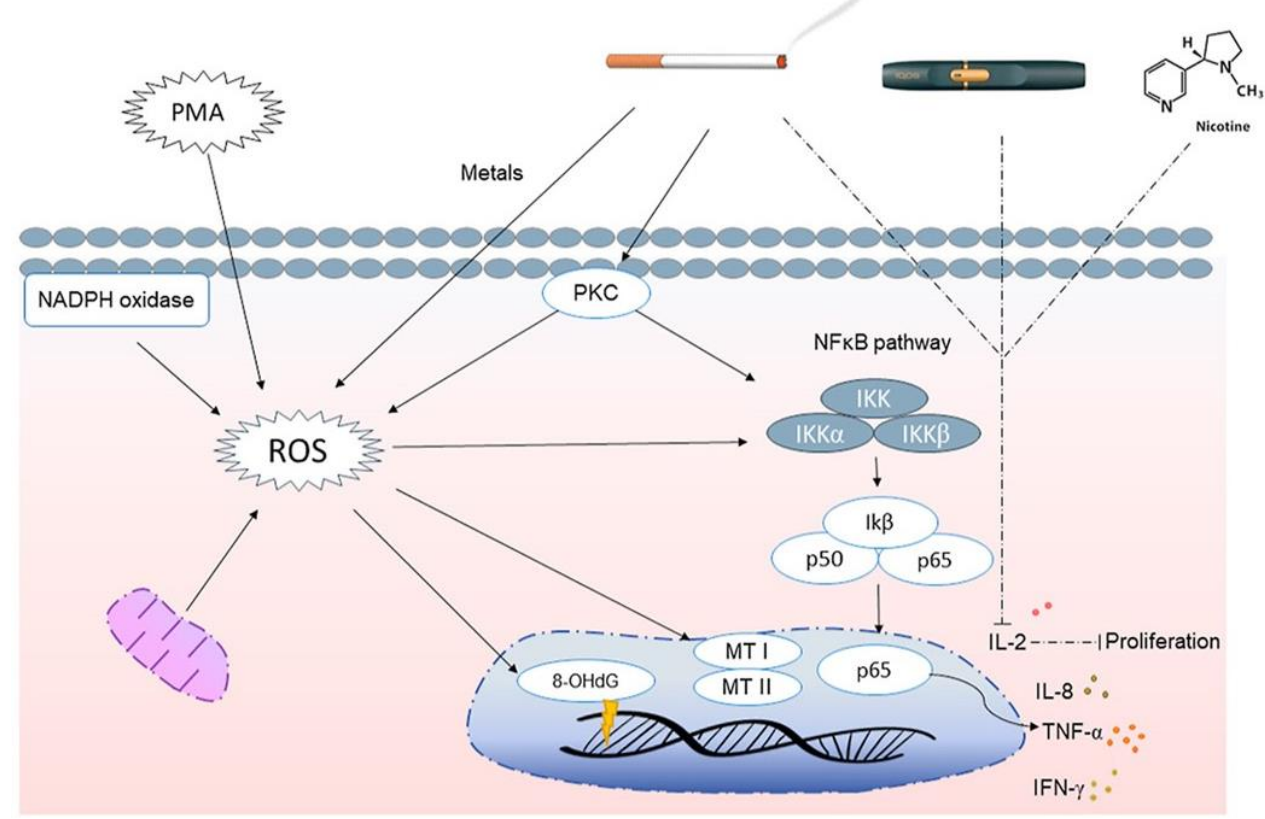

Figura 20. Esquema representativo dos principais dados obtidos in vitro 


\section{CONCLUSÂO}

O surgimento e o consumo deliberado de novos produtos de tabaco se tornaram preocupações de saúde pública, uma vez que a literatura sobre a toxicidade destes produtos ainda está em construção. Aqui, desenvolvemos modelos de exposição à fumaça do $\mathrm{CC}$ e ao vapor do HNBT que mimetizam exposições a fumantes, e descrevemos o impacto das exposições ao HNBT ou ao CC sobre os mecanismos fisiopatológicos da AR através do modelo de AIA. Embora exposições ao HNBT não desencadeiem a exacerbação da sintomatologia do modelo experimental de AIA ou não apresentem o mesmo potencial citotóxico que o $\mathrm{CC}$, ambos produtos levaram à supressão funcional de linfócitos, mostrados pela redução na celularidade de órgãos linfoides e por prejuízos na proliferação de linfócitos T e na secreção de IL-2. Desta forma, ambos produtos de tabaco apresentaram efeitos imunotóxicos capazes de suprimir funções imunológicas importantes na defesa do organismo frente a processos infeciosos e tumorais. Ainda, destacamos a expressão de MTs como um marcador sensível frente a exposição a produtos fumígenos, uma vez que a sua expressão está relacionada à liberação de produtos da combustão do tabaco, sendo expressas apenas nos grupos expostos ao CC. Embora a falta de amostras humanas ainda seja um limitante na compreensão da imunotoxicidade do HNBT, os dados aqui obtidos trazem novas perspectivas sobre a imunossupressão observada em fumantes e a toxicidade dos produtos liberados na combustão do tabaco. 


\section{REFERÊNCIAS}

ABELLA, V. et al. Pollutants make rheumatic diseases worse: Facts on polychlorinated biphenyls (PCBs) exposure and rheumatic diseases. Life sciences, v. 157, p. 140-144, 2016.

AGARWAL, Vikas; SINGH, Ram; WICLAF; CHAUHAN, Sandeep; TAHLAN, Anita; AHUJA, Chirag Kamal; GOEL, Deepak; PAL, Lily. A clinical, electrophysiological, and pathological study of neuropathy in rheumatoid arthritis. Clinical Rheumatology, [S.L.], v. 27, n. 7, p. 841-844, 15 dez. 2007.

AHN, K. S.; AGGARWAL, B. B. Transcription factor NF-kappaB: a sensor for smoke and stress signals. Annals of the New York Academy of Sciences, v. 1056, n. 1, p. 218-233, 2005.

ALETAHA, Daniel; ALASTI, Farideh; SMOLEN, Josef S.. Rheumatoid factor, not antibodies against citrullinated proteins, is associated with baseline disease activity in rheumatoid arthritis clinical trials. Arthritis Research \& Therapy, [S.L.], v. 17, n. 1, p. 1-13, 26 ago. 2015.

AMIN, M. Asif; FOX, David A.; RUTH, Jeffrey H.. Synovial cellular and molecular markers in rheumatoid arthritis. Seminars In Immunopathology, [S.L.], v. 39, n. 4, p. 385-393, 11 maio 2017.

ANNUNZIATO, F., COSMI, L., LIOTTA, F., MAGGI, E., ROMAGNANI, S. Type 17 Thelper cells origins, features and possible roles in rheumatic disease. Nature Reviews Rheumatology, v. 5, p. 325331, 2009.

ANTO, R. J. et al. Cigarette smoke condensate activates nuclear transcription factor-kappaB through phosphorylation and degradation of IkappaB(alpha): correlation with induction of cyclooxygenase-2. Carcinogenesis, v. 23, n. 9, p. 1511-1518, 2002.

ANTONIOU, K. M. et al. Interstitial lung disease. European respiratory review: an official journal of the European Respiratory Society, v. 23, n. 131, p. 40-54, 2014.

AUER, R. et al. Heat-not-burn tobacco cigarettes: Smoke by any other name. JAMA International Medicine, v. 177, n. 7, p. 1050, 2017.

BARTOK, Beatrix; FIRESTEIN, Gary S.. Fibroblast-like synoviocytes: key effector cells in rheumatoid arthritis. Immunological Reviews, [S.L.], v. 233, n. 1, p. 233-255, jan. 2010.

BEKKI K, Inaba Y, UCHIMAYA S, et al. Comparison of chemicals in mainstream smoke in heat-notburn tobacco and combustion cigarettes. J Uoeh 2017;39:201-7. 24 Schaller JP, Keller D, Poget L, et al. 
Evaluation of the Tobacco Heating System 2.2. Part 2: Chemical composition, genotoxicity, cytotoxicity, and physical properties of the aerosol. Regular Toxicology Pharmacology, 2016.

BENOWITZ, N. et al. Carbon monoxide, cigarette smoking and CYP2E1 activity. Clinical Pharmacology and Therapeutics, v. 65, n. 2, p. 154-154, 1999.

BENOWITZ, N. L.; HUKKANEN, J.; JACOB, P., 3rd. Nicotine chemistry, metabolism, kinetics and biomarkers. Handbook of Experimental Pharmacology, n. 192, p. 29-60, 2009.

BERINGER, Audrey; MIOSSEC, Pierre. Systemic effects of IL-17 in inflammatory arthritis. Nature Reviews Rheumatology, [S.L.], v. 15, n. 8, p. 491-501, 21 jun. 2019.

BIEDERER, J. et al. Correlation between HRCT findings, pulmonary function tests and bronchoalveolar lavage cytology in interstitial lung disease associated with rheumatoid arthritis. European Radiology, v. 14, n. 2, p. 272-280, 2004.

BILLATOS, E. et al. Impact of acute exposure to cigarette smoke on airway gene expression. Physiological Genomics, v. 50, n. 9, p.705-713, 1 set. 2018.

BIONDI-ZOCCAI, G. et al. Acute effects of heat-not-burn, electronic vaping, and traditional tobacco combustion cigarettes: The Sapienza university of Rome-vascular assessment of proatherosclerotic effects of smoking (SUR - VAPES) 2 randomized trial. Journal of the American Heart Association, v. 8, n. 6 , p. e010455, 2019.

BLACHÈRE, Nathalie E.; PARVEEN, Salina; FRANK, Mayu O.; DILL, Brian D.; MOLINA, Henrik; ORANGE, Dana E.. High-Titer Rheumatoid Arthritis Antibodies Preferentially Bind Fibrinogen Citrullinated by Peptidylarginine Deiminase 4. Arthritis \& Rheumatology, [S.L.], v. 69, n. 5, p. 986995, 26 abr. 2017.

BONGARTZ, T. et al. Incidence and mortality of interstitial lung disease in rheumatoid arthritis: a population-based study. Arthritis and Rheumatism, v. 62, n. 6, p. 1583-1591, 2010.

BRELAND, A. et al. Electronic cigarettes: what are they and what do they do? Annals of the New York Academy of Sciences, v. 1394, n. 1, p. 5-30, 2017.

BRINKMANN, V, Reichard U, Goosmann C, Fauler B, Uhlemann Y, Weiss DS, et al. Neutrophil extracellular traps kill bacteria. Science. 2004.

CAMENGA, D. R. et al. Trends in use of electronic nicotine delivery systems by adolescents. Addictive Behaviors, v. 39, n. 1, p. 338-340, 2014. 
CAO, C. et al. Smoking-promoted oxidative DNA damage response is highly correlated to lung carcinogenesis. Oncotarget, v. 7, n. 14, p. 18919-18926, 2016.

CAPPELLETTI, R. et al. Health status of male steel workers at an electric arc furnace (EAF) in Trentino, Italy. Journal of Occupational Medicine and Toxicology (London, England), v. 11, n. 1, p. 7, 2016.

CARMONA-RIVEIRA, C., Carlucci, P. M., Goel, R. R., James, E., Brooks, S. R., Rims, C., Hoffmann, V., Fox, D. A., Buckner, J. H., \& Kaplan, M. J. Neutrophil extracellular traps mediate articular cartilage damage and enhance cartilage component immunogenicity in rheumatoid arthritis. Journal of Clinical Investigation Insight. 2020.

CATRINA, Anca I. et al. Lungs, joints and immunity against citrullinated proteins in rheumatoid arthritis. Nature Reviews Rheumatology, v. 10, n. 11, p.645-653, 29 jul. (2014).

CASTRO, Glenda; LIU, Xuejun; NGO, Karen; LEON-TABALDO, Aimee de; ZHAO, Shanrong; LUNA-ROMAN, Rosa; YU, Jingxue; CAO, Tinghua; KUHN, Robert; WILKINSON, Patrick. ROR $\gamma \mathrm{t}$ and ROR $\alpha$ signature genes in human Th17 cells. Plos One, [S.L.], v. 12, n. 8, p. 1-12, 1 ago. 2017.

CDC. Eletronic Cigarettes. Centrers for Disease Control and Prevention - USA (CDC) 2019. Acesso em 15 de janeiro de 2021. Disponível em <https://www.cdc.gov/tobacco/basic_information/ecigarettes/index.htm>

CECCHI, Irene; ROSA, Ivan Aria; Menegatti, Elisa; Roccatello, Dario et al. Neutrophils: Novel key players in Rheumatoid Arthritis. Current and future therapeutic targets. Autoimmunity Reviews. nov. 2018

CHANG, Kathleen; YANG, So; KIM, Seong; HAN, Kyoung; PARK, Se; SHIN, Jae. Smoking and Rheumatoid Arthritis. International Journal Of Molecular Sciences, [S.L.], v. 15, n. 12, p. 2227922295, 3 dez. 2014.

CHANG, Kuang-Hsi; HSU, Chih-Chao; MUO, Chih-Hsin; HSU, Chung Y.; LIU, Hui-Chuan; KAO, Chia-Hung; CHEN, Chiu-Ying; CHANG, Mei-Yin; HSU, Yi-Chao. Air pollution exposure increases the risk of rheumatoid arthritis: a longitudinal and nationwide study. Environment International, [S.L.], v. 94, p. 495-499, set. 2016.

CHEN, Z. et al. Oxidative DNA damage is involved in cigarette smoke-induced lung injury in rats. Environmental Health and Preventive Medicine, v. 20, n. 5, p. 318-324, 2015. 
CHENG, L. et al. Unbalanced expression of aryl hydrocarbon receptor in peripheral blood CCR6+ CD4+ and CD4+ CD25+ T cells of rheumatoid arthritis. Revista Brasileira de Reumatologia, v. 57, n. 3, p. 190-196, 2017.

CHIAVERINI, Natalie; LEY, Marc de. Protective effect of metallothionein on oxidative stress-induced DNA damage. Free Radical Research, v. 44, n. 6, p.605-613, jan. 2010.

CHOI, J. M. et al. Hydroquinone, a major component in cigarette smoke, reduces IFN-gamma production in antigen-primed lymphocytes. Archives of Pharmacological Research, v. 31, n. 3, p. 337-341, 2008.

COBB, E.; HALL, J.; PALAZZOLO, D. L. Induction of metallothionein expression after exposure to conventional cigarette smoke but not electronic cigarette (ECIG)-generated aerosol in Caenorhabditis elegans. Frontiers in Physiology, v. 9, p. 426, 2018.

COPE, A et al. The Central role of $\mathrm{T}$ cells in Rheumatoid Arthritis. Clinical Experimental Rheumatology, v 25,suppl 46, sep. 2007.

CORSIERO, Elisa; PRATESI, Federico; PREDILETTO, Edoardo; BOMBARDIERI, Michele; MIGLIORINI, Paola. NETosis as Source of Autoantigens in Rheumatoid Arthritis. Frontiers in Immunology. 2016.

DAMGAARD, D; NIELSEN, M. Friberg Bruun; GAUNSBAEK, Quisgaard; PALARASAH, Y; SVANE-KNUDSEN, V; NIELSEN, C. Smoking is associated with increased levels of extracellular peptidylarginine deiminase 2 (PAD2) in the lungs. Clinical and Experimental Rheumatology. 2015.

DARRAH, Erika; ROSEN, Antony; GILES, Jon T; ANDRADE, Felipe. Peptidylarginine deiminase 2, 3 and 4 have distinct specificities against cellular substrates: novel insights into autoantigen selection in rheumatoid arthritis. Annals Of The Rheumatic Diseases, [S.L.], v. 71, n. 1, p. 92-98, 21 ago. 2011

DARRAH, Erika; ANDRADE, Felipe. Rheumatoid arthritis and citrullination. Current Opinion In Rheumatology, [S.L.], v. 30, n. 1, p. 72-78, jan. 2018.

DAVIS, B.; TO, V.; TALBOT, P. Comparison of cytotoxicity of IQOS aerosols to smoke from Marlboro Red and 3R4F reference cigarettes. Toxicology in vitro: an international journal published in association with BIBRA, v. 61, n. 104652, p. 104652, 2019.

Devisscher, L., Hindryckx, P., Lynes, M., Waeytens, A., Cuvelier, C., Vos, F., Vanhove, C., Vos, M. and Laukens, D. Role of metallothioneins as danger signals in the pathogenesis of colitis. The Journal of Pathology. 2014. 
DE ROOY, D. P. C. et al. Smoking as a risk factor for the radiological severity of rheumatoid arthritis: a study on six cohorts. Annals of the Rheumatic Diseases, v. 73, n. 7, p. 1384-1387, 2014.

DOYLE, Hester A.; YANG, Mei-Ling; RAYCROFT, Maurice T.; GEE, Renelle J.; MAMULA, Mark J.. Autoantigens: novel forms and presentation to the immune system. Autoimmunity, [S.L.], v. 47, n. 4, p. 220-233, 5 nov. 2013.

DONATE, P. B. et al. Cigarette smoke induces miR-132 in Th17 cells that enhance osteoclastogenesis in inflammatory arthritis. Proceedings of the National Academy of Sciences of the United States of America, v. 118, n. 1, p. e2017120118, 2021.

DITTRICH, D. J. et al. Approaches for the design of reduced toxicant emission cigarettes. SpringerPlus, v. 3, n. 1, p. 374, 2014.

DUSAUTOIR, R. et al. Comparison of the chemical composition of aerosols from heated tobacco products, electronic cigarettes and tobacco cigarettes and their toxic impacts on the human bronchial epithelial BEAS-2B cells. Journal of Hazardous Materials, v. 401, n. 123417, p. 123417, 2021.

EBBINGHAUS, Matthias; NATURA, Gabriel; VON BANCHET, Gisela Segond; HENSELLEK, Susanne; BÖTTCHER, Martin; HOFFMANN, Birgit; SALAH, Firas Subhi; GAJDA, Mieczyslaw; KAMRADT, Thomas; SCHAIBLE, Hans-Georg. Interleukin-17A is involved in mechanical hyperalgesia but not in the severity of murine antigen-induced arthritis. Scientific Reports, [S.L.], v. 7, n. 1, p. 1-14, 4 set. 2017.

ESSOUMA, M., Noubiap, J.J.N. Is air pollution a risk factor for rheumatoid arthritis?. Journal of Inflammation, 12, 48. 2015.

FARHAT, S. C. L. et al. Air pollution in autoimmune rheumatic diseases: a review. Autoimmunity Reviews, v. 11, n. 1, p. 14-21, 2011.

FARSALINOS KE, Yannovits N, Sarri T, et al. Nicotine delivery to the aerosol of a heat-notburn tobacco product: comparison with a tobacco cigarette and e-cigarettes. Nicotine Tobacco Research. 2018.

FDA. Vaporizers, E-Cigarettes, and other Electronic Nicotine Delivery Systems (ENDS). Food and Drug Administration - FDA USA. 2020. Acesso em 15 de janeiro de 2021. Disponível em <https://www.fda.gov/tobacco-products/products-ingredients-components/vaporizers-e-cigarettes-andother-electronic-nicotine-delivery-systems-ends>

FENG, Y. et al. Exposure to cigarette smoke inhibits the pulmonary T-cell response to influenza virus and Mycobacterium tuberculosis. Infection and Immunity, v. 79, n. 1, p. 229-237, 2011. 
FLANDRY, Fred; HOMMEL, Gabriel. Normal Anatomy and Biomechanics of the Knee. Sports Medicine And Arthroscopy Review, [S.L.], v. 19, n. 2, p. 82-92, jun. 2011.

FOSSATI, Gianluca; MOOTS, Robert; BUCKNALL, Roger, EDWARDS, Steven. Differential role of neutrophil Fcy receptor IIIB (CD16) in phagocytosis, bacterial killing, and responses to immune complexes. Arthritis and Rheumatology. maio. 2002.

FU, J. et al. Shared epitope-aryl hydrocarbon receptor crosstalk underlies the mechanism of geneenvironment interaction in autoimmune arthritis. Proceedings of the National Academy of Sciences of the United States of America, v. 115, n. 18, p. 4755-4760, 2018.

FUJII, T. et al. Expression and function of the cholinergic system in immune cells. Frontiers in Immunology, v. 8, p. 1085, 2017.

GALLICCHIO, L. et al. Cigarette smoking and metallothionein expression in invasive breast carcinomas. Toxicology Letters, v. 152, n. 3, p. 245-253, 2004.

GENG, Y; SAVEGE, S. M.; RAZANI-BOROUJERDI, S.; SOPORI, M. L. Effects of nicotine on the immune response. II. Chronic nicotine treatment induces T cell anergy. Journal of Immunology. 156 (7) 2384-2390, 1996.

GLANTZ, S. A. Heated tobacco products: the example of IQOS. Tobacco Control, v. 27, n. Suppl 1, p. s1-s6, 2018a.

GLANTZ, S. A. PMI's own in vivo clinical data on biomarkers of potential harm in Americans show that IQOS is not detectably different from conventional cigarettes. Tobacco Control, v. 27, n. Suppl 1, p. s9s12, 2018b.

GORLINO, Carolina; DAVE, Mabel; BLAS, Rodrigo; CRESPO, Maria, LAVANCHY, Alicia; TAMASHIRO, Héctor, PARDO-HIDALGO, Rodolfo; GENARO, Maria. Association between levels of synovial anti-citrullinated peptide antibodies and neutrophil response in patients with rheumatoid arthritis.

European Journal of Immunology. jun. 2018.

GOMES, J. P.; WATAD, A.; SHOENFELD, Y. Nicotine and autoimmunity: The lotus' flower in tobacco. Pharmacological Research, v. 128, p. 101-109, 2018.

GRANGER; V., Peyneau, M., Chollet-Martin, S., \& de Chaisemartin, L. Neutrophil Extracellular Traps in Autoimmunity and Allergy: Immune Complexes at Work. Frontiers in Immunology, 2019. 
GROSE, Randall H.; MILLARD, Deborah J.; MAVRANGELOS, Chris; BARRY, Simon C.; ZOLA, Heddy; NICHOLSON, Ian C.; CHAM, Weng Tarng; BOROS, Christina A.; KRUMBIEGEL, Doreen. Comparison of Blood and Synovial Fluid Th17 and Novel Peptidase Inhibitor 16 Treg Cell Subsets in Juvenile Idiopathic Arthritis. The Journal Of Rheumatology, [S.L.], v. 39, n. 10, p. 2021-2031, 15 ago. 2012.

GUYOT, E. et al. The AhR twist: ligand-dependent AhR signaling and pharmaco-toxicological implications. Drug Discovery Today, v. 18, n. 9-10, p. 479-486, 2013.

HAMBLIN, M. J.; HORTON, M. R. Rheumatoid arthritis-associated interstitial lung disease: diagnostic dilemma. Pulmonary Medicine, v. 2011, p. 872120, 2011.

HATTORI, Toshio; OGURA, Naomi; AKUTSU, Miwa; KAWASHIMA, Mutsumi; WATANABE, Suguru; ITO, Ko; KONDOH, Toshirou. Gene Expression Profiling of IL-17A-Treated Synovial Fibroblasts from the Human Temporomandibular Joint. Mediators Of Inflammation, [S.L.], v. 2015, p. $1-12,2015$.

HATSUKAMI, D. K.; STEAD, L. F.; GUPTA, P. C. Tobacco addiction. Lancet, v. 371, n. 9629, p. 2027-2038, 2008.

HASNIS et al. Mechanisms underlying cigarette smoke-induced NF-kappaB activation in human lymphocytes: the role of reactive nitrogen species. Journal of Physiological Pharmacology. Suppl 5(Pt 1):275-87. 2007.

HAYASHI, Y. et al. Peroxynitrite, a product between nitric oxide and superoxide anion, plays a cytotoxic role in the development of post-bypass systemic inflammatory response. European Journal of Cardiothoracic Surgery, v. 26, n. 2, p. 276-280, 2004.

HELUANY, C. S. et al. Hydroquinone exposure worsens the symptomatology of rheumatoid arthritis. Chemico-Biological Interactions, v. 291, p. 120-127, 2018a.

HELUANY, C. S. et al. In vivo exposure to hydroquinone during the early phase of collagen-induced arthritis aggravates the disease. Toxicology, v. 408, p. 22-30, 2018b.

HERNANDEZ, C. P. et al. Effects of cigarette smoke extract on primary activated T cells. Cellular Immunology, v. 282, n. 1, p. 38-43, 2013.

HOTCHKISS, Richard S.; STRASSER, Andreas; MCDUNN, Jonathan E.; SWANSON, Paul E.. Cell Death. New England Journal Of Medicine, [S.L.], v. 361, n. 16, p. 1570-1583, 15 out. 2009. 
HONORATI, M. C.; MELICONI, R.; PULSATELLI, L.; CANÈ, S.; FRIZZIERO, L.; FACCHINI, A.. High in vivo expression of interleukin-17 receptor in synovial endothelial cells and chondrocytes from arthritis patients. Rheumatology, [S.L.], v. 40, n. 5, p. 522-527, maio 2001.

HOOVER, D. B. Cholinergic modulation of the immune system presents new approaches for treating inflammation. Pharmacology \& Therapeutics, v. 179, p. 1-16, 2017.

ISIK, B.; CEYLAN, A.; ISIK, R. Oxidative stress in smokers and non-smokers. Inhalation Toxicology, v. 19, n. 9, p. 767-769, 2007.

IWANAGA, Toshihiko; SHIKICHI, Mitsumori; KITAMURA, Hiroko; YANASE, Haruko; NOZAWAINOUE, Kayoko. Morphology and Functional Roles of Synoviocytes in the Joint. Archives Of Histology And Cytology, [S.L.], v. 63, n. 1, p. 17-31, 2000.

JACCARD G, TAFIN Djoko D, MOENNIKIS O, et al. Comparative assessment of HPHC yields in the Tobacco Heating System THS2.2 and commercial cigarettes. Regulatory Toxicology and Pharmacology. 2017.

JHA, P.; PETO, R. Global effects of smoking, of quitting, and of taxing tobacco. The New England Journal Of Medicine, v. 370, n. 1, p. 60-68, 2014.

JOHNSON, C. Recent advances in the pathogenesis, prediction, and management of rheumatoid arthritisassociated interstitial lung disease. Current Opinion in Rheumatology, v. 29, n. 3, p. 254-259, 2017.

JU, J. H. et al. Modulation of STAT-3 in rheumatoid synovial T cells suppresses Th17 differentiation and increases the proportion of Treg cells. Arthritis and Rheumatism, v. 64, n. 11, p. 3543-3552, 2012.

KALRA, R. et al. Immunosuppressive and anti-inflammatory effects of nicotine administered by patch in an animal model. Clinical And Diagnostic Laboratory Immunology, v. 11, n. 3, p. 563-568, 2004.

KAPLAN, M.J. Role of neutrophils in systemic autoimmune diseases. Arthritis Research Therapy 15, $219,2013$.

KASAI, A. et al. High levels of dioxin-like potential in cigarette smoke evidenced by in vitro and in vivo biosensing. Cancer Research, v. 66, n. 14, p. 7143-7150, 2006.

KAZANTSEVA, M. G. et al. Dendritic cells provide a potential link between smoking and inflammation in rheumatoid arthritis. Arthritis Research \& Therapy, v. 14, n. 5, p. R208, 2012. 
KENNY, Elaine; HERZIG, Alf; KRUGER, Renate; MUTH, Aron et al. Diverse stimuli engage different neutrophil extracellular trap pathways. Elife. Jun. 2017.

KIEZEK, Rene et al. The Role of Metallothionein in Oxidative Stress. International Journal of Molecular Sciences, [s.1.], v. 14, n. 3, p.6044-6066, 15 mar. 2013.

KIMURA, A. et al. Aryl hydrocarbon receptor regulates Stat1 activation and participates in the development of Th17 cells. Proceedings of the National Academy of Sciences of the United States of America, v. 105, n. 28, p. 9721-9726, 2008.

KITAMURA, M.; KASAI, A. Cigarette smoke as a trigger for the dioxin receptor-mediated signaling pathway. Cancer Letters, v. 252, n. 2, p. 184-194, 2007.

KOBAYASHI, S. et al. A role for the aryl hydrocarbon receptor and the dioxin TCDD in rheumatoid arthritis. Rheumatology (Oxford, England), v. 47, n. 9, p. 1317-1322, 2008.

KOCHI, Y. et al. PADI4 polymorphism predisposes male smokers to rheumatoid arthritis. Annals Of The Rheumatic Diseases, v. 70, n. 3, p. 512-515, 2011.

KODURI, G.; NORTON, S.; YOUNG, A.; COX, N.; DAVIES, P.; DEVLIN, J.; DIXEY, J.; GOUGH, A.; PROUSE, P.; WINFIELD, J.. Interstitial lung disease has a poor prognosis in rheumatoid arthritis: results from an inception cohort. Rheumatology, [S.L.], v. 49, n. 8, p. 1483-1489, 11 mar. 2010.

LEIGH, N. J. et al. Cytotoxic effects of heated tobacco products (HTP) on human bronchial epithelial cells. Tobacco Control, v. 27, n. Suppl 1, p. s26-s29, 2018a.

LEIGH, N. J. et al. Tobacco-specific nitrosamines (TSNA) in heated tobacco product IQOS. Tobacco Control, v. 27, n. Suppl 1, p. s37-s38, 2018b.

Lerner L, Weiner D, Katz R, Reznick AZ, Pollack S. Increased pro-inflammatory activity and impairment of human monocyte differentiation induced by in vitro exposure to cigarette smoke. Journal of Physiology Pharmacology. 2009.

LEE, Jong-Hwan; CHAE, Ji-Won; KIM, Jang Kyoung; KIM, Hyung Jin; CHUNG, Jee Young; KIM, Yong-Hee. Inhibition of cisplatin-resistance by RNA interference targeting metallothionein using reducible oligo-peptoplex. Journal Of Controlled Release, [S.L.], v. 215, p. 82-90, out. 2015.

LEE, J. et al. Nicotine drives neutrophil extracellular traps formation and accelerates collagen-induced arthritis. Rheumatology (Oxford, England), p. kew449, 2016. 
LINDBLAD, S. S. et al. Smoking and nicotine exposure delay development of collagen-induced arthritis in mice. Arthritis Research \& Therapy, v. 11, n. 3, p. R88, 2009.

LÜDICKE, F. et al. Effects of switching to a heat-not-burn tobacco product on biologically relevant biomarkers to assess a candidate modified risk tobacco product: A randomized trial. Cancer epidemiology, biomarkers \& prevention, v. 28, n. 11, p. 1934-1943, 2019.

LUGLI, E. B. et al. Expression of citrulline and homocitrulline residues in the lungs of non-smokers and smokers: implications for autoimmunity in rheumatoid arthritis. Arthritis Research \& Therapy, v. 17, n. 1, p. $9,2015$.

LYNES, Michael A.; HIDALGO, Juan; MANSO, Yasmina; DEVISSCHER, Lindsey; LAUKENS, Debby; LAWRENCE, David A.. Metallothionein and stress combine to affect multiple organ systems. Cell Stress And Chaperones, [S.L.], v. 19, n. 5, p. 605-611, 2 mar. 2014.

MADRETSMA, G. S. et al. Nicotine inhibits the in vitro production of interleukin 2 and tumour necrosis factor-alpha by human mononuclear cells. Immunopharmacology, v. 35, n. 1, p. 47-51, 1996.

MAKRYGIANNAKIS, D. et al. Smoking increases peptidylarginine deiminase 2 enzyme expression in human lungs and increases citrullination in BAL cells. Annals Of The Rheumatic Diseases, v. 67, n. 10, p. 1488-1492, 2008.

MALINSKA, D. et al. Assessment of mitochondrial function following short- and long-term exposure of human bronchial epithelial cells to total particulate matter from a candidate modified-risk tobacco product and reference cigarettes. Food And Chemical Toxicology, v. 115, p. 1-12, 2018.

MANZEL, L. J. et al. Inhibition by cigarette smoke of nuclear factor-kB-dependent response to bacteria in the airway. American Journal Of Respiratory Cell And Molecular Biology, v. 44, n. 2, p. 155-165, 2011.

MATUTE-BELLO, Gustavo; DOWNEY, Gregory; MOORE, Bethany B.; GROSHONG, Steve D.; MATTHAY, Michael A.; SLUTSKY, Arthur S.; KUEBLER, Wolfgang M.. An Official American Thoracic Society Workshop Report: features and measurements of experimental acute lung injury in animals. American Journal Of Respiratory Cell And Molecular Biology, [S.L.], v. 44, n. 5, p. 725$738,2011$.

MCGOVERN, Jenny L.; NGUYEN, Dao X.; NOTLEY, Clare A.; MAURI, Claudia; ISENBERG, David A.; EHRENSTEIN, Michael R.. Th17 cells are restrained by Treg cells via the inhibition of interleukin-6 in patients with rheumatoid arthritis responding to anti-tumor necrosis factor antibody therapy. Arthritis \& Rheumatism, [S.L.], v. 64, n. 10, p. 3129-3138, 28 set. 2012. 
MIN J-K, KIM Y-M, KIM SW, et al. TNF-Related Activation-Induced Cytokine Enhances Leukocyte Adhesiveness: Induction of ICAM-1 and VCAM-1 via TNF Receptor-Associated Factor and Protein Kinase C-Dependent NF-אB Activation in Endothelial Cells. Journal of Immunology. 2005.

MOAZED, F. et al. Assessment of industry data on pulmonary and immunosuppressive effects of IQOS. Tobacco Control, v. 27, n. Suppl 1, p. s20-s25, 2018.

MORADI, B., SCHNATZER, P., HAGMANN, S., ROSSHIRT, N., GOTTERBARM, T., KRETZER, J. P., TRETTER, T. CD4+CD25+/highCD127low/-regulatory T cells are enriched in rheumatoid arthritis and osteoarthritis joints - analysis of frequency and phenotype in synovial membrane, synovial fluid and peripheral blood. Arthritis Research Therapy, v. 16, n. 2, p. R97, 2014.

MURPHY, J. et al. Assessing modified risk tobacco and nicotine products: Description of the scientific framework and assessment of a closed modular electronic cigarette. Regulatory Toxicology and Pharmacology: RTP, v. 90, p. 342-357, 2017.

NANKE, Yuki; YAGO, Toru; KOTAKE, Shigeru. The Role of Th17 Cells in the Pathogenesis of Behcet's Disease. Journal Of Clinical Medicine, [S.L.], v. 6, n. 7, p. 74-92, 21 jul. 2017.

NAKAHAMA, T. et al. Aryl hydrocarbon receptor deficiency in T cells suppresses the development of collagen-induced arthritis. Proceedings of the National Academy of Sciences of the United States of America, v. 108, n. 34, p. 14222-14227, 2011.

NGUYEN, N. T. et al. Aryl hydrocarbon receptor antagonism and its role in rheumatoid arthritis. Journal Of Experimental Pharmacology, v. 7, p. 29-35, 2015.

NGUYEN, C. H. et al. Expression of aryl hydrocarbon receptor, inflammatory cytokines, and incidence of rheumatoid arthritis in Vietnamese dioxin-exposed people. Journal of Immunotoxicology, v. 14, n. 1, p. 196-203, 2017.

NIE, H., ZHENG, Y., LI, R., GUO, T. B., HE, D., FANG, L., CHIN, Y. E. Affiliations Contributions, Phosphorylation of FOXP3 controls regulatory T cell function and is inhibited by TNF- $\alpha$ in rheumatoid arthritis. Nature Medicine, v. 19, p. 322-328, 2013.

NIELEN, Markus M. J.; VAN SCHAARDENBURG, Dirkjan; REESINK, Henk W.; STADT, Rob J. van de; HORST-BRUINSMA, Irene E. van Der; KONING, Margret H. M. T. de; HABIBUW, Moud R.; VANDENBROUCKE, Jan P.; DIJKMANS, Ben A. C.. Specific autoantibodies precede the symptoms of rheumatoid arthritis: a study of serial measurements in blood donors. Arthritis \& Rheumatism, [S.L.], v. 50, n. 2, p. 380-386, 2004. 
NIZRI, E. et al. Activation of the cholinergic anti-inflammatory system by nicotine attenuates neuroinflammation via suppression of Th1 and Th17 responses. The Journal of Immunology, v. 183, n. 10, p. 6681-6688, 2009.

NGUYEN, Hai; JAMES, Eddie A.. Immune recognition of citrullinated epitopes. Immunology, [S.L.], v. 149, n. 2, p. 131-138, 17 ago. 2016.

NIU, Q. et al. Disturbed Th17/Treg balance in patients with rheumatoid arthritis. Rheumatology International, v. 32, n. 9, p. 2731-2736, 2012.

NOURI-SHIRAZI, M.; GUINET, E. Evidence for the immunosuppressive role of nicotine on human dendritic cell functions. Immunology, v. 109, n. 3, p. 365-373, 2003.

O'DRISCOLL, C. A.; MEZRICH, J. D. The aryl hydrocarbon receptor as an immune-modulator of atmospheric particulate matter-mediated autoimmunity. Frontiers in Immunology, v. 9, p. 2833, 2018.

OHSAWA M. Heavy metal-induced immunotoxicity and its mechanisms. Yakugaku zasshi: Journal of the Pharmaceutical Society of Japan, v. 129, n. 3, p. 305-319, 2009.

O'NEIL, Liam J.; BARRERA-VARGAS, Ana; SANDOVAL-HEGLUND, Donavon; MERAYOCHALICO, Javier; AGUIRRE-AGUILAR, Eduardo; APONTE, Angel M.; RUIZ-PERDOMO, Yanira; GUCEK, Marjan; EL-GABALAWY, Hani; FOX, David A.. Neutrophil-mediated carbamylation promotes articular damage in rheumatoid arthritis. Science Advances, [S.L.], v. 6, n. 44, p. 1-15, out. 2020

OTTONELLO, Luciano; FRUMENTO, Guido; ARDUINO, Nicoletta et al. Delayed neutrophil apoptosis induced by synovial fluid in rheumatoid arthritis: role of cytokines, estrogens, and adenosine. Annals of the New York Academy of Sciences. 966, 1. jun. 2002.

OUYANG, Y. et al. Suppression of human IL-1beta, IL-2, IFN-gamma, and TNF-alpha production by cigarette smoke extracts. The Journal Of Allergy And Clinical Immunology, v. 106, n. 2, p. 280-287, 2000.

OROZCO VALENCIA, A. et al. Interleukin-2 as immunotherapeutic in the autoimmune diseases. International Immunopharmacology, v. 81, n. 106296, p. 106296, 2020.

PALAZZOLO, D. L. Electronic cigarettes and vaping: a new challenge in clinical medicine and public health. A literature review. Frontiers In Public Health, v. 1, p. 56, 2013. 
PALEOLOG, Ewa M. The role of the angiogenic molecule VEGF in the pathogenesis of rheumatoid arthritis. Histology And Histopathology, [S.L.], n. 17, p. 961-972, 7 jul. 2002.

PINTO, Larissa G.; CUNHA, Thiago M.; VIEIRA, Silvio M.; LEMOS, Henrique P.; VERRI, Waldiceu A.; CUNHA, Fernando Q.; FERREIRA, Sergio H.. IL-17 mediates articular hypernociception in antigeninduced arthritis in mice. Pain, [S.L.], v. 148, n. 2, p. 247-256, fev. 2010

POLlARD, K. M., Christy, J. M., Cauvi, D. M., \& Kono, D. H. Environmental xenobiotic exposure and autoimmunity. Current Opinion in Toxicology, 10, 15-22. 2018.

QARAJEH, R.; KITCHEN, J. THC vaping-induced acute respiratory distress syndrome. The American Journal Of Medicine, v. 133, n. 4, p. e147-e148, 2020.

QIAN, J. et al. Plasticity of the murine spleen T-cell cholinergic receptors and their role in in vitro differentiation of naïve CD4 T cells toward the Th1, Th2 and Th17 lineages. Genes and immunity, v. 12, n. 3, p. 222-230, 2011.

QIU, F. et al. Impacts of cigarette smoking on immune responsiveness: Up and down or upside down? Oncotarget, v. 8, n. 1, p. 268-284, 2017

QUINTANA, F. J. et al. Control of $\mathrm{T}(\mathrm{reg})$ and $\mathrm{T}(\mathrm{H}) 17$ cell differentiation by the aryl hydrocarbon receptor. Nature, v. 453, n. 7191, p. 65-71, 2008.

RAYCHAUDHURI, Siba P.; RAYCHAUDHURI, Smriti K.; GENOVESE, Mark C.. IL-17 receptor and its functional significance in psoriatic arthritis. Molecular And Cellular Biochemistry, [S.L.], v. 359, n. 1-2, p. 419-429, 6 set. 2011.

RICHTER, P.; FAROON, O.; PAPPAS, R. S. Cadmium and cadmium/zinc ratios and tobacco-related morbidities. International Journal Of Environmental Research And Public Health, v. 14, n. 10, 2017.

ROBBINS, C. S. et al. Cigarette smoke exposure impairs dendritic cell maturation and T cell proliferation in thoracic lymph nodes of mice. The Journal of Immunology, v. 180, n. 10, p. 6623-6628, 2008.

ROCK, K. L.; KONO, H. The inflammatory response to cell death. Annual Review of Pathology, v. 3, n. 1, p. 99-126, 2008.

RODGAM, A; PERfETIT. A; The Chemical Components of Tobacco and Tobacco Smoke (second ed.), 1473, CRC Press, Taylor \& Francis Group, Boca Taton, London, New York 2013. 
ROELEVELD, Debbie M.; KOENDERS, Marije I.. The role of the Th17 cytokines IL-17 and IL-22 in Rheumatoid Arthritis pathogenesis and developments in cytokine immunotherapy. Cytokine, [S.L.], v. 74, n. 1, p. 101-107, jul. 2015.

ROMÃO, V. C.; CANHÃO, H.; FONSECA, J. E. Old drugs, old problems: where do we stand in prediction of rheumatoid arthritis responsiveness to methotrexate and other synthetic DMARDs? BMC Medicine, v. 11, n. 1, p. 17, 2013.

ROODENRIJS, Nadia M T; HAIR, Maria J H de; GOES, Marlies C van Der; JACOBS, Johannes W G; WELSING, Paco M J; HEIJDE, Désirée van Der; ALETAHA, Daniel; DOUGADOS, Maxime; HYRICH, Kimme L; MCINNES, Iain B. Characteristics of difficult-to-treat rheumatoid arthritis: results of an international survey. Annals Of The Rheumatic Diseases, [S.L.], v. 77, n. 12, p. 1705-1709, 7 set. 2018.

ROSENBLUM, Michael D.; REMEDIOS, Kelly A.; ABBAS, Abul K.. Mechanisms of human autoimmunity. Journal Of Clinical Investigation, [S.L.], v. 125, n. 6, p. 2228-2233, 1 jun. 2015.

RUPRECHT AA, DE MARCO C, SAFFARI A, et al. Environmental pollution and emission factors of electronic cigarettes, heat-not-burn tobacco products, and conventional cigarettes. Aerosol Science and Technology. 2017.

RUTTKAY-NEDECKY, Branislav et al. The Role of Metallothionein in Oxidative Stress. International Journal Of Molecular Sciences, v. 14, n. 3, p.6044-6066, 15 mar. 2013.

SAEVARSDOTTIR, S. et al. Patients with early rheumatoid arthritis who smoke are less likely to respond to treatment with methotrexate and tumor necrosis factor inhibitors: observations from the Epidemiological Investigation of Rheumatoid Arthritis and the Swedish Rheumatology Register cohorts. Arthritis and Rheumatism, v. 63, n. 1, p. 26-36, 2011.

SARKAR, S.; COONEY, L. A.; FOX, D. A.. The role of T helper type 17 cells in inflammatory arthritis. Clinical \& Experimental Immunology, [S.L.], v. 159, n. 3, p. 225-237, mar. 2010.

SCHMIDT, Angelika; OBERLE, Nina; KRAMMER, Peter H.. Molecular Mechanisms of Treg-Mediated T Cell Suppression. Frontiers In Immunology, [S.L.], v. 3, p. 1-14, 2012.

SCHNEIDER, S. et al. Community reductions in youth smoking after raising the minimum tobacco sales age to 21. Tobacco Control, v. 25, n. 3, p. 355-359, 2016. 
SCHURGERS, E. et al. Pulmonary inflammation in mice with collagen-induced arthritis is conditioned by complete Freund's adjuvant and regulated by endogenous IFN- $\gamma$ : Cellular immune response. European Journal Of Immunology, v. 42, n. 12, p. 3223-3234, 2012.

SHEN, X.; LEE, K.; KÖNIG, R. Effects of heavy metal ions on resting and antigen-activated CD4+ T cells. Toxicology, v. 169, n. 1, p. 67-80, 2001.

SCOTT, David L; WOLFE, Frederick; HUIZINGA, Tom Wj. Rheumatoid arthritis. The Lancet, [S.L.], v. 376 , n. 9746 , p. $1094-1108$, set. 2010

SMOLEN, Josef S. et al. Rheumatoid arthritis. Nature Reviews Disease Primers, v. 4, p.01-21, 8 fev. 2018.

SI, Manfei; LANG, Jinghe. The roles of metallothioneins in carcinogenesis. Journal Of Hematology \& Oncology, [S.L.], v. 11, n. 1, p. 1-14, 23 ago. 2018.

SIMONAVICIUS, E. et al. Heat-not-burn tobacco products: a systematic literature review. Tobacco Control, v. 28, n. 5, p. 582-594, 2019.

SOHAL, S. S. et al. IQOS exposure impairs human airway cell homeostasis: direct comparison with traditional cigarette and e-cigarette. ERJ Open Research, v. 5, n. 1, p. 00159-02018, 2019.

SONDEREGGER, Ivo; KISIELOW, Jan; MEIER, Reto; KING, Cecile; KOPF, Manfred. IL-21 and IL21R are not required for development of Th17 cells and autoimmunity in vivo. European Journal Of Immunology, [S.L.], v. 38, n. 7, p. 1833-1838, jul. 2008.

SOPORI, M. Effects of cigarette smoke on the immune system. Nature reviews. Immunology, v. 2, n. 5, p. 372-377, 2002.

SPARKS, J. A.; KARLSON, E. W. The roles of cigarette smoking and the lung in the transitions between phases of preclinical rheumatoid arthritis. Current Rheumatology Reports, v. 18, n. 3, p. 15, 2016.

SPIERING, R. et al. Membrane-bound metallothionein 1 of murine dendritic cells promotes the expansion of regulatory T cells in vitro. Toxicological Sciences, v. 138, n. 1, p. 69-75, 2014.

SPOLSKI, R.; LI, P.; LEONARD, W. J. Biology and regulation of IL-2: from molecular mechanisms to human therapy. Nature reviews. Immunology, v. 18, n. 10, p. 648-659, 2018.

STABBERT, Regina et al. Studies on the contributions of smoke constituents, individually and in mixtures, in a range of in vitro bioactivity assays. Toxicology In Vitro, v. 42, p.222-246, ago. 2017. 
STÄMPFLI, M. R.; ANDERSON, G. P. How cigarette smoke skews immune responses to promote infection, lung disease and cancer. Nature Reviews. Immunology, v. 9, n. 5, p. 377-384, 2009.

STRZELAK, A. et al. Tobacco smoke induces and alters immune responses in the lung triggering inflammation, allergy, asthma and other lung diseases: A mechanistic review. International Journal Of Environmental Research And Public Health, v. 15, n. 5, p. 1033, 2018.

STAUDT, M. R. et al. Altered lung biology of healthy never smokers following acute inhalation of Ecigarettes. Respiratory Research, v. 19, n. 1, 2018.

ST HELEN GS, JACOB P, NARDONE N, et al. Because PMI application did not report the full range of HPHCs in IQOS aerosol, characterize HPHCs in sidestream emissions, include a non-targeted analysis of chemicals in emissions, or conduct clinical studies to describe exposure to toxicants during dual use with other tobacco products, FDA must deny PMI's application. Food and Drug Administration - FDA. 12: regulations.gov, 2017

SUGIYAMA, D. et al. Impact of smoking as a risk factor for developing rheumatoid arthritis: a metaanalysis of observational studies. Annals Of The Rheumatic Diseases, v. 69, n. 1, p. 70-81, 2010.

SUNDAR, I. K.; YAO, H.; RAHMAN, I. Oxidative stress and chromatin remodeling in chronic obstructive pulmonary disease and smoking-related diseases. Antioxidants \& Redox Signaling, v. 18, n. 15, p. 1956-1971, 2013.

SUN, Jinxia et al. Metallothionein-1 suppresses rheumatoid arthritis pathogenesis by shifting the Th17/Treg balance. European Journal Of Immunology, v. 48, n. 9, p.1550-1562, 22 ago. 2018.

TALBOT, J. et al. Smoking-induced aggravation of experimental arthritis is dependent of aryl hydrocarbon receptor activation in Th17 cells. Arthritis Research \& Therapy, v. 20, n. 1, 2018.

TURESSON, C.; JACOBSSON, L. T. H. Epidemiology of extra-articular manifestations in rheumatoid arthritis. Scandinavian Journal Of Rheumatology, v. 33, n. 2, p. 65-73, 2004.

VAN DEN BERG, W. B.; JOOSTEN, L. A. B.; VAN LENT, P. L. E. M. Murine antigen-induced arthritis. Methods in Molecular Medicine, v. 136, p. 243-253, 2007.

VAN DER VAART, H. et al. Acute effects of cigarette smoke on inflammation and oxidative stress: a review. Thorax, v. 59, n. 8, p. 713-721, 2004. 
VAN HAMBURG, J. P.; ASMAWIDJAJA, P. S.; DAVELAAR, A. M. C. et al. Th17 cells, but not Th1 cells, from patients with early rheumatoid arthritis are potent inducers of matrix metalloproteinases and proinflammatory cytokines upon synovial fibroblast interaction, including autocrine interleukin-17A production. Arthritis \& Rheumatology, 15 oct. 2010

VAN MAANEN, M. A. et al. Stimulation of nicotinic acetylcholine receptors attenuates collagen-induced arthritis in mice. Arthritis and Rheumatism, v. 60, n. 1, p. 114-122, 2009.

VAN PANHUYS, Nicholas; KLAUSCHEN, Frederick; GERMAIN, Ronald N.. T-Cell-ReceptorDependent Signal Intensity Dominantly Controls CD4+ T Cell Polarization In Vivo. Immunity, [S.L.], v. 41, n. 1, p. 63-74, jul. 2014.

VELDHOEN, M. et al. Natural agonists for aryl hydrocarbon receptor in culture medium are essential for optimal differentiation of Th17 T cells. The Journal Of Experimental Medicine, v. 206, n. 1, p. 43-49, 2009.

VERRI, Waldiceu A; SOUTO, Fabrício O; VIEIRA, Silvio M et al. IL-33 induces neutrophil migration in rheumatoid arthritis and is a target of anti-TNF therapy. Annals of Rheumatic Diseases. maio. 2010

VERSTAPPEN, S. M. M.; OWEN, S.-A.; HYRICH, K. L. Prediction of response and adverse events to methotrexate treatment in patients with rheumatoid arthritis. International Journal Of Clinical Rheumatology, v. 7, n. 5, p. 559-567, 2012.

VOJDANI, A. A potential link between environmental triggers and autoimmunity. Autoimmune Diseases, v. 2014, p. 437231, 2014.

VU, A. T. et al. Polycyclic aromatic hydrocarbons in the mainstream smoke of popular U.s. cigarettes. Chemical Research In Toxicology, v. 28, n. 8, p. 1616-1626, 2015.

YAMAGUCHI, N. H. Smoking, immunity, and DNA damage. Translational Lung Cancer Research, v. 8, n. Suppl 1, p. S3-S6, 2019.

YOUN, J. et al. Metallothionein suppresses collagen-induced arthritis via induction of TGF-beta and down-regulation of proinflammatory mediators. Clinical And Experimental Immunology, v. 129, n. 2, p. 232-239, 2002.

YOUNG, Adam; KODURI, Gouri. Extra-articular manifestations and complications of rheumatoid arthritis. Best Practice \& Research Clinical Rheumatology, [S.L.], v. 21, n. 5, p. 907-927, out. 2007. 
YU, H. et al. Nicotine-induced differential modulation of autoimmune arthritis in the Lewis rat involves changes in interleukin-17 and anti-cyclic citrullinated peptide antibodies. Arthritis and Rheumatism, v. 63, n. 4, p. 981-991, 2011.

YUNT, Z. X.; SOLOMON, J. J. Lung disease in rheumatoid arthritis. Rheumatic Diseases Clinics of North America, v. 41, n. 2, p. 225-236, 2015.

WEI, Hua et al. Differential expression of metallothioneins (MTs) 1, 2, and 3 in response to zinc treatment in human prostate normal and malignant cells and tissues. Molecular Cancer, v.7, n. 1, p.7-18, 2008.

WEITKUNAT, R. et al. Assessment of cigarette smoking in epidemiologic studies. Beiträge zur Tabakforschung International/Contributions to Tobacco Research, v. 25, n. 7, p. 638-648, 2013.

WHO. HEATED TOBACCO PRODUCTS: a brief report 2020. World Health Organization - WHO. 2020. Acesso dia 14 de janeiro de 2021. Disponível em <https://www.euro.who.int/en/healthtopics/disease-prevention/tobacco/publications/2020/heated-tobacco-products-a-brief-2020>

WHO. TOBACCO. World Health Organization - WHO. Acesso 12 de Janeiro de 2021, disponível em <https://www.who.int/health-topics/tobacco\#tab=tab_1>.

WICKENDEN, J. A. et al. Cigarette smoke prevents apoptosis through inhibition of caspase activation and induces necrosis. American Journal of Respiratory Cell and Molecular Biology, v. 29, n. 5, p. 562-570, 2003.

WING, K.; ONISHI, Y.; PRIETO-MARTIN, P.; YAMAGUCHI, T.; MIYARA, M.; FEHERVARI, Z.; NOMURA, T.; SAKAGUCHI, S.. CTLA-4 Control over Foxp3+ Regulatory T Cell Function. Science, [S.L.], v. 322, n. 5899, p. 271-275, 10 out. 2008.

WONG, E. T. et al. Evaluation of the Tobacco Heating System 2.2. Part 4: 90-day OECD 413 rat inhalation study with systems toxicology endpoints demonstrates reduced exposure effects compared with cigarette smoke. Regulatory Toxicology and Pharmacology: RTP, v. 81, p. S59-S81, 2016.

WU, S. et al. Attenuation of collagen induced arthritis via suppression on Th17 response by activating cholinergic anti-inflammatory pathway with nicotine. European Journal of Pharmacology, v. 735, p. 97-104, 2014.

WU, S. et al. Regulatory effect of nicotine on the differentiation of Th1, Th2 and Th17 lymphocyte subsets in patients with rheumatoid arthritis. European Journal of Pharmacology, v. 831, p. 38-45, 2018. 
ZHAO, C.-N. et al. Emerging role of air pollution in autoimmune diseases. Autoimmunity Reviews, v. 18, n. 6, p. 607-614, 2019.

ZHONG, C.-Y.; ZHOU, Y. M.; PINKERTON, K. E. NF-kappaB inhibition is involved in tobacco smokeinduced apoptosis in the lungs of rats. Toxicology and Applied Pharmacology, v. 230, n. 2, p. 150-158, 2008

ZHOU, Liang; CHONG, Mark M.W.; LITTMAN, Dan R.. Plasticity of CD4+ T Cell Lineage Differentiation. Immunity, [S.L.], v. 30, n. 5, p. 646-655, maio 2009.

ZHU, C.; XIE, Q.; ZHAO, B. The role of AhR in autoimmune regulation and its potential as a therapeutic target against $\mathrm{CD} 4 \mathrm{~T}$ cell mediated inflammatory disorder. International Journal Of Molecular Sciences, v. 15, n. 6, p. 10116-10135, 2014. 


\section{ANEXOS}

Anexo 1 - Protocolo CEUA - Ensaios in vivo

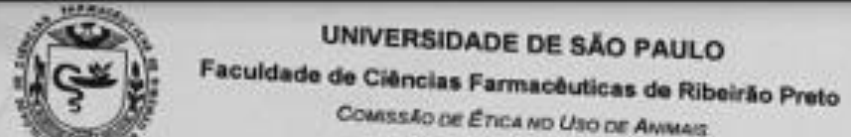

\section{A UTORIZAÇÃ O}

Certificamos a proposta intulada Tabegismo e doenças articulares: investigaçẫo dos mecanismos de aç̧o da hidroquinona e do aerossol gerado pelo tubo do tabaco", registrada sob n $n^{\circ} 19.1553 .60 .3$, sob a responsabïdade de Cintia Scucuglia Hahiany - Sandra Helena Polisell Farsky, que enwolve a manutençbo e utilizacalo de animais pertencentes ao filo Chardata, subfilo Vertebrata (excoto o homem) para fins de pesquisa cientifica encontra-se de acordo com as preceitos da Lei $\mathrm{n}^{\circ} 11.794$, de B de outubro de 2000 , do Decreto 9.899 , de 15 de julho de 2009 , e com as normas editadas pelo Conselho Nacional de Controle da Experimentapáo Animal (CONCEA), toi aprovada na reuniáo de 01/10/2019 pela Comissâo de Ética no Uso de Animais da Faculdade de Ciéncias Farmaceluticas de Ribeirsto Preto (CEUA FCFRP)

Lembramos da obrigatoriedade de apresentaçăo do relatbrio de abvidades, em modelo da CEUA, para emissdo do certificado, como disposto nas Resolupbes Normativas do CONCEA.

\begin{tabular}{|c|c|}
\hline Finalidade & () Ensino ( $x$ ) Pesquisa Cientifica \\
\hline Vigencia da Autorizaça & $16 / 10 / 2019$ a $16 / 10 / 2020$ \\
\hline EspecienLinhagem/Raça & Camundongo isogenico DBAt/d. \\
\hline $\mathrm{N}^{0}$ de animais: & 80 \\
\hline Pesollade & $18-23$ of $6-8$ semanas \\
\hline Sexo & Macho \\
\hline Origem & Centro de Criaça de Camundonpos Especiais - FMRP \\
\hline
\end{tabular}

Ribeirato Preto, 02 de outubro de 2019. 


\section{UNIVERSIDADE DE SÃO PAULO \\ FACULDADE DE CIENCIAS FARMACEUTICAS}

Comissăo de Ética no Uso de Animais - CEUA

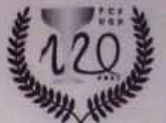

Proto

Oficio CEUAVFCF 033.2019

colo

CEU

IImo. Sr.

Plablo R. dos Santos Scharf

Profa. Dra. Sandra Helena Poliselli Farsky

FBC/FCF/USP

A -

Ensai

os in

São Paulo, 03 de maio de 2019.

vitro

Assunto: apreciação do Protocolo CEUA № 586.

\section{Prezado Senhor,}

A Comissão de Ética no Uso de Animais da Faculdade de Ciências Farmacêuticas da Universidade de São Paulo (CEUA/FCF/USP), em reunião realizada em 03/05/2019, APROVOU o projeto de pesquisa "Efeitos da exposição à produtos fumigenos sobe a metalotioneina e fator indutor de hipóxia 1 alfa no modelo experimental de artrite induzida por colágeno" (Protocolo CEUA $n^{\circ} 586$ ), apresentado por Vossa Senhoria, recomendando o que segue:

a) No Formulário (item 9.2), alterar para o item B.

b) No Projeto de Pesquisa (item Sumário), corrigir 2 linhas onde identifica erro.

Cabe lembrar que, as questões apontadas acima deverão ser atendidas (no prazo máximo até 03/07/2019), enviados por e-mail (ceuafcf@usp.br) e também impressos, com os seguintes documentos:

a) Carta resposta assinada pelos responsáveis;

b) Formulário, com as respectivas alterações destacadas em amarelo, assinada pelos responsáveis. 


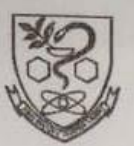

\section{UNIVERSIDADE DE SÃO PAULO \\ FACULDADE DE CIÊNCIAS FARMACÊUTICAS \\ Comissåo de Ética no Uso de Animais - CEUA}

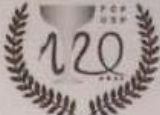

Mrto

c) Projeto de Pesquisa, com as respectivas alterações destacadas em amarelo, assinada pelos responsáveis

Cabe destacar que, as informaçōes contidas no Projeto de Pesquisa e Formulário devem ser as mesmas.

Caso não haja manifestação de V. Sa., no prazo de 60 (sessenta dias), o processo relativo ao protocolo em apreço Projeto CEUA № 586 será arquivado

Atenciosamente

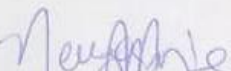

Profa. Dra. Neuza Mariko Aymoto Hassimotto Coordenadora da CEUA/FCF/USP 
Anexo 3 - Ficha do Aluno

Janus - Sistema Administrativo da Pós-Graduaçăo

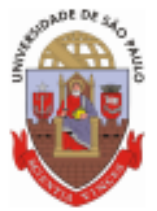

Universidade de Săo Paulo

Faculdade de Ciências Farmacêuticas

FICHA DO ALUNO

9143 - 11097080/1 - Pablo Rhasan dos Santos Scharf

Email:

scharfpablo@usp.br

Data de Nascimento:

07/12/1995

Cédula de Identidade:

RG - 6113437 - SC

Local de Nascimento:

Estado de Santa Catarina

Nacionalidade:

Brasileira

Graduaçăo:

Biomedicina - Universidade Regional de Blumenau - Santa Catarina - Brasil - 2018

Curso: Mestrado

Programa:

Área:

Farmácia (Fisiopatologia e Toxicologia)

Data de Matricula:

Toxicologia

14/01/2019

Inicio da Contagem de Prazo: 14/01/2019

Data Limite para o Depósito: $\quad$ 14/07/2021

Orientador:

Prof(a). Dr(a). Sandra Helena Poliselli Farsky - 14/01/2019 até o presente. Email: sfarsky@usp.br

Proficiência em Linguas:

Inglès, Aprovado em 14/01/2019

Data de Aprovaçăo no Exame de

Qualificaçăo:

Aprovado em 05/03/2020

Data do Depósito do Trabalho:

Titulo do Trabalho:

Data Máxima para Aprovaçăo da

Banca:

Data de Aprovaçăo da Banca:

Data Máxima para Defesa:

Data da Defesa:

Resultado da Defesa:

Histórico de Ocorrências:

Primeira Matricula em 14/01/2019

Aluno matriculado no Regimento da Pós-Graduaçăo USP (Resoluçăo nº 7493 em vigor a partir de 29/03/2018).

Última ocorrência: Mudança de Regulamento em 26/11/2020

Impresso em: 16/01/2021 15:54:16 
Janus - Sistema Administrativo da Pós-Gradusçăa

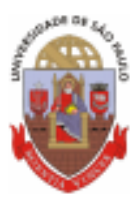

Universidade de São Paulo

Faculdade de Ciências Farmacêuticas

FICHA DO ALUNO

\section{3 - 11097080/1 - Pablo Rhasan dos Santos Scharf}

\begin{tabular}{|c|c|c|c|c|c|c|c|c|c|}
\hline Sigla & Nome da Disciplina & Inicio & Término & $\begin{array}{c}\text { Carga } \\
\text { Horária }\end{array}$ & Cred. & Freq. $\mathrm{C}$ & Eonc. & Exc. & Situaçăo \\
\hline$\underset{6 / 2}{B M 15881-}$ & $\begin{array}{l}\text { Regulacsa da Resposta Imune (Insthuso de Ciencias } \\
\text { Bicmedicas - Universidade de Salo Paulo) }\end{array}$ & $11 / 03 / 2019$ & $05 / 06 / 2019$ & 120 & 8 & 100 & B & $\mathrm{N}$ & Concluida \\
\hline$\underset{14 / 2}{\mathrm{FeC5793}}$ & Tópicos em Fisiopatologia e Tavicologia I & $12 / 03 / 2019$ & $24 / 06 / 2019$ & 15 & 1 & 88 & A & N & Concluida \\
\hline$\underset{1 / 1}{\text { FBC5958- }}$ & $\begin{array}{l}\text { Sinalizaçalo por GPCRs e descoberta de novos } \\
\text { tarmacos }\end{array}$ & $18 / 03 / 2019$ & $24 / 03 / 2019$ & 30 & 2 & 100 & A & $\mathbf{N}$ & Conclualda \\
\hline$\frac{1 \mathrm{CB} 5750}{3 / 2}$ & $\begin{array}{l}\text { Metodos Avançados em Biologia Celular (Instituto } \\
\text { de Ciencias Biomedicas - Universidade de Sso } \\
\text { Paulo) }\end{array}$ & $25 / 03 / 2019$ & 13/06/2019 & 60 & 0 & - & - & $\mathrm{N}$ & $\begin{array}{l}\text { Pré- } \\
\text { matrioula } \\
\text { indeferida }\end{array}$ \\
\hline$\underset{1 / 2}{\mathrm{FBC} 5954-}$ & Redaçào de Trabalhos Clentificos & $11 / 04 / 2019$ & $17 / 04 / 2019$ & 15 & 0 & - & - & N & $\begin{array}{c}\text { Turma } \\
\text { cancelada }\end{array}$ \\
\hline$\underset{8 / 3}{\mathrm{FeC} 5757}$ & Tópicos em Fisiopatologia e Taxicologia II & ot/ce/2019 & $18 / 11 / 2019$ & 15 & 1 & 87 & A & N & Concluilda \\
\hline$\underset{1 / 1}{\text { BMIs904- }}$ & $\begin{array}{l}\text { Reconhecimento Molecular pelo Sistema Imune } \\
\text { (Insthuto de Ciências Biomedicas - Universidade de } \\
\text { SSo Paulo) }\end{array}$ & $12 / 0 e / 2019$ & $15 / 09 / 2019$ & 60 & 0 & - & $\cdot$ & N & $\begin{array}{l}\text { Matricula } \\
\text { cancelada }\end{array}$ \\
\hline $\begin{array}{l}\text { FBFso5: } \\
27\end{array}$ & $\begin{array}{l}\text { Delineamento de Experimentos e Ferramentas } \\
\text { Estatisticas Aplicadas is Ciencias Farmactuticas }\end{array}$ & 20/0e/2019 & $28 / 10 / 2019$ & 90 & 6 & 100 & A & $\mathrm{N}$ & Concluida \\
\hline$\underset{1 / 1}{\mathrm{FeC5745}}$ & $\begin{array}{l}\text { Avalisçato da reduçáo de danos das formas } \\
\text { alternativas de exposiça a tabaco }\end{array}$ & $14 / 10 / 2019$ & $28 / 10 / 2019$ & 30 & 0 & - & - & N & $\begin{array}{c}\text { Turma } \\
\text { cancelada }\end{array}$ \\
\hline$\underset{1 / 1}{\mathrm{FeCs}}$ & Tópioos Especias em Fisiopatologia e Toxicologia & $16 / 12 / 2019$ & $22 / 12 / 2019$ & 15 & 1 & 100 & A & $\mathbf{N}$ & Concluida \\
\hline FBAS728- & Aprimoramento Pedagogico & $17 / 03 / 2020$ & $13 / 04 / 20020$ & 60 & 0 & . & - & $\mathrm{N}$ & $\begin{array}{c}\text { Turma } \\
\text { cancelada }\end{array}$ \\
\hline$\underset{1 / 1}{\text { FBC5959: }}$ & $\begin{array}{l}\text { Desenvolvendo sua comunicasalo cientifica no } \\
\text { mundo acadéricos }\end{array}$ & $19 / 03 / 2020$ & $29 / 04 / 20020$ & 90 & 6 & 100 & A & $\mathrm{N}$ & Conclualda \\
\hline $\mathrm{ICBS710}_{4 / 2}$ & $\begin{array}{l}\text { Controle Molecular da Morte Celular (Insthato de } \\
\text { Ciencias Biomedicas - Universidade de SAlo Paulo) }\end{array}$ & $30 / 03 / 2020$ & $12 / 04 / 2020$ & 60 & 0 & . & - & $\mathrm{N}$ & $\begin{array}{c}\text { Turma } \\
\text { cancelada }\end{array}$ \\
\hline$\frac{6045838}{4 / 3}$ & $\begin{array}{l}\text { Toxicologia da Reproduçalo e do Desenvolvimento } \\
\text { (Faculdade de Cilencias Farmactuticas de Fubeirso } \\
\text { Preto - Universidade de Sso Paulo) }\end{array}$ & $13 / 10 / 2020$ & $19 / 10 / 2020$ & 30 & 2 & 100 & A & s & Conckulda \\
\hline$\underset{1 / 1}{\text { ICBS776- }}$ & $\begin{array}{l}\text { Imunologia Sistemica (Insthiso de Ciencias } \\
\text { Biomedcas - Universidade de Sâo Paulo) }\end{array}$ & $03 / 11 / 2020$ & $04 / 12 / 20020$ & 60 & 0 & - & . & s & $\begin{array}{l}\text { Matricula } \\
\text { cancelada }\end{array}$ \\
\hline$\underset{2 / 3}{\text { BMI5897- }}$ & $\begin{array}{l}\text { Imunidade Inata e Adaptativa no Sistema Nervoso } \\
\text { Central (Instutu de Ciencias Biomedicas - } \\
\text { Universidade de SSo Paulo) }\end{array}$ & $09 / 11 / 2020$ & $06 / 12 / 2020$ & 60 & 4 & 100 & A & s & Concluida \\
\hline
\end{tabular}

\begin{tabular}{|c|c|c|c|}
\hline \multicolumn{3}{|c|}{ Créditos minimos exigidos } & \multirow{2}{*}{ Créditos obtidos } \\
\hline & Para exame de & o da dissertaçä̀ & \\
\hline Disciplinas: & 0 & 25 & 25 \\
\hline \multicolumn{4}{|l|}{ Estágios: } \\
\hline Total: & 0 & 25 & 25 \\
\hline
\end{tabular}

Créditos Atribuidos à Dissertação: 71 
Anexo 4 - Currículo Lattes

Link: http://lattes.cnpq.br/4399378864112504 